\title{
Errant Romanticism: Queering Gender and Sexuality in British Literature, 1790-1840
}

\author{
Teresa M. Pershing
}

Follow this and additional works at: https://researchrepository.wvu.edu/etd

\section{Recommended Citation}

Pershing, Teresa M., "Errant Romanticism: Queering Gender and Sexuality in British Literature, 1790-1840" (2016). Graduate Theses, Dissertations, and Problem Reports. 6408.

https://researchrepository.wvu.edu/etd/6408

This Dissertation is protected by copyright and/or related rights. It has been brought to you by the The Research Repository @ WVU with permission from the rights-holder(s). You are free to use this Dissertation in any way that is permitted by the copyright and related rights legislation that applies to your use. For other uses you must obtain permission from the rights-holder(s) directly, unless additional rights are indicated by a Creative Commons license in the record and/ or on the work itself. This Dissertation has been accepted for inclusion in WVU Graduate Theses, Dissertations, and Problem Reports collection by an authorized administrator of The Research Repository @ WVU.

For more information, please contact researchrepository@mail.wvu.edu. 


\title{
Errant Romanticism: \\ Queering Gender and Sexuality in British Literature, 1790-1840
}

\section{Teresa M. Pershing}

\author{
Dissertation submitted \\ to the Eberly College of Arts and Sciences \\ at West Virginia University
}

in partial fulfillment of the requirements for the degree of

Doctor of Philosophy in

English Literature

\author{
Dennis W. Allen, Ph.D., Chair \\ Lara Farina, Ph.D. \\ Marilyn Francus, Ph.D. \\ Adam Komisaruk, Ph.D. \\ Richard C. Sha, Ph.D. \\ Department of English
}

Morgantown, West Virginia
2016

Keywords: Romanticism, Error, Queer Theory, Feminism, Gender Studies, Femininity, Identity Copyright 2016 Teresa M. Pershing 


\section{ABSTRACT \\ Errant Romanticism: \\ Queering Gender and Sexuality in British Literature, 1790-1840}

\section{Teresa M. Pershing}

This dissertation argues that error is a productive lens for analyzing identity in the late-eighteenth and early-nineteenth centuries as well as the 21 st-century because error is polysemous and versatile. In alignment with and alongside queer, error makes possible an analysis that considers the processes that construct and reify normativity and challenges to that configuration. In part, error's productivity as a critical lens is due to its multiplicity. It is both negative, a thing we seek to avoid, and positive, something that often leads to learning, development, or self-reflection. Error is both a purposeless wandering and a purposeful identification of a mistake. Each chapter analyzes texts from the late-eighteenth and early-nineteenth centuries which feature female characters and the epilogue turns to the autobiographical writing of a man in the 21st-century. Chapters on William Godwin's memoirs of Mary Wollstonecraft, Amelia Alderson Opie's Dangers of Coquetry, Anne Plumptre's Something New, and Harriet Martineau's Illustrations of Political Economy, and Thomas Beatie's autography Labor of Love feature characters-both real and fictional— who destabilize what Bourdieu calls "collective[ly] misrecogn[ized]" understandings of identity as truth/error and "either/or." Utilizing notions of error developed by Zachary Sng and Seth Lerer, I take up the category of error as a provisional and tactical strategy to argue that identities, especially gender identities, are errant: wandering, nonsystematic, and nonsystematizable. In doing so, I dislodge the notion that identity is always systematic and demonstrate its queer errancy. I analyze British literature written during the Romantic era, specifically from 1790-1840, because these years help to set the stage for the emergence of sexual and gender identity categories throughout the rest of the 19th century-a period that shapes today's notions of sexuality and gender. Finally, the concept of errancy in particular addresses the concerns of scholars like Carla Freccero, Viviane Namaste and Steven Angelides who argue that "queer" has not yet gone far enough in its immateriality or in problematizing and addressing identity's fixity. 


\section{Acknowledgments}

In the process of discovering the potential of error as a critical methodology, I often found myself to be an errant subject. Like the scholars that Seth Lerer describes, I was wandering about - seeking answers to questions I hadn't yet asked and, at times, finding productivity in my mistakes. I am immensely grateful to my dissertation chair, Dr. Dennis W. Allen who insisted that my wandering was beneficial, even when I thought it in need of correction. You have consistently encouraged me to keep pushing, to think harder, and to imagine the potential impact of my ideas when carefully articulated. Your dedication to your students - even after they leave your classroom - is a reflection not just of your pedagogy, but also of your humanity. Over the last eight years I have been fortunate enough to study queer theory with you, and because of your influence, I am a better scholar and activist. The impacts of your work and mentorship reach far beyond the words on these pages. Thank you for all that you have done for me and for giving me the opportunity to count you as my mentor and friend.

I am thankful to each member of my dissertation committee: Drs. Marilyn Francus, Lara Farina, Adam Komisaruk, and Richard Sha. You discussed my ideas over coffee, gave me space to grow as an educator-sometimes in your classrooms, spilled ink to improve my thinking and my writing, and shared with me your time and intellect. My scholarship is stronger because of your efforts.

In addition, I am grateful to Drs. Laura Brady, Danette DiMarco, Catherine Gouge, Donald Hall, Mark O'Connor, Jennifer Orlikoff, and Timothy Sweet. Your influence on my teaching, thinking, and writing is unquestionable and I am honored to learn from each of you.

Thank you to West Virginia University and the Department of English for the funding that has aided in the completion of this project.

Thank you to the Carl H. Pforzheimer Collection of Shelley and His Circle at the New York Public Library for granting me access to archival materials and to Dr. Elizabeth Denlinger for her expertise and kindness.

This manuscript is stronger because of the insight offered by Yvonne Swartz. Thank you for being a tireless reader.

I cannot properly express my gratitude for the unflagging friendship of Drs. Andrea Bebell, Jessica Queener, and Erin Johns Speese. We've been integral to each other's scholarly and personal journeys; I cannot imagine how this might have gone without each of you. I am grateful that I met you in Baker Hall, A; that Colson Hall offices were organized alphabetically in 2008, Queener; and that I always have a friend in Greensburg, E. Thank you for taking time to read my work, to support and encourage my completion of this project, and, most of all, for being a reliable and funny-as-hell group of friends.

This list would be incomplete without thanking my brother and very first true friend: William C. Pershing. Your ability to lighten the mood when I am stuck is essential to my success. You put things in perspective. Thank you for your unending support and confidence. 
I'm eternally grateful to my parents: Pamela and William E. Pershing III. It is not possible for me to articulate all of the ways that you have shaped and supported me. Dad: Thank you for teaching me the meaning of hard work. More importantly, thank you for showing me the power of an open and loving heart. I am forever appreciative for all you have done to show me that you love me. Mom: Thank you for pursuing your education when I was in middle school. Watching you graduate altered the course of my life and instilled in me a deep value for education. Your work ethic and insistence on fair treatment in the workplace has been fundamental to my development as a woman and a feminist. I am stronger because I learned from you. Your commitment to your family and to showing each of us how to love ourselves and those around us are traits that I hope to emulate successfully.

Lastly, to my partner and husband, Keenan L. Bowens: thank you. When I started the doctoral program at WVU, we'd only been dating for a few months. You took a professional risk and uprooted your life to move to Morgantown to build our life together. Since then, in the moments when I find myself lost and wandering about, I am always rooted by you. Your belief in my ability to mastodon through and finish this project is one of the primary reasons that it is complete. Thank you for offering me space, comfort, and kindness when I needed them the most. I cannot imagine what life would be like had I not stepped on that 61A PAT bus in October of 2007. 


\section{Table of Contents}

\section{Chapter 1}

Introduction: Queerness and Errancy

\section{Chapter 2}

28

Sensibility and Errancy in William Godwin's

Memoirs of the Author of the Vindication of the Rights of Woman

Chapter 3

72

Unbecoming: Desire and Futurity in Amelia Alderson Opie's

Dangers of Coquetry

Chapter 4

"How Idle is Beauty": Interiority, Femininity, and the Queer Gaze

Chapter 5

Erring Populations \& Population Debates as Prophylactics

"Manternity": Gender Errancy, State Power, and Discourse 


\section{Chapter 1}

Introduction: Queerness and Errancy

Many Americans, especially boys that grew up in the 1970s through the 1990s, are familiar with a playground game called "Smear the Queer." In Smear the Queer one player is "it"—or in this case "the queer"—_and that person possesses an object, usually a ball or some other easy-to-possess item. Oftentimes, "the queer" is not a volunteer, but the larger group identifies them as such by throwing the item at them and/or yelling, "Smear the queer!" The nowvisibly "queer" individual then either immediately throws the item away from themselves, revoking their "queerness," or runs about the playground in a chaotic pattern as they attempt to avoid the grasp of the other players - constantly rerouting themselves, circling back, and changing speed. The aim of the game is for all of the other players to attack, or "smear," the "queer" until they are tackled; this usually results in a large pile of players "smearing the queer" so that they give up the object or are attacked in the physically cruel way that is only acceptable on a playground. Eventually, the "queer" is forced to give up the object or is attacked long enough that the other players move on; another person then becomes the queer or the game ends.

There are two ways of reading this playground game as a metaphor for queerness in society: 1) if you are the queer, you are under attack, and 2) queerness can make its way through the whole community if one wanders successfully enough. If this game is a metaphor for society's attack on queerness, then the larger group is representative of hegemonic society. The group attacks the queer - the Other-until they give up what makes them queer or they move on to the next subject - perhaps another queer. The act that makes them "the queer" in the gamepossessing the ball or being called "the queer" — serves as a materialization of queerness itself. In both cases, queerness is applied to the subject externally. Within the game, the "queer" does not 
pick up the ball or declare themselves queer. Likewise, queerness's definition depends upon cultural notions of what makes one queer in the first place: same-sex desire or sexual deviance, for example.

Unlike the game, in society, individuals can label themselves queer; however, this declaration is always a reference to an identity that is defined-its parameters resulting from deviation from heterosexuality — from without rather than within. The game's group attack of the queer parallels practices like conversion therapy, pray the gay away movements, or statements akin to "it is just a stage" which make an effort to rid queers of whatever it is that makes them queer. Once a playground participant is labeled the queer they are forced to either deny their queerness immediately (e.g. throw the item away) or accept their labeling and flee the oncoming attack. If the latter takes place, the queer attempts to keep themselves safe by running about in a seemingly erratic manner. Their running pattern, unintelligible as it may seem, is eventually readable enough for the queer to be captured.

In this reading of the game, Smear the Queer as a metaphor for queerness in culture-atlarge helps to make visible queerness' unsustainability. Eventually, society will be able to read the signifiers of queerness, identify and label them, and then go about capturing and correcting that queerness. In this configuration, queerness - embodied in the "queer"-is framed as erring in that it is a deviation from the norm. When thinking about queerness in the $21^{\text {st }}$ century-how gay and lesbian people are acceptable primarily when their sexual and gender practices are homonormative — such a reading speaks to how queerness was represented and then possibly repressed in earlier periods and how particular sorts of queerness remain under attack. If Smear the Queer is understood this way, and if queerness in society is understood this way, then we queers are always the mistake. Once identified, queerness will be corrected or silenced. 
Alternatively, the game represents a less apocalyptic reading of queerness: one where queerness successfully makes its way through society. In this reading, the "queer" is an example of an errant subject who foregoes and/or baffles normative structures and methodologies for organizing knowledge. As I noted earlier, once the "queer" is identified within the game, they run about in a seemingly chaotic pattern in an attempt to escape the other players. Imagine that rather than eventually being caught, the "queer" remains free and the other players keep reaching out to grasp their sleeve or tug their t-shirt, hoping to capture the "queer" finally, only for the "queer" to again pivot and leave their would-be-capturers moving forward on another running pattern. As the "queer" continues to run, the other players must give up their traditional tactics for capturing the "queer" as they become noticeably ineffective. The other players forsake the zig-zag, backward and forward, and/or side-to-side running patterns they once found effective for capturing the “queer." Instead, they begin to run about in unrecognizable patterns as well. Perhaps, the other players stop chasing as a group and instead subscribe to individual running patterns, or they cease running entirely and stand in place. The "queer" embodies the errant potential of queerness.

Queer errancy is not an identity; it is a practice that rejects traditional forms of knowledge organization, binaries and linearity in time and movement for example. Through this refusal, queer errancy, as a practice, disrupts pre-existing power/knowledge structures, especially those that make identity intelligible. Errant queerness is an example of what Carla Freccero describes as "a non-identity-based critical cultural and political practice that seeks to resist the humanist rights-bearing claims of collective identities understood to be based in a certain affective and sexual practice and a relation to same-sex object choice" (15). Freccero's queerness and what I've named errant queerness, are cultural practices rather than identities. Freccero's notion of queerness and my own are more difficult to capture because they are slippery-unattached to a 
body, to a sexual practice, or to desire. In the game, the queer's running pattern never becomes readable to their would-be captors. Since "smearing" is no longer possible, the game is not driven by attempts to capture the queer, but to mimic them. In this way, queerness successfully makes its ways through culture. By imagining Smear the Queer in this way, the queer becomes the metaphorical embodiment of queerness' metamorphosing potential. Queerness can change. The way that queer critics and practitioners deploy queerness as a tool for cultural critique morphs and shifts as our needs for its disruptive potential change. The way that queerness materializes in our daily lives, in literature and other cultural texts, and in our identity practices can look very different depending on where we are looking to and from.

In the chapters that follow, I analyze texts from the late-eighteenth and early-nineteenth centuries which feature female characters - both real and imagined. My analysis of these characters focuses on errant queerness to destabilize "collective[ly] misrecogn[ized]" understandings of identity as truth/error and "either/or" (Bourdieu 81). I take up the category of error as a provisional and tactical strategy to argue that identities, especially gender identities, are errant: wandering, nonsystematic, and nonsystematizable (Sng 5). In doing so, I dislodge the notion that identity is always systematic and demonstrate its queer errancy. I analyze British literature written during the Romantic era, specifically from 1790-1840, because these years help to set the stage for the emergence of sexual and gender identity categories throughout the rest of the 19th century. I argue that error is a productive lens for analyzing identity because it is polysemous and versatile. In alignment with and alongside queer, error makes possible an analysis that considers the processes that construct and reify normativity and challenges to that configuration. In part, error's productivity as a critical lens is due to its multiplicity. It is both negative, a thing we seek to avoid, and positive, something that often leads to learning, 
development, or self-reflection. Error is both a purposeless wandering and a purposeful identification of a mistake. Error is at times material, but often immaterial. Finally, the concept of errancy in particular addresses the concerns of scholars like Freccero, Viviane Namaste and Steven Angelides who argue that "queer" has not yet gone far enough in its immateriality or in problematizing and addressing identity's fixity.

Error: A Queer Intervention

"Queer" has existed in various forms throughout the past two decades and as a result, many queer theorists work with varying, though similar, definitions of queer. Throughout this manuscript, queer refers to the "space between [and beyond] hetero- and homo-, normative and non-"which "occup[ies] a place within but not containable by heteronormative phallogocentric logic;" it is "what is and is not there, what disaggregates the coherence of the norm from the very beginning and is ignored in the force to make sense out of the unintelligibilities" (Freccero 18). ${ }^{1}$ Freccero's definition of queer addresses various applications and thinking in queer theory, including theorizations related to bisexual and transgender people, the notion of queer times and places, and hermeneutic theorizations regarding the helpfulness of altered/altering horizons. ${ }^{2}$ It also foregrounds a queer cornerstone of thought: identities are culturally and discursively fabricated. Queer "seeks to expose, affirm and celebrate what identities are forced to deny" because of identity's insistence on unity, exclusion, and normativity (Angelides 164). If identities are fabricated, then they are subject to what Michel Foucault calls "the regime of truth"

\footnotetext{
${ }^{1}$ I've added "and beyond" to Freccero's definition because I seek to expand our notion of identity (and identity performance) beyond the binaries. By identifying space as existing only "between hetero- and homo-, and normative and non-," we erase individuals and experiences who live outside of this space, thereby creating further discomfort and a sense of alienation for some queer people.

${ }^{2}$ See Hall.
} 
wherein "truth" is "produced within discourses that, in themselves, are neither true nor false," but become true through repetitive and validation (Truth and Power 307). That which is not truth—error—offers a unique method for expanding what we think of as queer.

The Latin errare, from which the modern "error" is derived, means both "to wander freely" and "to wander from the right path" (Sng 3). According to Zachary Sng, "the former meaning is neutral, and could be used to describe, for example, the movement of a person or animal," but the "second meaning is pejorative" (3). ${ }^{3}$ Both forms of error persist today—both a motion of free wandering — henceforth "errancy" — and the identification of illusions, failures, deviations, false beliefs, misprints or lies—-henceforth "erring." The first form of error, "errancy," is a nonsystematic and non-systematizable form of movement and being. Errancy refuses to adhere to traditional forms of binary organization and understandings of linear movement and time; by understanding identity as errant we locate a potential to disrupt the current "regime of truth" surrounding identity and for these reasons, I align errancy with queerness (Truth and Power 316). "Erring," on the other hand, validates the "regime of truth"; it relies on culturally

\footnotetext{
${ }^{3}$ This meaning "became prevalent in English usage after the seventeenth century. In the Romantic languages and in German, the neutral meaning of error as mere 'moving about' survived much longer, even though the connection to some sort of intellectual or moral aberration also prevails in current usage" (Sng 3). Sng uses two examples to display the ambiguity of "error": the chevalier errant (the knight-errant) and the juif errant (the Wandering Jew). The knight's journey was imaged positively in the medieval period as courageous and adventurous; the Wandering Jew on the other hand "was seen as a perpetual exile straying from redemption and truth" (Sng 3). Sng's The Rhetoric of Error from Locke to Kleist has greatly influenced my ideas about the productivity of error. While he identifies the two originary definitions of error, I have labeled them "erring" and "errant" to clearly mark one from the other - though their interrelatedness is undeniable. Sng's text does not make this distinction, but his description of the forms of error which he plans to discuss in his primary texts is helpful in understanding what "nonsystematic and non-systematizable form of movement and being" could mean: "uncontrollable and uncontainable movement,... unpredictable convulsions in the machinery of knowledge production,... a troubling thirdness that undoes dialectical opposition and resolution, and... an originary and recidivist contamination" (5).
} 
established norms to define itself and therefore makes visible both the normative and the nonnormative.

Subjects and actions which fall under the category of "erring" reveal the cultural processes of rehabilitation and exclusion via normativity; "erring" reinforces the existence of the norm and helps to consolidate normativity. "Erring" is the most commonly discussed form of error and is often figured as the "region of things that go wrong" (Rescher ix). In his taxonomy of error, Nicholas Rescher focuses primarily on things that err by defining various categories and forms of error which result from belief, behavior, and evaluation. He labels these various forms of error “cognitive" error: resulting from failures to attain correct beliefs and linked to one's intellect, "practical" error: arising from failures in action and linked to one's competence, and "axiological" error: referring to mistakes in regard to evaluation and linked to one's judgment and sometimes character. All three forms of error are a result of a lack of information and reliance on generalizations. Our reflections and experiences constitute our knowledges and since both of these things are inherently limited, we are bound to err (Rescher 14). To better understand how error comes into being, Rescher again divides error into forms of omission and commission: "Errors of omission are failures to accept true facts in the cognitive case and failures to do what is circumstantially required in the practical. Errors of commission lie in accepting falsehoods in the cognitive case, performing counterproductive actions in the practical" (10). While largely a taxonomic project, Rescher's study furthers one's understanding of erring and the attempts to remedy and comprehend such errors.

Errant subjects and objects receive significantly less attention than their erring counterparts because such examples are easy to overlook precisely because they are not involved in the typical binary classification of right/wrong, error/truth-however problematic these 
binarisms may be. As a result of this lack of scholarly consideration of errancy, the chapters that follow offer several examples of errant subjects from late $18^{\text {th }}$ - and early $19^{\text {th }}$-century literature. In large part, my thinking about errancy in this period is inspired by Seth Lerer's study of errors and particularly, Lerer's consideration of Casaubon from George Eliot's Middlemarch (1871-2). Lerer argues that Casaubon is an example of an erring subject because he fails to complete his scholarly project and is "the ultimate in failed writing: someone incapable of anything other than marginal comment; someone who, as he is assisted by his Dorothea, abandons writing altogether and relies on his amanuensis to mark up texts read aloud to him, to sort what would be left as posthumous fragments of an unwritten book" (105). ${ }^{4}$ While these things are certainly true of Casaubon, I contend that Casaubon is also an errant subject because he refuses to adhere to the traditional path of the scholar. ${ }^{5}$ Casaubon refuses this traditional path by rejecting a linear narrative of scholarship oriented toward a concrete book project. While Casaubon imagines a book project, he never moves toward making that project concrete. Instead, he continually remains in the stages of research and data collection. Casaubon explores the various facets of his project without ever concluding them. As scholars, we can right Casaubon's wrongs and thereby get ourselves “on the straight path" of scholarly endeavor, but what if Casaubon never had a path to begin with (Rescher 106)? Instead, he ceaselessly wanders through the potential resources of history and enlarges his scholarly project at his whim. This makes him a subject that is both errant and erring.

\footnotetext{
${ }^{4}$ Lerer's project goals are drastically different than my own. He focuses on scholarly life and argues that "the professionalization of literary study took shape through such encounters with the erroneous; more specifically, through detailed engagements with the classical inheritance of rhetoric and philology. But my conception of error embraces both the erring and the errant ...Being wrong is also about being displaced, about wandering, dissenting, emigrating, and alienating" (2).

5 "Traditional" only if the "traditional path" is the one defined by what now make up tenure requirements wherein scholars are forced to finish their scholarship to progress professionally.
} 
Casaubon is a necessary example because he illustrates that erring and errancy are not yet another binary into which we map identity performance; it is, instead, a category that subjects can both move into and out of and occupy simultaneously.

Forms of error, both erring and errancy, reside in society's and the author's assessments since they are culturally constructed. Erring is created through a process of negation and develops when "a particular regime of truth, and therefore not an error, makes something that does not exist able to become something. It is not an [error] since it is precisely a set of practices, real practices, which established it and thus imperiously marks it out in reality" (Biopolitics 19). Errors are defined and upheld based on cultural norms. Conceiving of identities under the guise of erring is archaic; such an understanding fails to account for the "collective misrecognition" of normative identities, like heterosexuality, as truth. Perhaps unsurprisingly, this conception is maintained by hegemonic culture. As a result, histories of homosexuality, for example, recount attempts to rehabilitate individuals who displayed homosexual desire and/or took part in "homosexual acts" through the use of electro-shock therapy and/or conversion therapy.

Beginning as a liberating politics which offered a way out of the normalizing demands of identity and progressing to Lisa Duggan's critique of queer's normalizing potential, which she termed "homonormativity," 6 the notion of queer has expanded and narrowed over the last twentyfive years. "Queer” has offered ways for LGBT people as well as individuals who do not identify as LGBT to challenge the normative "logics and organizations of community, sexual identity, embodiment, and activity in space and time" (Halberstam 4). ${ }^{7}$ Queer continues to be a useful

\footnotetext{
${ }^{6}$ Duggan uses this term to refer to the integration of heteronormativity in the queer community. Homonormativity limits the "acceptable" images and formations of queer to those that are based on identity rather than difference.

7 "Queer" is not just useful for, directed at, or applicable to LGBT people and this fact is one of the critical successes of "queer." While queer has its own normalizing potential (for example, the
} 
paradigm for analysis because it offers us a theoretical and practical tool for resisting and questioning normativity. ${ }^{8}$ Queer is a theoretical and political tool, yet it is important that those who utilize this tool apply pressure to its limitations and exclusions, including the ways that queer politics of identity (rather than difference) have marginalized trans and bi individuals. ${ }^{9}$ By recognizing these limitations and exclusions, queer theory can continue to imagine its future; my use of "error" as an analytical tool is one such contribution to the ongoing conversation about the limits of "queer" and queer theory. Queer theory must begin to configure identity as errant to gain theoretical and political momentum and usurp current understandings of queers as erring (as deviating from the normalized path). It is necessary to understand cis and trans, "hetero- and homo-," "normative and non-," and the plentiful "space[s] between" and beyond as errant so as to deconstruct hetero-patriarchal power by continuing to unravel the cultural myths of masculinity and heterosexuality as originary (Freccero 18).

While queer theory falters in particular capacities in its current form, there are tangible, useful ways to develop queer theory, and authors like Angelides and Freccero reveal that queer has not outlived its analytic usefulness precisely because it is not stagnant. Queerness is slippery. My thinking about error as a category is heavily influenced by theories of bisexuality because of bisexuality's duality and erasure. Bisexuality, rather than complicating queerness and queer identification, offers a historical, theoretical, and political approach out of the trappings of binary

Human Rights Campaign and what Duggan has identified as homonormativity), it remains a place/space where sexual and/or gender identities are not the only determining factors and enables LGBT people to build alliances across identity groups.

${ }^{8}$ Normativity is a cultural construction and related to what Foucault calls "a regime of truth" and Bourdieu calls "collective misrecognition." It is the ability for something which does not exist to become something because of the hegemonic investment in and rearticulation of the 'thing' (for example: heterosexuality, whiteness) as 'natural' or 'normal.'

${ }^{9}$ For an explanation of 'identity' and 'difference,' see Cohen (73). 
logic and is a key to rethinking queer theory for the future. Some queer theorists have reinforced an either/or model of gender and sexuality (and related identities) and binary logic which, by definition and lived experience, ignores bisexual individuals. Angelides argues that the oversight of bisexuality is a result of "think[ing] the two axes of gender and sexuality vertically and hierarchically rather than relationally and obliquely," contrary to the stated aims of queer theory (163). By subordinating gender to sexuality "and insisting on a degree of analytic autonomy" for sexuality, bisexuality has been erased from the present tense (Angelides 164). Bisexuality can only exist in the past or the future because of queer's insistence on an either/or understanding of gender and sexuality. Bisexuality, rather than an either/or, presents a duality, a "both/and"; it is the "conjunction of hetero- and homosexuality" (Angelides 15). Historically, bisexuality has been erased from gay and lesbian communities because of its existence in a future "nowhere place," as an indicator of the potential sexual utopia which might exist without the sexist structure of society (126). Additionally, bisexuality was erased during the gay liberation movement (and again by radical lesbianism) because it threatened the homogeneity of the gay community and ushered heterosexual practices into a community which cohered based on its homosexuality. Bisexuality has been perceived as either a utopic existence which could never exist or a threat to the cogency of the gay liberation movement; it has repeatedly been displaced.

Similarly, the homonormative politics of the $21^{\text {st }}$ century erase queer people who do not align with the politicized images of normativity—people who identify with labels like trans, dyke, pansexual, intersex, boi, genderqueer, asexual or ecosexual. Homonormativity is used to advocate for rights like gay marriage and same-sex adoption. ${ }^{10}$ It is precisely this erasure that leads Shane Phelan to ask: "What is to be gained by inclusion" and "what are the costs—what

\footnotetext{
${ }^{10}$ See Namaste and Phelan.
} 
will be lost, either in cultural integrity, intragroup relations, or otherwise?" (85). As we "[confront] and [overcome] sexual strangeness" we, inevitably it seems, further marginalize the groups of people who are most essential to our community if, in fact, we are a community rooted in our experience of difference and our connection as a result of such experiences (Phelan 84). As we seek out normativity, we create a further stigmatized and marginalized group of people unable and/or unwilling to conform to homonormative expectations. Today's sexual politics often erase people for the supposed benefit of homonormative queers. If queer theory is a methodology for understanding the cultural systems that make up power hierarchies rooted in identity, then it must continue to address those who are left behind when the queer community's "aspiration [is] to see ourselves as normal" (Warner 59). Angelides insists that bisexuality is useful to queer politics and theory because it removes the emphasis from identity, something that queer theory has attempted (sometimes successfully, often not) since its inception; bisexuality helps us to escape the realm of identity because while the sexual practices of individuals throughout his/her lifetime may fit the description of "bisexuality," bisexuality has been "barely (if at all) visible as a palpable cultural identity until recent decades," particularly in the 1990s (Angelides 9). Similarly, when we shift the function of "queer" in language from an adjective to a verb and we begin "queering" subjects and objects, the potential for queer to disrupt power structures is even more palpable. This is precisely the power of queer.

When we use queer as critique, as a way to interrogate binaries, norms, and identity politics instead of using it to critique identity groups, we must confront the immateriality of queerness. It is only in this form that "queer" makes it possible to reveal the imaginary nature of homonormativity, the cultural construction of gender norms, the conflicting double standards surrounding promiscuity, and the instability of all through-imagination-made-real constructions 
when just a bit of pressure is applied. I have taken Angelides' and Freccero's leads, and through my application of error, work to deconstruct the seemingly axiomatic structures of gender and sexuality. In arguing for queer errancy, I make visible those performances of gender and sexuality that have been erased from the present tense of queer theory and offer queer theorists and politics a tool to alter the current manifestation of "queer."

Queerness, in its immaterial form, is often used to reframe a concept that is traditionally thought of as having a negative connotation and refiguring it. In that refiguring, what was once only negative is deployed as a tool for undermining normative value structures. In The Queer Art of Failure (2011), Judith Halberstam uses the productive potentiality of failure, a traditionally negative category, to find new and valuable ways of imagining and being queer. In a similar vein, I utilize the often negative and undesirable term "error" and the divisions "erring" and "errant" to "locate...in-between spaces that save us from being snared by the hooks of hegemony" (Halberstam 2). While in this project I primarily take up representations of gender in $18^{\text {th }}$ - and $19^{\text {th }}$ - century literature, I do so to intervene in our contemporary understanding of identities and personages.

Gender and Sexuality in $18^{\text {th }}$ - and $19^{\text {th }}-$ Century Britain

Throughout the Romantic period, gender and sexuality (understood through the paradigm of gender) were indeed shifting. In chapters two through five I interrogate gender and sexuality in the Romantic period and, just as sexuality is becoming less fluid, gender too shifts during the turn of the century. However, the process of change is snail-like; scholars cite individuals like Mary Wollstonecraft and the domestic practices of the mythical Angel of the House as catalysts for change, but the effects of their subversive actions (even if not consciously subversive as in the case of female friendships, for example) were not fully comprehensible and recognizable in 
the moment. ${ }^{11}$ Felicia Hemans's poetry captures some of the changes occurring in the social constructions of gender and a brief analysis of her poetry in Records of Woman reveals how errant queerness can be located in the Romantic period.

Hemans is framed by critics and readers as the feminine "Mrs. Hemans" and simultaneously challenges the organization and separation of the home and nation, demonstrating the process of change in the social construction of gender in particular. Additionally, Hemans's cultural framing, as argued by Susan Wolfson, further exposes the changes occurring in relation to gender. Wolfson traces Hemans' characterization in the literary economy in Borderlines (2006). Hemans is framed as Mrs. Hemans, the "poetess," the "female poet"- however contrary this was to her actual sentiments about gender roles and women's writing. She is not "Blue [stocking]" but true woman, that is as domestic, caring, compassionate and loving. However, to label her poetry "feminine poetry" is praise subverted. Such praise functions to separate her from male poets and the genres and topics which, according to the cultural narrative, "really matter" (i.e. masculine poetry, nature, genius, individualism); "distinct from the man of letters, a poetess radiated sentiments, effortless grace, domestic culture, and the lesser genres" (Wolfson 41). Hemans is kept in her place, and her skill as a writer is qualified as "feminine."

Hemans's poetry addresses the concerns of the nation as well as the family, and as a result, her voice crossed the boundaries between private and public. The two were no longer inherently separate as the home began to function as a symbol of the nation and the nation was modeled on the home. Hemans is applauded for her skills as a "poetess" and pushes the boundaries of what exactly that meant. She maintains her femininity as a poet, garnering both

\footnotetext{
11 The emergence of the New Woman at the end century indicates that gender was indeed under pressure in such a way that a new form of femininity (though often labeled 'mannish') was worthy of demarcation
} 
critiques and accolades. ${ }^{12}$ Her poetry is too feminine to be taken as seriously as Keats or Byron, but if her content becomes too masculine then she joins the ranks of "Amazons" like Wollstonecraft. For example, in "The Homes of England," printed in the "Miscellaneous Pieces" section of Records of Woman, Hemans celebrates domestic life and its material signifying practices. "The stately...the merry...the blessed... and the free, fair Homes of England" are the center of English life and prosperity; like Wollstonecraft, Hemans shifted femininity by empowering the home. The home, the traditionally private, feminine realm, explodes into the public sphere blurring the lines between home and nation, and (re)shaping the social construction of gender.

Many poems collected in Records of Woman narrate the shifts in gender paradigms, including "The Bride of the Greek Isle."13 The poem tells the story of Eudora, a bride-to-be who struggles to leave the safety of "her father's hall" for "love yet untried and new" and who then seeks vengeance for the death of her husband during their marriage ceremony (28-9). ${ }^{14}$ Part I and "The Bride's Farewell" tell a story of domesticity and daughterly-duty. The remainder of the poem is a tale of re-defined femininity and nationality. ${ }^{15}$ In "The Bride's Farewell” Eudora struggles to leave the memories, familiarity and comfort of her childhood home for Ianthis's home (her husband-to-be). Then, Eudora immediately faces danger during her wedding

\footnotetext{
${ }^{12}$ Here I'm referring to Wolfson's discussion of Hemans' poetry. Hemans is somewhat critiqued into a corner-her poetry is too feminine, but if she "becomes" more masculine then she is critiqued for failing to be feminine.

${ }^{13}$ Also as a struggle between being a poet and being a woman-I see these two conflicts nation/poet and woman/family as largely connected to one another.

${ }^{14}$ The section of the poem sub-titled "The Bride's Farewell" is narrated by Eudora; she cries, "A thousand thoughts of all things dear, / Like shadows o'er me sweep, / I leave my sunny childhood here, / Oh, therefore let me weep!" (48-51).

${ }^{15}$ Wolfson argues that "The Bride of the Greek Isle" is bound to no national cause either, just a culturally mapped traffic in women (64). Wolfson also argues that the poem can be read as a critique of "woman as a commodity in a patriarchal economy."
} 
ceremony when a pirate horde attacks $(131) .{ }^{16}$ She survives the attack, but Ianthis dies. ${ }^{17}$

Eudora, abducted by the pirates "for sale into slavery," lights the pirate ship on fire as her mother watches from shore, aware that her daughter will die on the burning vessel. ${ }^{18}$ Eudora's femininity empowers her to seek vengeance, and her Greek blood is the source of her strength (via anger) and her demise. ${ }^{19}$ Hemans pairs the pastoral femininity of Eudora's departure from home with the dark, war-like scenes of her marriage, her husband's death, and her revenge. Eudora is responsible for her fate, by calling on her Greek "blood" and the freedom that it allows hereven if that freedom is only obtainable through death. Her nation, as she experienced it in her family home, shapes her femininity. Eudora illustrates the shifting of gender by disallowing the piratical nation to narrate her role as a woman - she removes herself from the patriarchal economy by reconfiguring it, in this case through destruction. Similarly, destruction as a methodology for refusing the traditional boundaries of femininity influences my reading of Amelia Alderson Opie's Something New in chapter three.

Felicia Hemans' poetry is "appropriately feminine" and forces readers to examine the inherently limited definition of femininity, often via heroines like Eudora. Hemans, like her female characters, carefully balances Romantic gender expectations, teetering between the domestic Angel of the House and those wicked Blues. Her poetry's ability to traverse the borders

16 "Fling down the goblet, and draw the sword! / The groves are filled with a pirate-horde!" (130131)

17 "She knelt down beside him, her arms she wound, / Like tendrils, his drooping neck around / ...The sea's fierce rovers - they left him there" (146-151) Eudora's mental state changes throughout the poem; after the pirate attack, her mental state is clearly different than the fond, loving daughter at the beginning of the poem.

${ }^{18}$ Mother! who stands on the deck alone? / The child of thy bosom! ... /Oh! could this work be of woman wrought? / Yes! 't was her deed! - by that haughty smile / It was her's! - She hath kindled her funeral pile! /Never might shame on that bright head be, / Her blood was the Greek's, and hath made her free. (203-215)

19 "Proudly she stands, like an Indian bride / On the pyre with the holy dead beside" (216-7). 
of femininity and masculinity, often within traditionally feminine narratives - the home and marriage, for example - applies pressure to the problematic divisions between private and public and masculine and feminine. By interweaving family and nation in her poetry, Hemans expands the boundaries of British femininity to include nationhood and she does so under the guise of "Mrs. Hemans." ${ }^{" 20}$ I understand such fluidity locatable in Romanticism as errant queerness. Queer theory attempts to undo the interconnectedness between gender, sex, and sexuality and challenges a simplified, binary understanding of identity. For example, in Vice Versa: Bisexuality and the Eroticism of Everyday Life (1995) Marjorie Garber argues that bisexuality (specifically) is not an identity but a narrative, sexualities (generally) are not "identities" but "positions of identification," and "secure identities and divisions" are "on the way out" $(183,87)$ Garber forecasts the loss of coherent identities and identity narratives and the positive revaluing of discontinuity, but according to theorists such as Angelides and Namaste, queer theory still clings to such fixed, "secure identities and divisions," rather than embracing fluidity. It continues to insist on an "either/or" understanding of sexuality, gender, and their interrelatedness rather than "both/and." This approach necessarily limits and erases persons who do not easily map into

\footnotetext{
${ }^{20}$ As Wolfson discusses, Hemans was aware of the contradiction this position presented. Another example of shifting constructions of gender takes place in Middlemarch (1871-2). Dorothea is an example of shiftings in the construction of gender during the period, including the regression and advancement that occurs in the process of change. Dorothea dreams of having expanded influence and believes her marriage to Casaubon will grant her what she seeks. At the beginning of the novel, she seeks out a role as the "Angel of the House" and fancies herself a traditional domestic woman, but after she becomes a wife (and those expectations become real in her daily life) she is clearly uncomfortable with the expectations that come with domestic femininity. During her marriage to Casaubon, she is tethered to the role of domestic woman. Her later marriage to Will Ladislaw (and the fact that she forsakes the money from her marriage to Casaubon) is representative of the move toward the "New Woman" (related to the Blue Stockings of the Romantic period); she is independent and rational. Middlemarch was not published until the 1870s and while this is outside the range of dates I've specified in this project. However, the book is set in 1830-32, so it offers a reflection on Eliot's understanding of gender in the Romantic period.
} 
discrete "either/or" categories (Angelides 15). The British Romantic period is essential to understanding the emergence of such either/or categories.

The notion of queerness as some identifiable materiality is due to its connection to identity. Since the rise in judicial-medical discourse during the late 19th century, sexuality has largely been understood using the binary terms heterosexual/homosexual which linked one's sexual acts and identity. Underlying this false binary is the division between truth and error. Richard von Krafft-Ebing's 1894 publication of Psychopathia Sexualis ${ }^{21}$ helped to set cultural notions of sexuality as heterosexual and homosexual. Krafft-Ebing figures homosexuality as error by positing its removability: "[T]he object of post-hypnotic suggestion is to remove the...homosexual feeling and impulses and to encourage hetero-sexual feelings with a sense of virility" (324). Heterosexuality is figured as originary truth while non-heterosexual identities are figured as erring, deviating from established norms. Then, the discourse becomes even more convoluted as gender is attached to sexuality. Because the shift from acts to identity indicates a significant alteration in the ways that acts create meaning, it is impossible to trace identity backward in a cogent or coherent manner. Instead, as David Halperin argues in How to Do the History of Homosexuality, we are only able to trace particular facets of sexual identity backward. ${ }^{22}$ As Halperin points out, this often means identifying key elements that contribute to the construction

${ }^{21}$ The Oxford English Dictionary cites 1892 as the first use of "heterosexual" and "homosexual" by Krafft-Ebing in Psychopathia Sexualis, while the publication date of the text is 1894; this discrepancy is due to the OED's citation of the German edition and my use of the English translation.

${ }^{22}$ For Halperin, these facets include effeminacy, pederasty or sodomy, male friendship and love, and sexual inversion. These categories are distinct from "homosexuality" in that they do not reference "a sexual drive directed toward persons of the same save as the sex of the person who was driven by it" (131). Instead, they are, as Halperin argues, elements that in some ways make up our modern understanding of male homosexuality. 
of a sexual identity and seeking out those connections throughout history. For the Romantics, just as for many $21^{\text {st }}$-century Americans, gender and sexuality were inherently interconnected.

Since sexuality was not a specific and separate identity category for Romantics, sexual acts were often integrated into various gender identities. Sodomites and effeminates are excellent examples of this phenomenon. ${ }^{23}$ "We are now all too familiar with the Victorian beliefs that women and men were essentially opposite sexes, and that marriage to a man was the chief end of a woman's existence," Sharon Marcus points out (1). By focusing solely on women "as relative creatures" who are "defined by their different from and subordination to men," scholars inevitably "limit our understanding of gender, kinship, and sexuality" (Marcus 1). Marcus' study focuses on the Victorian period, but her observations about the perceived fixity of gender in the period, as well as the period's sexual conservatism, reflect a Victorian-era reaction to the perceived liberty of the Romantic period. Unlike the Victorians, the Romantics, as Thomas Laqueur argues, saw the two sexes as complimentary. Such a belief system meant that some individuals in the Romantic period thought the ovaries were an internalized version of the testes. Because of this belief system, sex was not as distinct for the Romantics as it was for the Victorians. There was an inherent, biological similarity between men and women; Richard Sha succinctly summarizes the impacts of the one-sex system: "[D]ifferences between the sexes are of degree, not kind" (79). Simultaneously, the two-sex model persisted wherein "differences are of kind, not degree" (Sha 79). The conflicting, often interwoven understandings of sex in the Romantic period makes it a period wherein notions of sex, and its connection to gender, are clearly in process, ultimately shaping theorizations like Krafft-Ebing's.

\footnotetext{
${ }^{23}$ Randolph Trumbach argues that sodomites and effeminates are a third gender, while Richard Sha argues for our understanding of them as a third sex. See Andrew Elfenbein for more on the connection between effeminacy and sodomy.
} 
Work by scholars such as Sha and Andrew Elfenbein reveal the centrality of sexuality in Romantic literature, and they do so via discussions of gender. For example, Sha argues that science becomes a sort of sexual pleasure for men like William Hunter, William Blake, Lord Byron, and Percy Shelley. This sexual pleasure derived from the masculine field of science was entirely distinct from the sexual pleasure that resulted from marriage or sex for reproductionsexual pleasure that is markedly connected to the feminine space of the home. Like Sha, Elfenbein utilizes gender to discuss sexuality; he demonstrates a connection between genius and homosexuality. In his discussion of Romantic notions of genius, genius is always gendered. He notes that "artistic genius has...been defined as male"; as a result, "traditional concepts of genius hide lesbian history" because women aren't noteworthy. When "female geniuses are acknowledged" they are likely to also be considered "too masculine" (Elfenbein 5). Despite the fact that Romantics saw "masculine women" as "abnormal, only they can achieve anything valuable because merely feminine women are worthless"; in spite of this "misogynistic tradition," Wollstonecraft still "appropriate[ed] the link between homosexuality and genius for lesbian representation" (5). Within Elfenbein's discussion, sexuality is linked to gender and gender to sex, reflecting the interconnectedness of these categories in Romantic culture.

What contemporary culture would label "sexuality" was often understood within the paradigm of gender for British citizens of the late 18th and early 19th centuries. Though perceived as fixed, notions of gender and sexuality are constantly in process in the individual and in culture at large. Even those same-sex practices which $21^{\text {st }}$-century American culture would categorize under the label of "sexuality" were understood as a betrayal of gender roles, not a part of a distinct sexual identity (Elfenbein 19) ${ }^{24}$ Rather than thinking of the changes to the social

\footnotetext{
${ }^{24}$ See also Marcus.
} 
constructions of gender and sexuality as "significant," which implies that the changes were considerable or drastic, it is most productive to understand the changes occurring in relation to gender and sexuality as constant and protracted. Anne Mellor's 1993 landmark study of gender in the Romantic period challenges the then-dominant understanding of Romanticism as a definitively male and masculine period of literary history. She demands that we expand our understanding beyond the scope of the "Big 6" (Blake, Byron, Coleridge, Keats, Shelley, and Wordsworth) as well as their commitment to "imagination, vision, and transcendence" and incorporate the female writers of the period to reconfigure our understandings of Romanticism (Mellor 1). By expanding the Romantic canon we discover that Romanticism is not only about the "achievements of the imagination"; women writers "tended to celebrate...the workings of the rational mind, a mind relocated — in a gesture of revolutionary gender implications — in the female as well as the male body" (Mellor 2). Mellor's argument is essentially that gender is a continuum and any author can occupy any place in that continuum at any time, even changing locations within a single work. Not only does Mellor insist that our view of Romanticism has been historically limited and sexist, but she also argues that our understandings of gender in the period have suffered from such a limitation. The essential work by critics such as Claudia Johnson and Susan Wolfson take up Mellor's argument to further complicate our understanding of how gender operated in the Romantic period. Like Mellor, Johnson, and Wolfson, this text seeks to complicate how we frame our understanding of gender and sexuality in British literature of the Romantic period.

Overview of Chapters

In the remaining chapters of this text, I seek to demonstrate the usefulness of errancy as a concept alongside and in conversation with queerness. In chapters two through five, the primary 
texts are those written in the British Romantic period. Each author's narrative results in a female character who, according to my analysis, posits that there are more options available to women than mother, harlot, or spinster. My goal in each chapter is to demonstrate how narratives about women in the Romantic period sought to normalize femininity in a particular way-by aligning it with sensibility, for example. Any deviations from this norm were treated as mistakes in need of correction. Each narrative also, perhaps mistakenly, enabled another form of femininity to emerge, subverting normativity, if only for just a moment. These forms of femininity, I demonstrate, are errant because they confound the normative system for comprehending gender. Finally, in the epilogue, I return to the present day in my analysis of Thomas Beatie's autobiography, Labor of Love. I utilize Beatie's narrative of his life as a forward-looking example of why queer theorists must continue to question our assumptions and push the uses of our theories even further if we hope to advocate for our entire community.

In chapter two, "Sensibility and Errancy in Godwin's Memoirs of the Author of the Vindication of the Rights of Woman," I explore the intersections of error and morality. I argue that Memoirs troubles the stability of categories perceived as normalized, such as masculine and feminine, upsetting the social productivity of these categories in determining established behaviors and morals. The publication of Memoirs led to outrage from the conservative press; it stimulated existing debates (initiated by Vindications) about Wollstonecraft's ideas and her femininity by way of her morality. The facts of Wollstonecraft's life and Godwin's narration display her supposed erring femininity: she loved both men and women and carried on affairs with married men, even bearing a child with Imlay which led to her "vilifi[cation] by [England] as a whore and an 'unsex'd Female"' (Todd ix). I turn what is negatively perceived by late $18^{\text {th }}$ - and early $19^{\text {th }}$-century mass culture as a refusal of the normative in Wollstonecraft's life into a 
productive errancy (because of her ability to undermine the "regime of truth" via fluidity and refusal of clear-cut classification) by tracing Wollstonecraft's wandering between and beyond normative and non-normative embodiments and articulations of femininity. Godwin's unique approach to biography was largely responsible for the immensely negative public reaction to Memoirs which validated cultural notions of Wollstonecraft as an erring woman. Godwin felt that the details of Wollstonecraft's life, because she was an individual "who contributed to moral and social improvement in [her] own time," would inspire readers with the spirit of social reform (Clemit and Walker 13). He discarded the division between Wollstonecraft's private and public lives (sharing her most intimate sexual and psychological moments) to "[transform] the moral consciousness of his readers" (Clemit and Walker 13). In Memoirs, Wollstonecraft is treated as a literary character; like Caleb Williams, she is meant to provoke philosophical reflection and eventually cultural change, at the (perhaps unexpected) expense of her personal and professional reputation.

The third chapter investigates the strictures and freedoms associated with monogamy, the supposed ideal state of adulthood and sexual development, and "call[s] attention to the mythology by which marriage is idealized" (Warner 88). In "Unbecoming: Coquetry and Futurity in Amelia Alderson Opie's Dangers of Coquetry," I argue that the portrayal of coquetry in Dangers is an example of feminine errancy that makes visible an alternative femininity. My application of "error" to Dangers shows that Opie's portrayal of Louisa's coquetry is an example of feminine errancy which makes visible a femininity that challenges the way that families and nations organize futurity. By projecting Louisa's desire beyond and within her monogamous marriage, Opie's narrative reveals marriage's inability to contain emotional and erotic desire, ultimately challenging eighteenth-century myths of marriage as an institution which helped to 
delimit acceptable feminine performances by linking femininity to "wife" and "mother." Louisa's death, and the death of her fetus, is the ultimate rejection of such heteronormative futurity. She births not a child, but an alternative, critical femininity.

Building upon the potential for alternative futures, I argue for the potentiality of a queer gaze in chapter four. In “'How Idle is Beauty’: Interiority, Femininity, and the Queer Gaze” I argue that Anne Plumptre's Something New: or, The Adventures at Campbell-House (1801) critiques the normative notions that align femininity and beauty, primarily Edmond Burke's objectification and commodification of women in A Philosophical Enquiry into the Origin or our Ideas of the Sublime and Beautiful (1757), through the use of a queer gaze and the creation of a heterotopic space. I utilize the concept of the queer gaze to argue for an alternative way of looking that embodies queerness' propensity for destabilizing established binaries. In Something New, Olivia is Burke's "rugged," "negligent” object $(1757,115) .{ }^{25}$ Her beauty "deviates" from "the right line" and her physical ugliness is repeatedly emphasized. In just the first fifteen pages she is described as "proverbially plain," "uncommonly plain," (5) "not handsome," (6) "damned ugly" (10), and "a little ugly, black-faced thing, with eye-brows in a straight line from one side of her face to the other" (15). Yet, as Lionel observes Olivia's behaviors and her moral character, he begins to see that beauty lacks the transformative power of the sublime. Lionel's temporary transformation into a queer seer is traceable in his acknowledgment of beauty's shallowness. He begins to reckon with how his absorption of beauty's value may have limited his notions of love to qualities that end with "the tomb" (Plumptre 122). Olivia and her queer gaze are not viable

\footnotetext{
25 "Sublime objects are vast in their dimensions, beautiful ones comparatively small; beauty should be smooth, and polished; the great, rugged and negligent; beauty should shun the right line, yet deviate from it insensibly; the great in many cases love the right line, and when it deviates, it often makes a strong deviation; beauty should not be obscure; the great ought to be dark and gloomy; ... one being founded on pain, the other on pleasure" (Burke 1757, 115).
} 
outside of Campbell-House or Something New, yet the emergence of Olivia's gaze alters "the national imaginary" and demonstrates the possibility of difference (Freccero 8).

"Erring Populations \& Population Debates as Prophylactics" considers the ways that the Romantic population debates framed working-class, poor, female bodies as erroneous. The mistake of a growing, impoverished population was in need of correction because of the inevitable effects on the national body. To understand the evolution and effects of political economy in the Romantic period, I contextualize two pivotal texts: William Godwin's Enquiry Concerning Political Justice and Thomas Malthus's An Essay of the Principle of Population. I then go on to analyze Harriet Martineau's Illustrations of Political Economy using theories of power, value and bodies. The Romantic population debates were power negotiations about the ways that female sexuality and reproduction should be managed in the interest of the national body. The bodies of working-class women, especially those capable of reproduction, represented all that the population discourses addressed: concerns about population growth, poverty, availability of subsistence and female sexuality. Martineau's narrative changed the focus of the population debates by forging a particular domain for women; the impoverished female characters in Illustrations intuitively practice population control. Martineau's narrativization of political economy in Illustrations of Political Economy, published from 1832-1834, challenges the subordination of the female body by making every body, regardless of sex and gender, subordinate to the needs of the nation. She alters the direction of political economy by acknowledging women's effect over population outside of their role as the citizens who quite literally reproduce. She makes them the agent for controlling erroneous populations. Simultaneously, she supports Malthusian theories that disempower poor people. The power to control female sexuality is the power to control population and the growth and wealth of the 
national body. Romantic population debates falsely claim that population control helps create greater security for vulnerable people; in fact, the effects of the population debates increase the vulnerability of people, particularly those who are impoverished and female. Despite Martineau's anti-patriarchal deployment of political economy, she does uphold the hierarchy of the class system. While she holds both men and women responsible for checking population, she places the responsibility of population control squarely on the shoulders of poor citizens. The potential for reading Martineau as a queer errant subject of the Romantic period is problematized by her investment in population theories that disempower impoverished people. Ultimately, she is complicit in the master discourse of (masculine) population theory, a discourse that values the nation's body over the female individual's, and she frames impoverished English citizens as an error in need of correction.

Finally, in the epilogue I turn to contemporary queer politics and identity to reiterate the usefulness of error as a heuristic for thinking about identity across time. Via my analysis of Thomas Beatie's biography, Labor of Love: The Story of One Man's Extraordinary Pregnancy (2008), I demonstrate how understanding identity as errant offers queer theory ways to grapple with the materiality of the body and the immateriality of sexual and gender identities. Responses to Beatie, from the popular media as well as lesbian and gay media outlets, reveal the inability of the hegemony and the queer community to grapple with difference, especially when that difference cuts across multiple medical, judicial, and identity boundaries. From The Advocate to The Oprah Winfrey Show, Beatie is framed as an erring subject, but his personal, experiential narration in his autobiography Labor of Love: The Story of One Man's Extraordinary Pregnancy is that of an errant subject. Throughout Labor of Love Beatie narrates his life as wandering, his identity as nonsystematizable, and his marriage to Nancy as uncontainable; he self-identifies as a 
lesbian woman and then as a heterosexual man. His marriage to Nancy is contingent on their awareness of legal and state boundaries and his ability to maneuver through and around those boundaries. Beatie's account of his life allows me to look forward to the productivity of error in queer theory, both in the classroom and on the street. The current division in queer politics between homonormativity and radicalism perpetuates the division between truth and error and steers the queer political movement in the same direction as heteronormative politics. I question how such political maneuvering abandons "both/and" queers like Beatie in favor of "either/or" queers like those who model the politically charged t-shirts and messenger bags of the Human Rights Campaign. 


\section{Chapter 2}

\section{Sensibility and Errancy in William Godwin's Memoirs of the Author of the Vindication of the Rights of Woman}

In the preface to the first volume of Mary Wollstonecraft's "Letters and Miscellaneous Pieces," published alongside Memoirs of the Author of the Vindication of the Rights of Woman $(1798),{ }^{26}$ William Godwin writes, "The following letters may possibly be found to contain the finest examples of the language of sentiment and passion ever presented to the world...They are the offspring of a glowing imagination, and a heart penetrated with the passion it essays to describe" (2: preface). Godwin uses his preface to position Wollstonecraft as the epitome of femininity: a "sentiment[al]" woman driven by "passion," a mother whose literary works are her "offspring"; in doing so, he reframes her authorial life to correct her movement away from traditional femininity and reinforces culturally traditional gender roles. Through Memoirs, Godwin narrates Wollstonecraft's gender performance as error.

In this chapter, I analyze Memoirs of the Author of A Vindication of the Rights of Woman to show that "error" is a useful category for understanding and deconstructing the ways gender identity was organized and articulated in the Romantic period. Following Zachary Sng's theorization of error, I divide error into two forms: erring and errancy. ${ }^{27}$ "Erring" indicates

\footnotetext{
${ }^{26}$ The text of Memoirs of the Author of the Vindication of the Rights of Woman used throughout this chapter is the Broadview critical edition edited by Pamela Clemit and Gina Luria Walker. ${ }^{27}$ To date, Sng's analysis of error is one of the most thorough and thoughtful scholarly texts on the subject. In The Rhetoric of Error from Locke to Kleist (2009) Zachary Sng deploys a dual reading of error in the eighteenth century: the first reading "is a reconstruction of the rhetorical strategies that such texts employ to produce the category of 'error' and to allow for its containment or conversion into gain"; the second reading examines "how error itself produces a vertigo-inducing suspension of the strategies revealed by the first reading" (Sng 9). The focus of Sng's study remains rhetorical as he reveals the ways in which error upsets "models of influence, borrowings, or continuity without re-invoking these as heuristic or critical tropes" in the works of Leibniz, Horne Tooke, Coleridge, Adam Smith, Goethe, and Kant (10). My purposes differ from Sng's in that I wish to show that certain forms of error are in fact heuristic and help us to
} 
illusions, mistakes, failures, and deviations; as a result, "erring” subjects bear a negative connotation. Subjects which "err" validate what Michel Foucault calls "the regime of truth" because "to err" one must define subjects against cultural norms and determine whether or not cultural norms are supported or challenged by the subject under examination ("Truth and Power" 316). ${ }^{28}$ In the process of identifying those which err, normative and non-normative identities and subjects are defined and made visible. Marking individuals who fluidly move between these two gender labels as "erring" problematically reinforces notions of fixity in relation to gender identity. Understanding gender through only two categories (masculine and feminine) that are largely associated with and attached to one's sex furthers the cultural mythology that all samesexed individuals inhabit their bodies and minds in the same ways; this cultural mythology systematically excludes and stigmatizes individuals who do not experience their bodies and minds in the expected manner. When deviations from the norm are identified, those deviations become subject to cultural processes of rehabilitation and exclusion, reinforcing the existence of the norm and helping to consolidate it. ${ }^{29}$ Understanding particular subjects as "erring" supports

understand an alternative way of being in the world - a way of being which offers a potential to disrupt current "regimes of truth" and power/knowledge production, particularly regimes which define and normalize gender. Despite such differences, Sng's definitions of error provide a useful starting point. He begins with the Latin errāre, from which the modern term "error" is derived; errāre means both "to ramble, roam, stray, wander" and "to go astray to stray from (one's path or line of direction)" (err).

${ }^{28}$ In The Birth of Biopolitics, Foucault discusses his own theorization of how error occurs. Erring subjects are created through a process of negation and develop when "a particular regime of truth, and therefore not an error, makes something that does not exist able to become something. It is not an [error] since it is precisely a set of practices, real practices, which established it and thus imperiously marks it out in reality" (Birth of Biopolitics 19).

${ }^{29}$ Arguably, this is why butch lesbians are often left out of the imagery of the homonormative agenda. Two femme lesbians with a baby, however, are easier to place within gendered discourse and therefore are more palatable to the American viewing (and voting) public. They are easy to read as "feminine" and fit within a heteronormative understanding of femininity: mother, family member, caregiver, soft. 
the cultural narrative that non-normative subjects and actions are readily identifiable and capable of being "corrected." When applied to gender this means that individuals who do not fix themselves to a singular identity ("masculine" or "feminine") are labeled as "erring," when in fact, as I argue, a better way of understanding gender generally is through the guise of "errancy." "Errancy" offers a helpful label when identifying subjects which "ramble, roam, stray, [and] wander" (Sng 3). Errant subjects refuse to adhere to traditional forms of binary organization and challenge the notion of a cultural norm entirely. They shed the negative connotation of error because they have not "failed"; there is no originary, no "cultural truth" or norm against which to judge their acts because they refuse the idea that such things even exist. By identifying errant subjects we make space for an analysis which insists that cultural norms are divisive tools that create a hierarchy in favor of the identities perceived as "originary" (which also often aligns with the social majority). I value errant subjects because they undermine gender as a fixed category by refiguring the available vocabularies and resultant narratives about gender as "rambl[ing], roam[ing], stray[ing], [and] wander[ing]" in Romantic England. Errant subjects abandon hierarchy because nothing is fixed, nothing is originary; they defy intelligibility because they refuse the current system used to make meaning. Throughout this chapter, I emphasize the revolutionary potential of errors that do not judge movement and are suspect of fixity. Errant subjects open up discursive space that invites us to reconsider the ways in which we narrate gender and the ways that such narrations trap us; errant subjects show us that gender is more complicated that our current vocabulary and imaginary allows us to say or think. While an 
individual's gendered experiences may be fixed, the way that individual is forced to identify those experiences, collectively and individually, as "feminine" or "masculine" is quite fluid. ${ }^{30}$

In Memoirs Godwin seeks to restore Mary Wollstonecraft's public reputation, focusing on her traditionally "feminine" roles as teacher, daughter, and mother, rather than on her more "masculine," and therefore controversial positions as cultural critic, revolutionary, and feminist. Godwin does so because he thinks this will help rehabilitate her public reputation; by making her "appropriately feminine," he hopes that readers will be more receptive to understanding her life the way he does: as an example of productive citizenry because her life was in service of the betterment of the nation. ${ }^{31}$ Godwin believed that biography was a way to improve the British people by offering exemplary lives as models for citizenship. If the public perceives Wollstonecraft as too masculine, this opportunity is preemptively foreclosed because she cannot even be considered as a role model for women, let alone citizens generally. He displaces any movement away from such femininity as erring on her part—deviations from the norm, oddities

\footnotetext{
${ }^{30}$ For example, when I go from a "masculine" task to a "feminine" task, I do not experience a shift in the way I understand my identity or self. Though this example may seem reductive the advertising industry makes it quite clear that these are particularly gendered household tasks. It is when I am asked to identify as either "masculine" or "feminine" that my movement between the categories becomes visible to me. In such a situation most individuals select the option under which a majority of his/her behaviors fall, or simply select the signifier that s/he knows to be most culturally appropriate.

${ }^{31}$ Femininity was under construction throughout the Romantic period, largely in part due to Wollstonecraft's own proto-feminist work. However, via Wollstonecraft's work, we can locate a form of femininity from the old regime, so to speak. Wollstonecraft put forth a revolutionary ideology, what Anne Mellor (Romanticism and Gender, New York: Routledge, 1993) calls "the feminine Romantic ideology," in reaction to the traditional version of femininity enacted by Romantic women and supported by patriarchal culture's continued oppression of women, including denying women access to education and legal independence (Mellor 33). Wollstonecraft reacted to "traditional femininity" by proposing "an ideology grounded on a belief in the rational capacity and equality of woman" (Mellor 33). It follows, then, that she redefined an existing version of femininity which denied rational capacity and instead centered on "the female as innately emotional, intuitive, illogical, capable of moral sentiment but not of rational understanding"-what I term "traditional femininity" (Mellor 33).
} 
when considered against the narrative of the whole, behavioral outliers. One of Godwin's primary approaches to "properly" gendering Wollstonecraft is by using sensibility; in any instance when Wollstonecraft's behavior is not "appropriately feminine" Godwin makes great efforts to construct a narrative where personal events lead to her slipping into the "Amazonian," masculine he/she woman that England so feared. ${ }^{32}$ Godwin errs by narrating gender identity as cohesive and fixed. Throughout Memoirs he works to situate Wollstonecraft's work as an author and cultural critic within her personal and sensory experiences, rather than deriving from her intellect or processes of reasoning. This division creates a false binary that refuses the interplay between emotions (derived from the senses $\sim$ the body) and intellect (derived from rational thinking $\sim$ the mind). He embraces fixed notions of gender in doing so. In attempting to fix Wollstonecraft into a narrative of traditional femininity throughout Memoirs, Godwin errs because he fails to understand Wollstonecraft's lived errancy. This failure reflects his inability to shake the bounds of gender; because of his assumptions about gender, shaped by his (largely normative) masculine cultural position, Godwin was less likely to consciously think about the ways in which gender limited or freed him to take on certain roles. Godwin's inability to narrate Wollstonecraft's gender as errant reflects his hegemonic imagining of gender as distinct and fixed.

32 "Amazon" became "the "Augustan code word for female pride and gender crossing"” (BarkerBenfield 351). For male writers, terming women authors "Amazons" served as a method to silence those who stepped outside "the "bounds of female authorship," but "to female writers...the Amazon was a figure of remarkable ambiguity, one to which they were attracted and one from which they attempted to distance themselves" (Barker-Benfield 351). For more on the development of the Amazonian female author, please see G. J. Barker-Benfield, "Wollstonecraft and the Crisis over Sensibility in the 1790s," particularly 351-60 (The Culture of Sensibility. Chicago: U of Chicago P, 1992.). 
In Wollstonecraft's lived experience, she embraced her errancy: her movement between roles and behaviors culturally defined as masculine and feminine. In an individual life, gender is quite malleable and free - moving between cultural notions of "masculine" and "feminine," at times simultaneously occupying both roles. When an individual shifts from "masculine" to "feminine" behavior, said individual does not necessarily reposition or alter his/her understanding of gender in relation to selfhood. It is when an individual attempts to situate his/her lived experience within the available cultural vocabularies that discord arises. Available cultural vocabularies insist on fixity within the categories: one is either masculine or feminine. The categories thereby stifle our ability to articulate gender's freedom and malleability. Language forces individuals into a binary system of masculine and feminine; this binary system and the cultural narratives which support it insist that these two categories are distinct, related only through contrast—not similarity. Because of this vocabulary, when one attempts to articulate gendered experience, the narrative takes on an "either/or" nature, rather than "both/and" or "neither/nor," as we can see in Godwin's Memoirs. Throughout Wollstonecraft's life she moved between gendered roles without any shift in her understanding of self; she was both "masculine" and "feminine." Her belief that most of her fellow citizens experienced gender as errant rather than fixed is tangible throughout Vindication of the Rights of Woman;

Wollstonecraft called on the men and women of England to recognize the potential for women in the public sphere and the failures of the then-current system of gender organization which influenced the division of physical and intellectual labor. The idea that "feminine" and "masculine" were particularly distinct roles flummoxed her. Her positioning within both gendered categories is visible in a letter written to Joseph Johnson in 1792: "I am a mere animal, and instinctive emotions too often silence the suggestions of reason" (Collected Letters of Mary 
Wollstonecraft 220). She wants "reason" to direct her, but at times her "emotions" guide her thinking; she simultaneously occupies "masculine" and "feminine." At times, even Wollstonecraft is "made [slave]" to her senses, highlighting her "femininity" (Vindication 226). Unlike Godwin, Wollstonecraft did not have the ability to ignore gender's role in shaping her life; women in particular were subject to social criticism because of gender's errancy and Wollstonecraft's movement between feminine and masculine had tangible social consequences. Though multiplicity may be the reality of lived experience, particularly Wollstonecraft's, there is no way to articulate simultaneous masculine and feminine experience without indicating some shift in selfhood. Instead, a mythology of "feminine" and "masculine" persists, insisting that these identities are intelligible and distinct. Movement between and beyond the established categories creates discomfort for culture at large because it makes visible the unutterable. Romantic England lacked a vocabulary for multifarious lived experiences and utilized a narrow, exclusive vocabulary for self-definition. ${ }^{33}$ When Godwin defines Wollstonecraft in strictly feminine terms that she would reject, he fails to understand how Wollstonecraft lived her gender. The fact that Godwin feels the need to articulate and define Wollstonecraft's gender is quite revealing because this means that gender is not as intelligible as we would like to think. If gender were intelligible, readers would be able to recognize it without Godwin's gesturing to Wollstonecraft's sentimentality or motherhood, but he feels it necessary to do so continuously in Memoirs. In trying to restore Wollstonecraft's reputation via femininity, he makes visible the gaps and overlaps in conceptions of gender, unwittingly exposing the play between positions, and making it clear that coherent gendered systems are normalizing cultural myths. Though

\footnotetext{
${ }^{33}$ This, of course, is not just a problem for the Romantics; it persists today. We are still unable to talk about identity without fixing it into a particular signifying category.
} 
Godwin attempts to fix Wollstonecraft's movement between feminine and masculine, he unintentionally shows that gender is not fixed or intelligible.

We must understand Wollstonecraft as both the woman of Godwin's narrative-a woman who, despite her best efforts, was unable to overcome the tyranny of her senses, highlighting her "femininity" - and the revolutionary author of Vindications portrayed in literary scholarship. Refusing a single way of being in the world, she insists on errancy, moving between and beyond the gendered binaries of the $18^{\text {th }}$ century; she fails to conform to a narrative of right and wrong, normative and non-. Through this analysis, we gain a greater understanding the disruptive potential of errancy for understanding gender, including the ways that gender is narrated, how such narratives attempt to fix gender and refuse its errancy, as well as public response to errantly gendered subjects and the narratives that reveal them.

Gender in Romantic England

Constructions of gender and sexuality were fluid and unstable throughout the Romantic period; they have a complex, complicated, and at times co-dependent relationship. ${ }^{34}$ Despite this fluidity, Romantic culture still organized gender into two primary categories: masculine and feminine, and conceptions of sexuality were largely based on this gendered division. ${ }^{35}$ In this

\footnotetext{
${ }^{34}$ See Thomas Laqueur and Catherine Gallagher, The Making of the Modern Body: Sexuality and Society in the Nineteenth Century (Berkeley: U of California P, 1987); G.J. Barker-Benfield, The Culture of Sensibility (Chicago: U of Chicago P, 1992); Claudia Johnson, Equivocal Beings (Chicago: U of Chicago P, 1995); and Christopher C. Nagle, Sexuality and the Culture of Sensibility in the British Romantic Era (New York: Palgrave Macmillan, 2007).

${ }^{35}$ In Sex and the Gender Revolution (Chicago: U of Chicago P, 1998) Randolph Trumbach argues that a third gender existed in post-1700 London. This third gender was defined by one's sexual acts, in particular, male sodomites. Trumbach's study convincingly argues that while the actors in this "third gender" were primarily men, the consequences for women were wideranging since it made visible an alternative to heterosexuality. Trumbach's analysis is peripheral to my discussion of Wollstonecraft, Godwin, and gender because while sex acts did have a role in defining gender (particularly the public perception of Wollstonecraft), they were not central to that understanding in the way that Trumbach argues.
} 
(patriarchal) system masculinity is imagined as the default and femininity the derivative. ${ }^{36}$ As a result, femininity's primary place in Romanticism is rather traditional in that it emphasizes women's sentimentality and their role as mothers. Discussing Romantic conceptions of gender under the guise of errancy helps us better articulate the way that individuals actually experienced their genders in the Romantic period because it allows us to acknowledge the fluidity with which individuals moved between (and at times beyond) masculine and feminine, despite the culturally anticipated fixity, indicated by the labels themselves. Anne Mellor's landmark study, Gender and Romanticism (1993), is arguably the first earnest scholarly attempt to destabilize narratives of Romantic gender as fixed. Throughout Gender and Romanticism Mellor destabilizes the ways in which masculine and feminine are divided from one another, insisting instead that what is masculine is at times feminine and vice versa. Mellor situates Wollstonecraft (primarily her ideas as she articulated them in The Vindication of the Rights of Woman) as the catalyst for what Mellor calls the "feminine Romantic ideology"-a Romantic ideology that opposes or complicates "masculine Romanticism." The rational, educated woman inspires this feminine Romantic ideology which includes the idea of rational love over impermanent sexual passion. Of

\footnotetext{
${ }^{36}$ Anne Mellor's landmark study of gender in the Romantic period, Romanticism and Gender (1993), argues that then-current notions of Romanticism as a field of study were "unwittingly gender-biased" and based almost exclusively on "the writings and thought of six male poets," those we now call "the big six" (1). Mellor writes:

To the extent that the masculine Romantic ideology entails a commitment to the creative process, to erotic love, to the exploration of self-consciousness, and to an ethic of justice which acknowledges the value and rights of the common man, it also entails a gender ideology which subtly denies the value of female difference. Positive feminine characteristics - sensibility, compassion, maternal love - are metaphorically appropriated by the male poet, while attributes of difference - independence, intelligence, willpower, aggressive action - are denigrated. This form of Romantic sexism is particularly insidious because it denies to women even their traditional gender roles and cultural authority as experts in feeling, love, and maternal care, as the educators and moral guardians of the young, and as the respected rulers of the domestic
} sphere. (29) 
course, there is cultural backlash to this construction: "By identifying the rational woman with the repression, even elimination, of female sexual desire, Wollstonecraft initiated a legacy of female self-denial with which, as Cora Kaplan has forcefully argued, current feminism is still uncomfortably grappling” (Mellor 34). Though Mellor's works led Romanticists to reconsider the ways we think about gender in the period, she still narrated gender as erring. She expanded the categories from simply the traditional "feminine" and "masculine" to what we could reasonably label "rational feminine," "emotional feminine," "rational masculine," and "emotional masculine." ${ }^{37}$ Although Mellor destabilizes what was once a clear division between masculine and feminine she maintains that such a division exists, thereby continuing to narrate Romantic gender as erring. ${ }^{38}$

The historical events influencing Romantic England, in particular, the French Revolution, led to the fall (or at least the decay) of the symbolic system, and not just for those symbols related to religion but also those connected to gender and "the poets." Susan J. Wolfson captures

${ }^{37}$ Even the organization of the text itself mirrors this division; Part 1 is titled "Masculine Romanticism" while Part 2 is "Feminine Romanticism." In Part 3, "Ideological Cross-Dressing: John Keats/Emily Bronte" Mellor claims that it was "possible for a male Romantic writer to embrace all or parts of feminine Romanticism, just as it was possible for a female to embrace aspects of masculine Romanticism" - the "effeminate"” John Keats and "ccrude' and "virile"” Emily Bronte serve as examples of such ideological cross-dressing (171). According to Mellor, authors were able to "cross-over" genders, indicating that feminine and masculine remain discrete rather than intertwined.

${ }^{38}$ Anne Mellor's ideas regarding love are also of ancillary interest to me. In composing Memoirs, Godwin is writing "from the heart," so to speak - he has just lost the woman he loves and is now a widower with two children, including a newborn baby. Love, a traditionally feminine quality, played a "central role...in masculine Romanticism" because it helped the male poet to transcend human, bodily experiences (Mellor 25). The male poet fails to valorize the role of women in such an experience and instead of "embracing the female as a valued other" he "effaces her into a narcissistic projection" of himself (25). Like Nature, the object of love for male Romantic poets offers an opportunity to reflect on himself and his poetic prowess-he reappropriates the feminine and masculinizes it to claim it as his own with the purpose of disempowering a threatening feminine Other. 
gender's blurriness in Borderlines (2006). Though she does not use the term, Wolfson does argue in favor of gender's errancy by showing that the signifiers of gender have lost their meaning; if the signifiers are not fixed, if we can reappropriate them to shift meaning (or refuse it entirely), then gender itself cannot be fixed. Wolfson also insists that the Romantics were unable to conceive of or articulate gender as errant. Though gender is a confusing amalgamation of missignifying signifiers, hierarchy remains: "Gender is in free play: rational women may have 'masculine' intellect...; foolish boys and servile, or sense-driven men may earn description as 'unmanly' and 'effeminate.' Far from betraying a complicity with adjectival gender-norms, these reversals shape a defamiliarizing satire that draws its force precisely from reference to a still forceful normative hierarchy" (Wolfson 13). ${ }^{39}$ Though the signifiers for gender are shifting, it is still the case that masculinity, particularly when connected to a male body, remains the most powerful performance. Therefore, when masculinity is linked to a female body it remains

\footnotetext{
${ }^{39}$ Susan J. Wolfson complicates Mellor's theory of Romantic gender; she argues that masculine and feminine work as borderlines, fluid divisions which are constantly crossed, rather than strict divisions that particular outliers defy. Wolfson uses the idea of borderlines to alter our geographical configurations of gender; rather than a border, "an outward limit of a concentric structure," she proposes that we conceive of Romantic gender using borderlines, "differential[s] across which both women and men face each other and continually negotiate, and across which occur more than a few strange shifts and transactions" (xviii). As Wolfson shows, using borderlines opens multiple avenues to understanding gender:

On these medial lines, senses (and sensations) of gender shape and are shaped by sign systems that prove to be arbitrary, fluid, susceptible of transformation...Borderlines shifts the language of gender essence (culturally organized and supported as it is) into mobile, less determinate syntax, tuned to such figures as the stylized 'feminine' poetess, the aberrant 'masculine' woman, the male poet deemed 'feminine,' the campy 'effeminate,' hapless or strategic cross-dressers of both sexes, and the variously sexed life of the soul itself. On the borderlines, essence figures more as a point of origin, or cultural identity, from which gender, too, is a departure - or even, in extreme instances, a 'mistake' (this is Wollstonecraft's bold claim). (xviii)

Unlike Mellor's theorization of gender, Wolfson sees gender as fluid and vexing, established by cultural signifiers that are constantly in flux.
} 
problematic. Scholars such as Wolfson and Mellor make clear that gender is not a coherent system for the Romantics; it is laden with contradictions and overlaps. ${ }^{40}$ All of the codes and signs of gender mix.

As illustrated by Mellor and Wolfson, our critical understanding of gender in the Romantic period is constantly evolving. Like Wolfson, I argue that from a $21^{\text {st }}$-century perspective, it is undeniable that gender was shifting and complicated in the Romantic period; despite this reality, one's lived experience of gender is still largely conceived of in a fixed manner throughout the period. Wollstonecraft's revolutionary agenda for women was built upon her awareness of gender's errancy, hence her position that women's roles in the public sphere were unnecessarily limiting. Wollstonecraft's life and her authorship reflect her tangible knowledge of gender's messiness, but Godwin refuses this history. Godwin's Revisionist History: Sexing Wollstonecraft

Wollstonecraft waned in and out of public favor throughout her life; no matter whether an individual adored or despised her, she was a source of division. Following the publication of The Rights of Woman, Wollstonecraft became "a minor celebrity" (Mary 188). Many English (Jacobin or Jacobin-leaning) citizens found in Wollstonecraft a refreshing voice, "Aaron Burr, a future Vice-President, wrote to his wife from the seat of government in Philadelphia, '...Be assured that your sex has in her an able advocate'...'It is, in my opinion, a work of genius"” (Gordon 154). Contrastingly, Wollstonecraft was treated as a disgrace to her sex, and "when an effigy of Paine was burnt, people spoke of 'immortalizing Miss Wollstonecraft in the like manner'” (Gordon 154). Godwin downplays Wollstonecraft's autonomy, instead focusing on her

\footnotetext{
${ }^{40}$ Though $20^{\text {th }} / 21^{\text {st }}$-century critics are aware of the contradictions of gender in the Romantic period, many Romantic authors treat gender as coherent.
} 
sensibility; he works to alter public memory of Wollstonecraft. He tries to mend her errors and help the reading public see that she never strayed from the normative path at all in an attempt to save her from an unsavory public reputation; in his attempts to do so, he composes a revisionist history of Wollstonecraft's life. Her erring is forgivable for the reading public if they can situate her within the system of intelligibility as a woman whose emotions got the best of her; her femininity is her excuse for her "bad behavior" according to this framing. For Godwin, it is necessary that the reading public embrace Wollstonecraft not only so that she is fondly remembered, but also because he has revolutionary purposes of his own in mind.

Part of Godwin's intentions in writing Wollstonecraft's biography was to offer her to English citizens as an example of a person whose fate is connected with "public welfare and improvement" (Memoirs 43); essentially, by understanding Wollstonecraft's life, readers could discover a pathway to a more productive, beneficial (and reformative) form of citizenship. Godwin believed that by eliminating error, ${ }^{41}$ citizens would free themselves from government, in that government would no longer be necessary; the imagined result was a society based on rationalism, leading to both freedom and equality. This process would thereby create better citizens precisely because they would be individually responsible for the future of the nation. Godwin's intention to utilize Wollstonecraft's life as a model for future citizens is clear from the start of Memoirs:

It has always appeared to me, that to give the public some account of the life of a person of eminent merit deceased, is a duty incumbent on survivors... The justice which is thus done to the illustrious dead, converts into the fairest source of animation and encouragement to those who would follow them in the same

${ }^{41}$ Godwin means error in the sense of "erring": mistakes, failures, etc. 
career. The human species at large is interested in this justice, as it teaches them to place their respect and affection, upon those qualities which best deserve to be esteemed and loved. (Memoirs 43)

Wollstonecraft is Godwin's "person of eminent merit," and he, the "survivor" has a "duty" to provide "the public" with "some account of [her] life." He furthers this agenda by illustrating Wollstonecraft's influence over his life in the final chapters of Memoirs, offering himself as a model for his readers. "[H]e traces the growth of their egalitarian affection" and Wollstonecraft's influence on his thinking and feeling-- exactly the thing he hopes his readers will do in their lives ("Writing a Revolutionary Life"). Godwin's theory of biography demanded truth-telling; it derived from "the Dissenting principle of 'candour,' which might best be described as the disposition to form impartial judgments in all affairs. Such a principle was central to Godwin's theory of anarchism, in which the exercise of rational judgment will lead to individual men and women gradually becoming wiser, until government withers away because it is no longer necessary" (Clemit and Walker 14). In many of Godwin's other works, particularly Enquiry Concerning Political Justice (1793) and Things as They Are; or, The Adventures of Caleb Williams (1794), (erring) error arises out of humanity's inability to embrace rationality and base actions and behaviors on reason; hence, he believes that if citizens allow reason to be our guardian and guide, we will eventually free ourselves from the bonds of government. ${ }^{42}$ For Godwin, government is only necessary to regulate error; ${ }^{43}$ the governing are influenced by the

\footnotetext{
${ }^{42}$ Rationality is based on erring because it asserts that there are "right" and "wrong" ways of thinking, decision making and acting; it validates the "regime of truth" because it relies on culturally established norms to define itself and therefore makes visible both the normative and the non-normative.

${ }^{43}$ Godwin's definition of error aligns with what I call "erring”- mistakes, deviations from the norm, etc.
} 
governed (and, arguably, vice versa), and therefore government is always flawed and reflective of social failures developed through the social collective's moral errors. Godwin's support of anarchy and his ultimate trust in the power of rationality is a result of this belief system.

Godwin's approach to biography derived from this line of thinking and was essentially that truthtelling rids of error. ${ }^{44}$ Government mediates error and if we, the citizens, can rid of error, then we can free ourselves from government. So in writing Memoirs Godwin is continuing the spirit of revolution that so shaped the period and his thinking; by telling "some version" of Wollstonecraft's experiences and life, in this case the "truth" as Godwin understood it, he is actively taking part in progress toward anarchy. ${ }^{45}$

The significance of "truth" in biography can be traced back to Samuel Johnson; Johnson's influence on the genre significantly shapes Memoirs' content. Mitzi Meyers occludes the history of the genre when he overlooks Godwin's similarities to Samuel Johnson; Meyers calls Godwin "something of an innovator in life-writing" because of his "biographical frankness" (Meyers 301). Johnson also believed it necessary to portray subjects accurately-including negative aspects of the subject's life. Johnson's theory of biography, as articulated in Rambler \#60 (October 13, 1750), aligned with Godwin's in that both focused on truth, knowledge, and virtue in the authorship of biography. Unlike Godwin, Johnson was aware of the likelihood of

\footnotetext{
44 This raises inevitable questions about what truth $i s$ and who establishes truth. Furthermore, it supports the idea that "truth" exists in only one form or version. In Godwin's Political Justice Mark Philp notes that "Godwin's arguments for the demise of government" and "human perfectability...derive from his commitments in philosophy and ethics: in particular, from his belief that moral truth is objective, that men and women are capable of grasping this truth through the exercise of their reason and judgment, that perceiving this truth is sufficient to motivate the corresponding performance, and that our capacities for reasoning and our grasp of these truths have improved through history and will continue to improve" (2).

45 This of course raises questions about what truth is and how we are able to access it. Godwin told his individual truth, but part of his assumption in the philosophy I've laid out is that there is a universal truth and that we can access it to better ourselves, our governments, and our nations.
} 
public backlash in the face of such honesty as readers imagined themselves in the life of the biographical subject:

All joy or sorrow for the happiness or calamities of others is produced by an act of the imagination, that realizes the event however fictitious, or approximates it however remote, by placing us, for a time, in the condition of him whose fortunes we contemplate; so that we feel, while the deception lasts, whatever emotions would be excited by the same good or evil happening to ourselves.

Our passions are therefore more strongly moved, in proportion as we can more readily adopt the pains or pleasure proposed to our minds, by recognising them as once our own, or considering them as naturally incident to our state of life. (S. Johnson 105)

Readers "become" the subject and as a result, according to Johnson, feel to a greater extent the "pains or pleasure[s]" of the subject. When a subject betrays the reader-by trying to kill herself, for example - readers become angry. Johnson, like Godwin, utilized emotion to reach his readers; he felt it was his responsibility to compose a truthful account of his subject's life. Godwin takes part in this biographical tradition rooted in sincerity with the purpose of inciting "lessons applicable to" the reader's life (S. Johnson 105). Indeed, Godwin tells the intricacies of Wollstonecraft's life for public benefit, but his authorial perspective shapes his interpretation and representation of her life.

Godwin's authoring of Wollstonecraft's life was driven not only by his theory of biography as potentially reformist, but also by his sorrow and sense of loss. There is little question that love and the specter of death inspired Godwin's authorship of Memoirs; during Wollstonecraft's funeral on September 15, 1797, he wrote to Anthony Carlisle, "I am here sitting 
alone in Mr Marshal's lodging during my wife's funeral... Nothing could be more soothing to my mind than to dwell in a long letter upon her virtues \& accomplishments, \& our mutual happiness past $\&$ in prospect. But the attractions of this subject are delusive, \& I dare not trust myself with it" (Memoirs 161). By October 4, 1797 Godwin had begun the project alluded to in his letter to Carlisle—composing Memoirs. In a letter to Hugh Skeys, husband of Wollstonecraft's friend Frances (Fanny) Skeys (Blood), Godwin writes:

My loss is indeed, as you say, irreparable....I ought to add some questions to this letter, for mrs Bishop \& Everina, who I understand are with you, respecting my wife's past history, but I am not prepared on the subject. I find that she has furnished me with considerable materials in the course of our conversations, \& that I know a good deal respecting every period of her life. The period about \{which\} I know lest is that of her early life...I think the world is entitled to some information respecting persons that have enlightened \& improved it. I believe that it is a tribute due to the memory of such persons, as I $\{\mathrm{am}\}$ strongly of opinion that the more intimately we are acquainted with their hearts, the more we shall be taught to respect \& love them. (Letters of William Godwin 250-51).

Godwin's emotional vulnerability and philosophical project are articulated hand-in-hand; his "irreparable" loss of a woman he "respect[ed]" and "love[d]" shapes his authorship, as do his political purposes via biography. Across literary genres Godwin was "engaged in a lasting reform programme" and biography's purpose was no different (Clemit and Walker 12). Through biography Godwin offers an "individual history," rather than a collective history, to "inspire the reader with an analogous spirit of reform" (Clemit and Walker 13). As a result of Godwin's reformative purposes, reaching anti-Jacobin sympathizers was critical to his program of reform, 
and Wollstonecraft (or so he thought) offered inspiration for change. ${ }^{46}$ Ironically, Godwin uses sensibility to further his rational project; despite his best efforts to narrate gender as fixed, "masculine" and "feminine" regularly blur into one another.

Throughout Memoirs Godwin refuses gender's tangled and tumultuous state and Wollstonecraft's embodiment of gender's messiness by repeatedly framing her life in ways that support her performance of traditional femininity. Janet Todd's articulate distinction between sentiment and sensibility is attentive to the significance of embodiment, particularly female embodiment, in the development of the two terms, and as a result I rely on her definitions as articulated in her landmark study Sentiment: An Introduction (1986). Todd defines sentiment as "a moral reflection, a rational opinion usually about the rights and wrongs of human conduct," but "also a thought, often an elevated one, influenced by emotion, a combining of heart with head or an emotional impulse leading to an opinion or principle" (Sensibility 7). Sentiment, according to Todd, is managed by the mind and rationality, therefore potentially ridding of one's tendency to err. Sensibility, on the other hand, "denote[s] the faculty of feeling, the capacity for extremely refined emotion and a quickness to display compassion for suffering," often characterized by an outpouring of emotion in the form of "spontaneous...crying, swooning, and kneeling" (Sensibility 7). A clear distinction arises from these definitions: sentiment is of the mind-- influenced by rational thinking-- and sensibility is of the body, and while distinct, the two are undeniably connected. From the start, Godwin begins his revisionist history by constructing Wollstonecraft's life as one rooted in feminine sensibility, "Mary was distinguished in early

\footnotetext{
${ }^{46}$ As Lyndall Gordon points out attempting to reach anti-Jacobin readers was particularly problematic since "he was writing at the height of anti-Jacobin ferment. As Napoleon swept into Italy, Switzerland and the Low Countries in 1797, alarmed Englishmen feared a conspiracy of liberal intellectuals would bring revolution to all of Europe" (385-6).
} 
youth, by some portion of that exquisite sensibility, soundness of understanding, and decision of character, which were the leading features of her mind through the whole course of her life" (Memoirs 45). Her "understanding" derives from her "sensibility," which work together to define her "character." Already Godwin has connected Wollstonecraft's mind to the impulses of her body. In doing so, Godwin utilizes “traditional femininity” to define Wollstonecraft (and he'll later use this to defend her erringly unfeminine behaviors): her character and mind derive from her senses. This is an effective strategy because "sensibility is often read in English studies...through an anthropology focused on civic usefulness and on rationality as autonomy. Though given some cognitive value, sensibility is seen as an excess, a trap of a specifically feminine nature, and a threat to autonomy" (Rajan 520). This understanding of sensibility, like Todd's, is rooted entirely in emotional reaction. Sensibility's emotional basis provided Godwin with a way to emphasize Wollstonecraft's "feminine nature," even with the threat of excess, so that he could salvage her image in the public sphere. He had to overcome her reputation as a toomasculine woman; by emphasizing her feminine characteristics, Godwin stood a chance of reframing her "masculine" behaviors so that the public understood them to be a result of her sensibility.

Godwin positions nearly every one of Wollstonecraft's authorial works as though they derived exclusively from her personal experiences; such an effort supports his attempts to emphasize Wollstonecraft's “properly aligned” sex and gender. Readers' understanding of Wollstonecraft as female/feminine is necessary to their acceptance of Wollstonecraft as a model for citizenship. According to Godwin's narrative in Memoirs, The Wrongs of Woman; or, Maria (1797), though distanced in time from the actual experiences, is inspired by the "sorrow and subjection" Wollstonecraft experienced while living with her mother and father (45). Godwin 
speculates that when writing Wrongs of Woman, Wollstonecraft based Maria's experiences on her own home life and the removal, silence, and degradation she felt as a child. Her home life again serves as inspiration for her authorship in Godwin's narration of Thoughts on the Education of Daughters (1786); Wollstonecraft's experiences as a child, in particular her mother's approach to parenting, motivated her to seek alternatives for rearing and educating women. Her efforts as a teacher in the day-school "superintended by Fanny Blood, herself, and her two sisters" further influenced her philosophies in Thoughts on the Education of Daughters (Memoirs 55). Each of these examples shows how Godwin's narrative of Wollstonecraft's authorship silences her intellect in favor of sentiment; her intellect does not influence or inspire her mind, her feelings do. Godwin does the same with Mary: A Fiction (1787); he explains that the text was inspired by Wollstonecraft's experiences in Bristol with Lady Kingsborough and claims that the story "consists, with certain modifications, of the incidents of [Wollstonecraft's] own friendship with Fanny" (Memoirs 66). He goes on to dismiss the story, but heralds the feelings therein: "[T]he feelings are the truest and most exquisite class; every circumstance is adorned with that species of imagination, which enlists itself under the banners of delicacy and sentiment" (Memoirs 66). The value of Mary isn't in the authorial skill and imagination it exhibits - things that would certainly garner praise if the author were male, but in what it reveals about Wollstonecraft's femininity and womanhood via her emotions. Each time one of Wollstonecraft's texts potentially challenges the reader's impression of her as feminine/female, Godwin crafts his narrative so that readers can see that even if her writing appears masculine because of its imagination or rationality, it is only mistakenly so; the portrayal of Mary as a rational, self-taught woman may be masculine in nature, but Wollstonecraft did not knowingly enter into masculine space, her feminine emotions, inspired by her time in Bristol and friendship 
with Fanny, led her there. Then, in Chap. VI of Memoirs, which narrates Wollstonecraft's immensely provocative years as an author, 1790-92, Godwin feverishly works to situate Wollstonecraft's revolutionary ideas as inspired by sentiment: "Mary, full of sentiments of liberty, and impressed with a warm interest in the struggle that was now going on, seized her pen in the first burst of indignation, an emotion of which she was strongly susceptible" and the result was Vindication of the Rights of Men, in a Letter to the Right Honourable Edmund Burke (1790). Godwin's narration of Wollstonecraft's response to Burke neglects her intellect and concentrates on her emotional, indignant reaction. Mary was "full of sentiments" and so "seized her pen in the first burst of indignation.” According to Godwin, Wollstonecraft's views on men as despots and women as their subjects provided the "feelings with which she warmed her mind" (emphasis mine, Memoirs 74). In other words, her revolutionary agenda wasn't driven by ideas, but by feelings.

In positioning Wollstonecraft's authorship as initiated by her surroundings, day-to-day life, and her emotional reactions to life's triumphs and traumas, particularly with her revolutionary, feminist tracts, Godwin helps to make her more palatable to the English reading public by undoing her reliance on rationality—or so he believed. He works to place her life back on the path of proper, acceptable femininity. Had Godwin presented Wollstonecraft as primarily rational rather than sentimental, he might have increased the public outrage about her "Amazonian" tendencies, and his biography would have failed as the kindling for reform; rather than providing readers with an example of a life which would inspire them toward social reform, he would have abandoned those readers because of his subject's liberal, troublingly gendered behaviors. Therefore, Godwin's narration of Wollstonecraft's authorship strives to place her back on the path of acceptable authorship for women. 
In Godwin's efforts to present a truthful version of Wollstonecraft's life, including her domestic affections, he unknowingly goes too far and offends Romantic notions of what is proper for women and the public sphere. While sensibility may have been a successful tool for reframing Wollstonecraft's professional life, it serves as a signifier for excess in her personal life. ${ }^{47}$ When narrating Wollstonecraft's personal life, Godwin tells a story of her vulnerabilities and desperations as a heartbroken woman willing to do anything to free herself from emotional pain. Lyndall Gordon's biography of Wollstonecraft, Vindication (2005), supports my reading of Memoirs: "Godwin narrowed [Wollstonecraft's] motives to emotional fits and starts: in his version, Mary goes to France not because she wished to see the Revolution, but to escape her crush on Fuseli; and she abandons Hamburg not because she was appalled by fraud (as the Travels tell us), but solely in response to Imlay's neglect" (372). Godwin felt that the "domestic [w] as part of the political, intimated in his reflections on what makes up 'true' history," and so in an attempt to truthfully outline this "history," Memoirs famously over-shares (Rajan 520). Memoirs details Wollstonecraft's affairs with Fuseli and Imlay. Godwin unabashedly writes about Wollstonecraft's affection for Fuseli, despite Fuseli being married:

She visited him; her visits were returned. Notwithstanding the inequality of their years, Mary was not of a temper to live upon terms of so much intimacy with a man of merit and genius, without loving him. The delight she enjoyed in his society, she transferred by association to his person. What she experienced in this respect, was no doubt heightened, by the state of celibacy and restraint in which

\footnotetext{
${ }^{47}$ Godwin did not anticipate this; it wasn't until after Memoirs was released to the public and outrage ensued that it became clear that he had, essentially, said too much. His philosophy regarding truthful biography clearly guided him, leading him to share the most personal details of Wollstonecraft's life.
} 
she had hitherto lived, and to which the rules of polite society condemn an unmarried woman. She conceived a personal and ardent affection for him. Mr.

Fuseli was a married man, and his wife the acquaintance of Mary. (Memoirs 78) In sharing this particular part of Wollstonecraft's life Godwin gives Wollstonecraft's detractors fodder; her affection for Fuseli allows them to paint her a husband-stealing whore who is unable to acknowledge the boundaries of friendship and marriage. The Anti-Jacobin Review calls her an "amorous lady" who "fell in love with Mr. Fuseli, a married man" and claims that she "continued long to have a violent affection for him.." ${ }^{48}$ Then, when Godwin gives account of Wollstonecraft's love affair with Gilbert Imlay he includes every salacious detail, including their meeting "at the house of Mr. [Thomas] Christie," her objection to marriage, and her seemingly contrary decision to "take the name of Imlay" to "obtain a certificate from the American ambassador, as the wife of a native of that country" (Memoirs 85-6). After introducing the reader to these facts, Godwin takes an entire paragraph to outline what he sees as failures in Wollstonecraft's life: the few endearments of her childhood, her father's temper, the darkening of her entrance into womanhood by her mother's death, the failure of the day-school, Fanny's early death, and the fruitless affair with Fuseli. Godwin concludes that "evils take their rank,

${ }^{48}$ Godwin follows the passage quoted above (where he reveals Wollstonecraft's emotional affair with Fuseli) with Wollstonecraft's theory of the relations between the sexes, as though to (perhaps inadvertently) argue that her theories were reflective of her emotional practices. Godwin interprets Wollstonecraft's claim " "that the imagination should awaken the senses, and not the senses the imagination" to mean "that whatever related to the gratification of the senses, ought to arise, in a human being of a pure mind, only as the consequence of an individual affection" (Memoirs 79). His interpretation of Wollstonecraft's statement could have emphasized the importance of an inspired mind and intellect, but instead, he remains focused on emotion and Wollstonecraft's reaction to her senses.

The Broadview critical edition notes that "the imagination should awaken the senses, not the senses the imagination" was likely a paraphrasing of one of Wollstonecraft's letters to Imlay (79, note I). 
more from the temper of the mind that suffers them, than from their abstract nature" (Memoirs 87). According to Godwin, the effects of life events are reflective of an individual's disposition. Such a framing argues that Wollstonecraft was simply a product of her environment; her choices were based on her life, her circumstances, and her surroundings. His argument is essentially that she was just a simple woman whose emotions drove her to write and think things; this echoes the popular view of women as individuals whose bodies and minds were often tyrannically ruled by emotion. Godwin's hard work at framing Wollstonecraft as sensible and sentimental argues that she was not a detestable woman who "didn't know her place" and utilized rational thinking to make revolutionary arguments or portray female characters in ways that challenged the patriarchal societal structure; instead, she just reacted to her emotions.

Godwin then returns to his goal of telling the truth about Wollstonecraft's life; he explains that Wollstonecraft's emotional vulnerabilities were only furthered by the heartbreak she experienced with Imlay. After "finding reason to suppose herself with child," Imlay continually postpones meetings with Wollstonecraft until their relationship seems nonexistent (Memoirs 89). In Memoirs, Godwin presents this stage of Wollstonecraft's life through his love for her. His narration forgives her of all indiscretions and responsibilities, instead framing her as a hapless victim to the emotionally abusive Imlay. Wollstonecraft's previous life experiences led her to "[struggle] to entertain a favourable opinion of human nature" (Memoirs 91). Godwin claims that "Imlay undertook to prove, in his letters written immediately after their complete separation, that his conduct towards her was reconcilable to the strictest rectitude," and concludes that "undoubtedly Mary was of a different opinion" (Memoirs 91). Godwin's bias is particularly evident in his conclusions about Imlay: "Whatever the reader may decide in this respect, there is one sentiment that, I believe, he will unhesitatingly admit: that of pity for the 
mistake of the man, who, being in possession of such a friendship and attachment as Mary, could hold them at a trivial price, and, 'like the base Indian, throw a pearl away, richer than all his tribe"” (Memoirs 91-2). Unlike the reading public who (following Memoirs' publication) held Wollstonecraft accountable for her emotional and sexual indiscretions, Godwin holds Imlay accountable — it is Imlay's mistake, not Wollstonecraft's. Her reactions are reasonable considering the tyranny her senses held over her thinking. This pattern continues in Godwin's account of Wollstonecraft's first suicide attempt.

After returning to London in April 1795 Wollstonecraft attempted suicide — arguably a lapse in rational thought. Distraught by Imlay's reported connection with another woman, as well as his "cold and embarrassed" reception of Wollstonecraft, "life became an intolerable burthen" and Wollstonecraft "formed a desperate purpose to die" (Memoirs 94). Imlay intervened, and even by Godwin's account, saved her life by asking her to be his agent in Norway. Her second suicide attempt followed shortly after her return to England from Norway; upon her return, Wollstonecraft discovered that Imlay was living with another woman and she "resolved to plunge herself in the Thames" (Memoirs 96). Godwin reveals her desperation as he tells of her attempts to soak herself with water, jump from bridges, and sink silently into the cold abyss of the Thames. He concludes that Wollstonecraft survived her "gloomy purpose," but continues:

Probably no man would destroy himself from an impatience of present pain, if he felt a moral certainty that there were years of enjoyment still in reserve for him...Moral reasoning is nothing but the awakening of certain feelings; and the feeling by which he is actuated, is too strong to leave us much chance of impressing him with other feelings, that should have force enough to counterbalance it. But, if the prospect of future tranquility and pleasure cannot be 
expected to have much weight with a man under an immediate purpose of suicide, it is so much the more to be wished, that men would impress their minds, in their sober moments, with a conception, which, being rendered habitual, seems to promise to act as a successful antidote in a paroxysm of desperation. (Memoirs 97)

The purpose of Wollstonecraft's suicide attempt in Godwin's narrative is an illustration of her failure to think rationally, an illustration of her reliance of sentiment, of her femininity-no matter its excess. Her suicide attempts, like her affairs with Fuseli and Imlay, help to emphasize the power of her feelings over her mind; though they are undeniably excessive, excess in women was not surprising. Though it was cause for criticism, it was at least properly gendered compared to the specter of masculinity over a female body. Post-facto it is easy to see why Godwin failed to woo the public in telling Wollstonecraft's story, but considering his philosophical outlook and biographical goals, Wollstonecraft's emotional vulnerabilities, including her failures at love and suicide, serve Godwin's purpose: to save her from public memory as an errantly gendered woman who dangerously blurred the boundaries of feminine and masculine, and situate her firmly in feminine behavior and thought.

Godwin's efforts to mend Wollstonecraft's erring femininity via sentiment famously backfire when Memoirs is released and public outrage ensues over his frank account of her life. The excess of Wollstonecraft's emotions as portrayed in Memoirs shaped public reaction. While Godwin intended for sensibility to restore Wollstonecraft's sensibility, it only served to further damage her reputation. Wollstonecraft was certainly viewed as a woman whose senses led her, but they led her astray. While sensibility can signal feminine virtue, it is also be dangerous because of its effects on women's sexuality. When sensibility over-determines the reaction of the 
body unleashed (female) sexuality can result, then serving as commentary on a woman's moral character; such was the case with Wollstonecraft. The Anti-Jacobin Review's review of Memoirs illustrates this connection between sensibility, (perceived or real) sex acts, and character:

Mrs. W having ardent sensibility, and a vigorous imagination, possessed no small excellence in description, but had neither materials nor habits of close reasoning and cautious investigation...Mr. Godwin himself allows that in her decisions respecting truth, she proceeded from taste and feeling, and not from logical disquisition...The amorous lady fell in love with Mr. Fuseli, a married man, and continue long to have a violent affection for him: to what length it was indulged has not appeared... She became the concubine of Mr. Imlay, an American. The biographer does not mention many of her amours. Indeed it was unnecessary: two or three instances of action often decide a character as well as a thousand. (95-7) Her decisions come from "taste and feeling,...not... logical disquisition" leading her to fall in love with "a married man" and become a "concubine"; just these few examples are enough to “decide [her] character.” Because of her affairs with Fuseli and Imlay, as well her perceived marriage to Imlay and then her actual marriage to Godwin-which inevitably made it clear that she was never married to Imlay, sensibility no longer functioned as a symbol of refinement, but as a figure for her excess and sexuality, for her erring femininity.

Over-sharing the details of Wollstonecraft's personal life opened the door for criticism and ultimately revealed that despite his best attempts, Godwin's efforts at reform were spoiled; public outrage toward Wollstonecraft's life and memory increased. He failed to rehabilitate her reputation. Literary and cultural magazines seized Memoirs as an opportunity to criticize and attack Wollstonecraft and defame her character. The Anti-Jacobin Review claimed that 
Wollstonecraft's life "serves as a buoy; if it does not shew what it is wise to pursue, it manifests what it is wise to avoid" (94). The Monthly Review "regret[s] the necessity of observing that not only the general reader, but the most judicious and reflecting part of mankind, will arraign the prudence and the utility of these memoirs," and describe the narrative as one they "read with pity and concern, but which [they] should have advised the author to bury in oblivion" (321). In Godwin's depiction of Wollstonecraft readers “saw a wanton, wafting from Fuseli, to Imlay, to Godwin himself" (Gordon 371). The Analytical Review complained that while the narrative was "eventful and touching," it "gives...no correct history of the formation of Mrs. G.'s mind" (238). This particular review highlights Memoirs' focus on sentiment as an attempt to fix Wollstonecraft's femininity and simultaneously wonders about Memoirs' noticeable silence when it comes to Wollstonecraft's intellect. Throughout Memoirs Godwin works to silence any indication of Wollstonecraft's independence and strength of mind, instead focusing on her emotional vulnerabilities in an attempt to memorialize her as an ideal woman and citizen. In his effort to right what he fears the public may perceive as Wollstonecraft's wrongs, Godwin forces Wollstonecraft into a narrow definition of "femininity" and problematically revises her life to fit his hegemonic notion of "feminine" behavior and thinking. Despite Godwin's efforts to reframe his wife's life, the reviewer at the Analytical Review gestures toward Wollstonecraft's lived reality: for her, gender was not fixed (though cultural notions of gender were), she slipped almost unnoticeably between various gendered roles throughout her life.

\section{Gendered Errancy: Re-Sexing Wollstonecraft}

Unlike Godwin's version of gender in Memoirs, Wollstonecraft was acutely aware of the difficulty in pinning down gender. Her letters show that she struggled to balance the cultural demand that women's emotions be front and center while rationality takes a back seat. In Mary 
Wollstonecraft: A Revolutionary Life (2000) Janet Todd claims that Wollstonecraft "could not bring herself to use the rational language of The Rights of Woman on herself; her life was always delivered in the language of sensibility" (202). Todd's evidence centers around one of Wollstonecraft's letters to Joseph Johnson; Wollstonecraft writes, "I have nourished a sickly kind of delicacy, which gives me many unnecessary pangs...I am a strange compound of weakness and resolution! However, if I must suffer, I will endeavour to suffer in silence. There is certainly a great defect in my mind — my wayward heart creates its own misery" (Collected Letters of Mary Wollstonecraft 221). Her "delicacy" and "wayward heart" emphasize the role of feeling in her life. While Wollstonecraft used sentimental language in her letters, she was not shy of utilizing rationality in her personal communication either. In a letter to Mary Hays on the $12^{\text {th }}$ of November 1792, rationality and emotion shape Wollstonecraft's critique:

I do not approve of your preface — and I will tell you why. If your work should deserve attention it is a blur on the very face of it.-Disadvantages of education \&c ought, in my opinion, never to be pleaded (with the public) in excuse for its defects of any importance, because if the writer has not sufficient strength of mind to overcome the common difficulties which lie in his way, natures seems to command him, with a very audible voice, to leave the task of instructing others to those who can. This kind of vain humility has ever disgusted me - and I should say to an author, who humbly sued for forbearance, 'if you have not a tolerably good opinion of your own production, why intrude it on the public? we have plenty of bad books already, that have just gasped for breath and died.' (Collected Letters of Mary Wollstonecraft 219) 
Wollstonecraft begins with a reactionary statement: "I do not approve." She then goes on to develop her normative premise: that the disadvantages of education should never be pleaded with the public, and she derives her conclusions by evaluating Hays' preface against that normative concept. Such thinking is illustrative of rational intellect. She goes on to say that she "particularly objects" to the last paragraph because "it is so full of vanity" (Collected Letters of Mary Wollstonecraft 219). Unlike her letter to Johnson, her letter to Hays is methodical; her tone is authoritative rather than vulnerable. ${ }^{49}$ She also warns Hays of the dangers of being a female author: "your male friends will treat you like a woman — and many a man...have insensibly been led to utter warm elogiums in private that they would be sorry openly to avow without some cooling explanatory ifs. An author, especially a woman, should be cautious lest she too hastily swallows the crude praises which partial friend and polite acquaintance bestow thoughtlessly" (Collected Letters of Mary Wollstonecraft 219). Wollstonecraft is acutely aware of the ways in which her "femaleness" shapes the way that men speak with and respond to her as an author. When considering her correspondence with Johnson through this knowledge, it is clear that while Wollstonecraft's correspondence with Johnson is sincere, she also plays up her femininity to appease her reader's expectations. Wollstonecraft's effort to navigate the omnipresent social limitations of gender is tangible in these two letters; she moves between traditionally feminine sensibility and traditionally masculine rationality without indicating any alteration in how she conceives of her identity. In both letters she speaks frankly with her reader, aware of both her own and their gendered cultural positions.

\footnotetext{
${ }^{49}$ It is worth noting that the sex of her letter's recipient may have shaped her tone; this would indicate that Wollstonecraft was acutely aware of the impropriety of her "masculine" rationality and so therefore switched from such a tone in her letter to Johnson.
} 
As an author of fiction Wollstonecraft also sought out a balance that would please her reading public. Within Maria: or, The Wrongs of Woman readers can locate Wollstonecraft's commentary on gender's errancy, particularly the ways in which individuals utilize sensibility and rationality separately, simultaneously, and interchangeably. Wollstonecraft's Maria: or, Wrongs of Woman illustrates her errant conception of gender; ${ }^{50}$ locating errancy in Maria is possible largely because the story remains unfinished until Godwin interprets Wollstonecraft's fragments to conclude the story for publication in Posthumous Works. Because of the unfinished nature of Maria, I read the story as an illustration of Maria's use of both sensibility and rationality in support of each other. In Roxanne Eberle's study of transgressive women and the characters they imagined, she agrees that "because of its unfinished state and Godwin's editorial decision to include multiple concluding fragments, The Wrongs of Woman invites readers to compose their own endings" (60). ${ }^{51}$ Maria's sentimental memoirs make a rational argument about her sanity by illustrating her victimization through patriarchal social structures; through her memoirs, Maria manufactures a path to freedom.

Maria blurs the distinction between rational and sentimental, thereby blurring gender distinctions in the story entirely and revealing its errancy. The preface emphasizes the rational intentions of the sentimental story: "The Wrongs of Woman, like the wrongs of the oppressed part of mankind, may be deemed necessary by their oppressors: but surely there are few, who will dare to advance before the improvement of the age, and grant that my sketches are not the

\footnotetext{
${ }^{50}$ Many critics, including Roxanne Eberle, read Maria in relation to, in conversation with, and/or representative of Mary Wollstonecraft, particularly the Wollstonecraft who wrote Vindication (Eberle 21-54).

${ }^{51}$ Such an invitation makes the story itself errant; each reader has the ability to make the story his/her own, meaning that the story technically fails to conclude and it fails to maintain a single, linear narrative.
} 
abortion of a distempered fancy, or the strong delineations of a wounded heart" (Wollstonecraft and Shelley 59). The rational argument presented is that oppressors will deem oppression necessary. Sentiment is what hooks the reader, though. The reader's attachment to Maria pushes us to read on and discover her fate. Maria's life story, as imagined by Wollstonecraft, utilizes sentiment to drive a rational argument: Maria argues that she should be freed from her unjust imprisonment in the asylum; she makes this argument through her memoirs written to her child and read by Darnford and Jemima. Wollstonecraft argues that women should be freed from the unjust restrictions of traditional gender roles because such roles are culturally constructed bologna; individuals do not act exclusively on the narrow roles allowed by the labels "masculine" and "feminine," but often occupy both roles simultaneously or reject them entirely. Wollstonecraft makes this argument through Maria.

Maria utilizes an emotional, personal narrative to make a rational argument; her story, as written by Wollstonecraft, artfully blends "masculine" and "feminine" behaviors to justify her freedom from the asylum and ultimately argue that her imprisonment is unjust and possible only because she is a woman. Maria's narrative of her personal history begins via the memoirs in chapter seven and continues through chapter fourteen; Maria's "memoirs broke off abruptly" and three chapters follow wherein Jemima enables Maria's escape. ${ }^{52}$ The memoirs relate Maria's experiences as a woman imprisoned in an insane asylum by her husband, George Venables. Like Wollstonecraft, Maria has concerns about the plight of her sex. Maria begins with the narrator

\footnotetext{
52 The Advertisement that follows the second section of the text (where Maria's memoir concludes) asks the reader to "gladly accept even of the broken paragraphs and half-finished sentences, which have been found committed to paper, as materials for the remainder" because "an inquisitive temper willingly accepts the most imperfect and mutilated information, where better is not to be had" (Wollstonecraft and Shelley 136). Godwin then includes several fragments to gesture toward possible conclusion to the story.
} 
explaining that Maria is tortured by thoughts of her infant daughter, that she "lamented she was a daughter, and anticipated the aggravated ills of life that her sex rendered almost inevitable, even while dreading she was no more" (Wollstonecraft and Shelley 61). Immediately Maria’s concerns about the dangers of being a woman are highlighted as she "lament[s]" that her child "was a daughter." Maria's mission is to "escape, to fly to the succor of her child, and to baffle the selfish schemes of her tyrant—her husband" (Wollstonecraft and Shelley 62). Because the story's heroine is trapped within a mental institution, her mental and emotional stability is immediately put into question. Her nurse, Jemima, is told that her madness "is hereditary, and the fits not occurring but at very long and irregular intervals, she must be carefully watched; for the length of these lucid periods only renders her more mischievous" (Wollstonecraft and Shelley 63). Jemima and Maria both indicate that Maria's "madness" is caused by excessive emotion. When Maria asks Jemima if anything other than madness could " "produce such disgust for food," Jemima says, “'Yes, grief” (Wollstonecraft and Shelley 63). Maria’s emotions, particularly because she is a woman, have the ability to control her body and mind. As Maria tries to prove her sanity, she forces herself to suffocate her voice which "betrayed the agonizing emotions she was laboring to keep down" (Wollstonecraft and Shelley 63). Before obtaining contact with Darnford, Maria spends her days reading and writing. In the moments when Maria seems most rational she seems untrustworthy; Jemima is cautious to trust Maria, noting that when Maria seemed "an extraordinary woman" she might actually be in the midst of "one of [her] lucid intervals" - that is, a moment which will surely pass only to be replaced by the “extraordinary animation" of madness, driven by excessive sentiment (Wollstonecraft and Shelley 66). Rationality and insanity, driven by emotion, blur here. Jemima finds herself unable to pin Maria down and fully understand her; Jemima seeks "surer ground" before she "wrought 
on to do more than soften the rigour of confinement" (Wollstonecraft and Shelley 66-67). Maria, a keen observer throughout the text, is aware of Jemima's hesitation and continues to seek a sympathizer to aid in her escape, though she suspects Darnford to be the more likely of the two.

Maria gains greater understanding of Darnford and Jemima through their personal narratives. She remains silent about herself and allows outside individuals, like Jemima's master, to narrate her mental state and personal history. Even before Maria hears Darnford's or Jemima's personal histories her intent to escape the madhouse and her desire "to find a sympathetic auditor who will listen to her tale of 'wrongs' and then aid her escape" is firmly established (Eberle 36). As a result, Maria has motive to craft her personal history to suit her plans and audience; she is driven by both sentiment and reason-her desire to return to her daughter leads to what I read as shrewd, rational planning to enable her to escape from the asylum.

Maria's personal narratives illustrate the ways in which rationality and sensibility blur into one another, deliberately obscuring the boundaries of gender. Once Maria discovers the death of her child (via Jemima in chapter six), she is prepared to share her personal history with both her madhouse co-inhabitant and nurse. Maria's memoirs are given to Darnford "according to promise," in order "to beguile the tedious moments of absence, by dwelling on the events of her past life" (Eberle 94). Maria's memoirs have just as much potential to be fictitious as Maria; or, Wrongs of Woman itself. These memoirs are Maria's thoughtful attempt to evoke an emotional response from her readers to enable her escape from the asylum. Maria's memoirs serve as the catalyst to establish Darnford's and Jemima's trust in her and sympathy for her experiences. Maria's narrative highlights the ways in which society, men in particular, have caused her downfall —including her mistreatment by her father, George's self-misrepresentation and true libertine nature, George's rape of her and the resulting pregnancy, George's attempts to 
later sell Maria, and finally, her story culminates in her imprisonment by George in the asylum. The concluding chapters of Maria illustrate that Maria has effectively used her personal history to convince her readers of her victimization, her sanity, and, ultimately, that she should be freed from the confines of the asylum; she combines sentiment and logic, moving fluidly between the two, to argue for her freedom from the institution. Maria succeeds in eliciting an emotional response from her readers; Darnford gives her "a most affectionate letter...He adverted to her narrative, and spoke with warmth of the oppression she had endured" (Wollstonecraft and Shelley 137). In chapter sixteen Jemima comes to Maria's room and informs her that she is “"prepared...to accompany [her] in [her] flight"” (Wollstonecraft and Shelley 138). Maria's efforts to convince her reading audience of her sanity and right to freedom are ultimately successful. Following her escape Maria discovers that her child is alive, she and Jemima attempt to set up a life, but "the dogs of law were let loose on her" (Wollstonecraft and Shelley 142). The fragment concludes with Maria's rational argument in court regarding Mr. Venables' neglect and therefore, her innocence. The final chapter allows Wollstonecraft to weave together fiction and politics as she uses Maria to make an argument about the injustice of marriage. Here sentimental, gothic fiction and rational, political argument again weave together to complicate Wollstonecraft's gender performance as an author.

Wollstonecraft's letters and fiction illustrate the tension she felt in relation to gender's fixity. Wollstonecraft's work as a cultural critic and author and the artifacts of her personal life highlight her ability to fluidly move between gendered subject positions without altering her sense of self. Wollstonecraft challenges the "model of gendered binary oppositions that lies behind social prescriptions...her own written statements and personal actions suggest a quickly changing, and perhaps even fluid, model of womanhood" (Eberly 62). This model, perhaps 
unconsciously, challenges gender norms by moving between and beyond gendered binaries of behavior and thinking, including sentiment and reason; in doing so Wollstonecraft reveals that individuals move between conceptions of masculine and feminine, showing that individuals, regardless of sex, are far more similar than different.

$\underline{\text { Unintelligible Gender: Godwin's Errancy }}{ }^{53}$

Godwin's goals in writing Memoirs were to help the public better understand the woman he loved so dearly and to put forth a truthful, useful account of her life. As illustrated earlier, Godwin relies on sentiment to bolster Wollstonecraft's femininity. His device fails him, however, because sensibility is a flawed word for gendering Wollstonecraft. When considered in their historical context, sensible subjects can actually be (re)appropriated as a method of refusal and resistance to gender norms and societal expectations of sexuality. Subjects situated under the auspices of sensibility and sentimentality are errant because they are multivalent and resist order.

Throughout the eighteenth and early nineteenth centuries, the definitions of "sentiment" and "sensibility" were in flux. It was impossible to fix fluid concepts that were constantly blending and merging, then separating and being re-defined. As the cult of sensibility took shape in the middle of the eighteenth century the terms were often used interchangeably, but then toward the end of the eighteenth century, as sensibility became code for the cultural restraints which fixed women into a domestic femininity, the concepts became more distinct. The use of the terms to define specific types of literature added to the confusion. Sensibility simultaneously became a way in which women (primarily) existed in the world and reacted to their surroundings, as well as a literary genre in which refined feeling played a central, instructive role. Even Todd's definitions blend rationality and emotion, arguing that sentiment is both "a

${ }^{53}$ Memoirs 112 
moral reflection, a rational opinion" and "a thought, often an elevated one, influenced by emotion," while sensibility is defined solely on "the faculty of feeling" and "the capacity for extremely refined emotion" (Sensibility 7). Godwin's Memoirs repeatedly situates Wollstonecraft's authorial motivations within the traumas of her life, thereby arguing that her authorship was driven by a primarily emotional sensibility; he does so to bolster her femininity for the reading public and, as I've argued, he seemingly reifies culturally established, traditionally gendered behaviors that Wollstonecraft worked to destabilize. However, since sensibility was not always understood as a solely feminine, or solely emotional, characteristic (nor was it always assigned to humans, but sometimes to things) Godwin's strategy does not fix Wollstonecraft's gender but furthers its errancy.

One way that the readers of Memoirs would have understood sensibility was through the literature which boar the term. In the literature of sensibility "one of the best known representations... is the figure of 'virtue in distress,' the virtue a woman's, and her distress caused by a man" (Barker-Benfield xviii). The conventional sentimental outpouring of female characters, including fainting and lengthy crying spells, serves to derail the linear narrative sequence. As female characters weep, swoon, faint, and fall, their narratives are stuck in limbo; while the rest of the narrative moves forward, these women spoil the traditional storytelling sequence and the progression of time in the narrative. The heroines of sentimental fiction "are forced into an inactivity that hinders the fulfillment of the very desire uncovered by their fainting" (Csengei). Readers are left to imagine the character's thoughts, including whether she has any, and her feelings seem inaccessible because they are so extreme. While the women pour forth sentiment, often the male characters move forward. For example, in Inchbald's Nature and Art (1796), Agnes Primrose's emotions are "beyond the stimulus and...propriety" (Sensibility 8); 
after several instances of weeping, pausing, and convulsing during her trial, her emotional outpouring finally halts the progress of her narrative. After her guilty conviction "she fainted as he [William] closed the period, and was carried back to prison in a swoon; while he adjourned the court to go to dinner" (Inchbald). Agnes never again appears in the narrative; the conclusion of her life is conveyed on "a printed sheet of paper" that William reads (Inchbald). It tells of her "loss of her senses," "insanity," devout prayer, and the "weeping" of the crowd" as she was "launched into eternity" (Inchbald). Agnes' sentiment creates an errant narrative and reinforces her gendered weaknesses. By understanding sensibility as errant because of its ability to derail narrative progress and skew both the reader's and the character's sense of time and feeling, I challenge our current understanding of sensibility as an often limiting role for women and instead frame it as a mode of being which challenges hegemonic power and the cult of rationality.

Sentimentality was not strictly assigned to women, though. The Man of the Feeling offers an example of gender's fluidity throughout the period, as feminine sentiment shapes male subjects and elides the boundaries between masculinity and femininity. The Man of Feeling was "the ideal of sentimental masculinity" because of his "sensitivity, tenderness, 'benevolent nerves,' allegiance to the good old ways, courtesies to the fair sex, endearing irrationality, and even slowness, frailty, and ineptitude itself' (Johnson 198). The Man of Feeling embodied quickly disappearing remnants of the past and anxieties about masculinity's reconstruction throughout the Romantic period. Most important to my analysis, however, he displays the absolute inability to clearly demarcate sensibility's gendered purposes in Romanticism. Christopher C. Nagle describes the Man of Feeling as occupying a "liminal space as a result of his excessive propensities...[The] immoderate behavior and the normative assumptions [the Man 
of Feeling] challenged were perceived throughout the eighteenth century as threatening to...patriarchy and heterosexuality" (9). Alternatively, critics such as Claudia Johnson and Michael McKeon argue that the Man of Feeling fails to threaten patriarchy, but rather reinforces it because the construct turns a traditionally feminine model of virtue into a masculine model. The Man of Feeling's cultural significance lies between these two extremes. On the one hand, the Man of Feeling illustrates patriarchal power's ability to overtake and colonize feminine ideas and subjects; on the other hand, he threatens patriarchy's power. The Man of Feeling was an idealized, "softened" version of masculinity, perfectly fit for domestic space (Barker-Benfield 248). Through the Man of Feeling men were reformed: “made conscious of women's minds, wishes, interests, and feelings, in sum, their sensibility" (Barker-Benfield 249). Women utilized their sensibility to evoke sensibility in men, creating a reformed version of masculinity better suited to feminine, domestic spaces. The consequence of this construction, however, was that the Man of Feeling became a troubling model of patriarchal masculinity; the Man of Feeling "was always something of a novelty, and a rather suspect one because his undisciplined emotions brought him suspiciously close to the older model of effeminacy"-a model based on men whose vice and excess generated "unmanly but also potentially feminine," behavior (Elfenbein 24, 20). Sensibility, when embodied by the Man of Feeling, challenges gendered, patriarchal "regimes of truth" and further illustrates sensibility's failure as a methodology for illustrating gender's fixity; the gendered influence of sensibility makes it nearly impossible to pin him down ideologicallyhe simultaneously threatens and supports patriarchy and gendered norms of behavior and feeling. Rather than always limiting women, sensibility can serve as a mode of being which challenges hegemonic power and the cult of rationality. Rather than sensibility serving to support Wollstonecraft's "traditional femininity," it served only to highlight her errancy and, despite his 
best efforts, Godwin's inability to effectively map and normalize gender onto her history. He mistakenly reveals gender's fluidity, rather than fixity in his use of sentiment.

One of the most famous charges against Wollstonecraft was that she was "unsexed." In Memoirs Godwin is "[a]nxious to 'defend' Wollstonecraft from the aspersion of being unsexed and unfeminine" and, as I've already established, did so by "describe[ing] Wollstonecraft's sensitivity" (Johnson 11). Godwin's description of Wollstonecraft as “a female Werter" is his attempt to "describe Wollstonecraft's feminine delicacy," but according to Claudia Johnson he ultimately unsexes her: "She is a female mutation of a male hero, a man whose exquisite, delicious, and finely textured sensibility mark him not as effeminate....but as an estimable man of feeling" (Memoirs 26, Johnson 12). I take up Johnson's notion that Godwin's efforts "backfired," not because he unsexes Wollstonecraft, but precisely because he attempts to sex her. Wollstonecraft is often discussed as "unsex'd" because she occupies neither feminine nor masculine space, because she is therefore, according to Romantic understandings of gender and sex, both male and female. The argument that Wollstonecraft is unsexed highlights Wollstonecraft's gendered errancy and reveals the cultural discomfort with the ways in which she entirely disposed of the system which made sex and gender legible. Godwin works feverishly throughout Memoirs to show us Wollstonecraft's gender, but such frantic attempts to make her gender legible unintentionally reveals just how illegible gender is in the first place. When Godwin casts the decisions Wollstonecraft made in her personal and public lives as driven by sentiment, which he frames as a particularly feminine mode, he construct gender as a coherent system. However, if this system were as coherent and intelligible as Godwin's Memoirs would have us to believe, we would already be able to see it. Wollstonecraft's femininity would be unmistakable. 
The best example of how Godwin's narrative of gender in Memoirs betrays him takes place while discussing Letters Written during a Short Residence in Sweden, Norway, and Denmark. Much like all of Wollstonecraft's other works, Godwin situates An Historical and Moral View of the Origin and Progress of the French Revolution and the Effect it Has Produced in Europe (1794) so that it originates from her life experiences - in this case with Imlay in Paris, and of course Letters Written during a Short Residence in Sweden, Norway, and Denmark (1796) then bears the mark of her heartache and longing for Imlay. She travelled to Norway as Imlay's agent, believing that the travel would help to heal their relationship, but soon discovered that her life in Norway mirrored the isolation and abandonment she felt in Paris. Godwin praises Letters because of the emotional vulnerability he locates within:

If ever there was a book calculated to make a man in love with its author, this appears to me to be the book. She speaks of her sorrows, in a way that fills us with melancholy, and dissolves us in tenderness, at the same time that she displays a genius which commands all our admiration. Affliction had tempered her heart to a softness almost more than human; and the gentleness of her spirit seems precisely to accord with all the romance of unbounded attachment. (Memoirs 95)

Initially it seems that Godwin adores Letters because of Wollstonecraft's "softness" and "gentleness," and perhaps this is why he felt particularly attracted to Wollstonecraft as the author of this text, but also in this evaluation of Letters Godwin reveals his unintended understanding of gender's errancy. In narrating his reaction to Letters, Godwin shows that gender is not as intelligible or clearly demarcated as he'd like us to believe. Godwin "dissolves in tenderness" over the beauty of Wollstonecraft's prose and the presence of emotion in the text (Memoirs 95). 
Rather than responding to Letters with traditionally masculine rationality, Letters inspires an emotional reaction from Godwin, causing him to fall "in love with" Wollstonecraft (Memoirs 95). Godwin experiences "melancholy" as a result of Wollstonecraft's skillful presentation of her experiences (Memoirs 95). As discussed earlier, according to Dr. Johnson the purpose of biography was to elicit emotion, empathy in particular, from readers. Godwin's work as biographer appears to be a rational, political project, but is actually rooted in a personal affection. Its appeal to audience is actually feminine in nature, like Letters, Memoirs hopes to elicit emotions from the audience which inspire affection for Wollstonecraft and a spirit of revolution. Godwin's slippage between gender distinctions in Memoirs is itself errant and serves to deconstruct gender in the way that Wollstonecraft's revolutionary project intended.

Godwin's defense of Wollstonecraft in terms of traditional femininity is undercut in his turn to genius, further revealing the instability in his understanding of gender and his understanding of Wollstonecraft's gender. Godwin's description of Letters as representative of Wollstonecraft's genius reveals her masculinity, rather than masks it. Andrew Elfenbein argues that genius, whether male or female, served as a signifier for sexual deviance. Through the label "genius" authors and artists seized an opportunity to take risks; "men and women who did not belong to the conservative establishment appropriated the role of genius to stake a claim to attention...they were the outsiders for reasons of gender, education, nationality, or even health" (Elfenbein 18). Genius was traditionally defined as male, and "when female geniuses are acknowledged, they run the risk of being labeled as too masculine" (Elfenbein 5). Throughout Memoirs Godwin works to recuperate Wollstonecraft's public image and does so by trying to account for her seemingly masculine qualities — revolutionary intent, reason over emotion, sexual liberation - by situating them within sentiment. Godwin's narrative purports that we can account 
for all of her gendered faux pas if we, the readers, just understand the situations which influenced her, the resulting emotions - her life, but within this praise for Letters Godwin notes Wollstonecraft's "genius," and herein lies his errancy. Despite his attempts to situate Wollstonecraft's gender within a coherent system, he fails, and he fails because such a system does not exist, so in the process of attempting to fix Wollstonecraft's erring and inevitably failing, he makes visible the gaps and overlaps in conceptions of gender. "Genius" shows that gender isn't fixed and doesn't work the way he wants it to work in his narrative. Though unintentionally, Godwin becomes an errant subject—he resists systemization despite his best efforts at locating it.

Godwin, benefiting from Wollstonecraft's influence, concludes his biography of her life by highlighting her "intellectual character," a facet of her selfhood which he roots in sentiment (Memoirs 122). Godwin, however, claims that he is "improve[d]" by Wollstonecraft's intellectual character and Godwin scholars argue that this "improvement" is made visible in his continual revisions of Enquiry Concerning Political Justice where he alters his philosophy of rationality to make space for sentiment, as well as in his volume of essays, The Enquirer: Reflections on Education, Manners, and Literature. In a Series of Essays (1797). ${ }^{54}$ Godwin's life was dramatically affected by Memoirs' publication, "He was being castigated as a moral monster. His beautifully restrained memoir of his wife was read as scatological literature" (Smith and Smith 74). Godwin's errancy, like Wollstonecraft's, had tangible cultural consequences; his reputation and the public's perceptions of his works were significantly influenced by his gendered performance of authorship and self.

\footnotetext{
${ }^{54}$ See Mark Philp, Godwin's Political Justice (Ithaca: Cornell UP, 1986), particularly chapter eight, "Mary Wollstonecraft and Political Justice"; D. H. Monro's Godwin's Moral Philosophy: An Interpretation of William Godwin (London: Oxford UP, 1953), particularly 31-56.
} 
Wollstonecraft's multifarious life reveals errancy at work. Her death inspired Godwin to author Memoirs, and in doing so, he attempts to fix Wollstonecraft's perceiving erring in relation to femininity, thereby erring himself. As Godwin tries to situate Wollstonecraft's gender within a coherent system, the system inevitably fails him and his errancy is revealed. Memoirs, Godwin's narrative of Wollstonecraft's erring, highlights the cultural potential of errancy as a concept with which we can destabilize rigid conceptions of gender and make visible gender's amorphous state. 


\section{Chapter 3}

Unbecoming: Desire and Futurity in Amelia Alderson Opie's Dangers of Coquetry

Henry Mortimer visits the "amiable widow" Mrs. Mordaunt to meet Louisa Conolly, a young woman known for her "beauty and accomplishments" and "her disposition to coquetry" (Opie 194-5). As the day passes into evening, Mordaunt questions Henry about his bachelorstatus and insists that he "cannot be insensible to [the] charms" of women, "Miss Beaumont, for instance" who is a young woman known to be "a finished coquette," as Henry calls her (Opie 197). Mordaunt's response to Henry labeling Beaumont "a coquette" is perhaps the most succinct articulation of the Romantic cultural contradiction that the coquette embodies. Mordaunt marvels, "“You are a strange young man...[Y]our sex, in this age, seem to idolize coquetry, for when were they more attentive to ours? Search throughout the beau monde, and you will scarcely see a woman that is not versed in every art of it. Surely, then, you ought to excuse an error your indulgence has encouraged"” (Opie 197). Henry responds, stereotypically, that he "can excuse nothing”(Opie 197). As Mordaunt's insightful commentary indicates, coquetry is treated as “an error." Though patriarchal culture invites coquetry in service of heteronormative marriage, particularly in the interest of pleasing a potential male suitor, the label "coquette" simultaneously disciplines women, warning them that their behavior exceeds the boundaries of acceptable femininity.

Contrary to readings of coquettes that theorize their behavior as "an error," as erring and therefore in need of correction, or alternatively, as a liberating, outright rejection of gender expectations and acceptable feminine behavior, I argue that Amelia Alderson Opie's Louisa Conolly is an example of feminine errancy, a freeing wandering that refuses both correction and liberation, because she makes visible the cultural inability to locate and limit femininity. Louisa 
serves as a warning to women about the dangers of flirting. Remarkably, Louisa's coquetry does not limit her marriage options, and even when she does marry, she continues her coquetry anyway. Though Louisa dies, her coquette narrative diverges from the typical didacticism of the coquette's story. Because Louisa actually gets married, unlike many coquettes of the 1790s, Louisa's flirtatious behavior is situated within marriage, and therefore, her insistence on flirting challenges futurity and femininity's obligatory service to family and nation.

Louisa rejects the narratives of wife or whore, the feminine performances readily available to her. ${ }^{55}$ Though Henry continually exhibits anxiety because of his wife's behavior, Louisa never physically transgresses the boundaries of her marriage. She transgresses the expectation that her desires will be fulfilled by marriage, and one of the expectations of marriage is that Louisa will place her husband's desire for a normative wife whose only concerns are her husband and future family before her. Louisa wants other things: to flirt, to feel desired, to buy rings and china at the market, to save a poor family from economic ruin. Because Opie's treatment of coquetry in Dangers reflects mainstream Romantic ideology, it is impossible for Louisa to survive if she continues to subscribe to an errant version of femininity. Though Louisa's survival is not possible, an alternative feminine narrative challenges the status quo. Though she cannot survive as both a devoted wife and a coquette, her story disrupts the notion that "devoted wife" and "coquette" are mutually exclusive ways of being in the world.

Louisa's narrative differs from those commonly available to coquettes. Coquette narratives from the early eighteenth century commonly concluded in "marriage, financial

\footnotetext{
${ }^{55}$ Other narratives are available, such as unmarried coquette or spinster (oftentimes coquette becomes spinster). These narratives demonstrate a disciplinary function similar to Louisa's. For more about spinster narratives and their disciplinary nature, see Kristina Straub, Divided Fictions: Fanny Burney and Feminine Strategy (Lexington: UP of Kentucky, 1987. Print).
} 
security, and cheerful sociability with the coquette's levity or gaiety channeled into proper directions"; these narratives framed coquettish behavior as something that could be rehabilitated and integrated into the normative order (Braunschneider 140). By the time Dangers was written at the start of the 1790 s, the coquette's story generally ended in tragedy; "[t]he coquette herself might die, but only after being disowned by her family, finding herself financially destitute, birthing an illegitimate and/or dead child, and/or causing the death of other adults she loves" (Braunschneider 140-1). Louisa's death differs from these traditional coquette tropes: she gets married, and then she dies. Few coquette narratives from the 1790s give a fallible, flirtatious woman an opportunity to marry, let alone marry and become pregnant.

Throughout Dangers Louisa serves as an example of failed femininity, but in fact, the narrative ends up demonstrating that "femininity" itself is a failure. The lack of social space for women like Louisa indicates the strict limitations on women's roles. The narrative consequence is Louisa's death, along with the death of her husband and fetus. These deaths are symbolic rejections of femininity's compulsory service to the family and the nation. Her death disrupts the heteronormative narrative and, though destructive, enables readers to imagine coquetry's cultural potential as a set of behaviors that deconstruct normative gender and its cultural function(s). Though Louisa can be read as a warning to women, she also provides a version of femininity akin to Edelman's sinthomosexual, a queer figure that "assert[s] itself...against futurity, against its propagation, insofar as it...designate[s] an impasses in the passage to the future" (Edelman 33). Louisa empowers women to imagine new versions of the future, versions not based entirely on roles as wife and/or mother, but versions that merge and/or entirely avoid the two roles. In other words, Louisa demonstrates that femininity has the potential to be more than the limiting cultural narratives of femininity that are most acceptable for women. The act of imagining such a 
future destroys femininity’s “fictional coherence and stability” (Edelman 34). By marrying Henry and continuing her coquettish behavior anyway, Louisa works from within heteronormative marriage to destabilize it, culminating in the destruction of her unborn child and the symbolic future. Though Louisa's non-normative femininity leads to her death, the glimpse of an alternative mode of feminine comportment deconstructs the status quo.

In this chapter, I take up the category of error as a tactical strategy to demonstrate that femininity is inherently unstable and constantly relocating. I utilize error as a heuristic in two senses: as "erring," which indicates failures and deviations and as "errancy," which identifies subjects that wander and rove. First, I trace Opie's ideological position in relation to normative culture. I also consider various historical figurations of the coquette and the way that such figurations intersect with developing conceptions of marriage. Then, I demonstrate that Henry and Romantic culture-at-large understand Louisa and coquettes generally as erring, and I finally argue for the revolutionary potential of understanding Louisa's gender as errancy. Louisa refuses the fixity of both normative and non-normative femininity, instead moving between coquette and devoted wife and, most often, occupying both positions simultaneously. She insists on maintaining the freedoms that culture means only to conditionally afford her. When it comes to Louisa's version of "femininity," she opts for "both/and" or "neither/nor," rather than “either/or," freeing her version of feminine performance from domesticity (Angelides).

\section{$\underline{\text { Dangers in Historical Context }}$}

Communicating the ideas, contradictions, and complexities inspired by the Revolution, especially their effects on women's lives, was the focus for many British women authors in 
$1790 .{ }^{56}$ Even though Opie anonymously published Dangers in 1790, her authorship did not support a shift in women's cultural roles.$^{57}$ Though Opie was connected to many revolutionaryminded, Jacobin thinkers (including Godwin and Wollstonecraft), her authorial practices rarely aligned with theirs. ${ }^{58}$ In Opie's early works, critics and readers understood Opie as an individual whose politics were radically "anti-classist and anti-racist"; but despite such radicalism, "her

\begin{abstract}
${ }^{56}$ Texts published in 1790 include: Anna Laetitia Barbauld's An Address to the Opposers of the Repeal of the Corporation and Test Acts, Catharine Macaulay's Letters on Education, Helen Maria Williams's Julia, A Novel and Letters Written in France in the Summer of 1790, and Mary Wollstonecraft's Vindication of the Rights of Men.

By the very act of writing, women contributed to one of the key elements of the "woman question": "the moral sphere of reputation" (Walker 145). Writing itself expanded the space(s) in which women were visible, but precisely because of this expansion of women's involvement in the public sphere, writing "suggested a lack of decorum which...hinted at sexual impropriety" (Walker 145). Though, Anne K. Mellor destabilizes our notion of clearly demarcated public and private spheres; see Romanticism and Gender (New York: Routledge, 1993).

${ }^{57}$ For readers of Opie's later, more popular novels, The Father and Daughter (1801) and Adeline Mowbray (1805), Robespierre had already fallen and along with him, Jacobin hopes that the French Revolution might serve as a model for reform in England, bringing about a more liberal and egalitarian society. Dangers of Coquetry preceded all of this; Dangers was written early in Opie's life. Published in 1790 by William Lane, it was her "first publication (beyond, perhaps, a few newspaper poems)" (Chandler 181). It was published less than a year after the fall of the Bastille when the spirit of revolution was still alive and well. According to Memorials of the Life of Amelia Opie, Opie was experiencing this enlivened spirit at home: "Dr. Opie was among those who hailed the dawn of the French revolution with pleasure; and, though he afterwards saw cause to moderate his expectations as to the results of that movement, he seems (in common with many sincere patriots) to have held his allegiance true to the original revolutionary cause" (40-1). ${ }^{58}$ Adeline Mowbray and The Father and Daughter followed the publication of Godwin's
\end{abstract} Memoirs which helped foster an anti-liberal sentiment regarding women's roles and (further) discredited Wollstonecraft, one of England's leading voices for fostering and enacting a broader understanding of women's cultural roles.

Before meeting Wollstonecraft, Godwin maintained a serious relationship with Opie. According to C. Kegan Paul "[t]here is some reason to suppose that Godwin had at one moment seriously thought of asking Amelia Opie to be his wife, and that not long before his intimacy with Mary Wollstonecraft, but whether the lady or her father declined the alliance, or whether no offer was actually made, it is plain that the feeling between the two was at no time warmer than a sincere friendship" (William Godwin, 158). For a study of Amelia Opie's marriage to her husband John, see Shelley King's "Portrait of a Marriage: John and Amelia Opie and the Sister Arts" (Studies in Eighteenth Century Culture, Vol. 40 [2011]: 27-62). Opie does not meet John until 1797, seven years after Dangers' publication. 
poetry increasingly conformed to a feminine poetics" (King). The Anti-Jacobin Review even "singled [her] out for favourable response" in their review of Southey's Annual Anthology, which "as a whole received a cutting response in the conservative" Review (King). Significantly more critical attention has been paid to Opie's politics in her later works and though Dangers was Opie's "first publication (beyond, perhaps, a few newspaper poems)," the text "is remarkable mainly for having the strong moral emphasis that would so strongly feature in her later novels" (Chandler 181). ${ }^{59}$ Unlike authors such as Wollstonecraft or Macaulay, Opie's novels "emphasize the importance of individual morality as a religious and social duty, rather than as part of a political system" (Todd 515). Opie's writing reminds readers of already circulating moral precepts, of what they (as good English citizens, must) already know. Her primary goals are to reinforce existing ideas and cultural constructions to help readers properly align their behaviors with what is socially acceptable. This approach is most clear in the Preface to Illustrations of Lying, in All Its Branches (1825). ${ }^{60}$ Opie writes:

My second apology is, for presuming to come forward, with such apparent boldness, as a didactic writer, and a teacher of truths, which I ought to believe that every one knows already, and better than I do.

\footnotetext{
${ }^{59}$ Of more canonical writing, Dangers probably comes closest to Elizabeth Inchbald's A Simple Story (1791)" (Chandler 181). Other than another short story, "The Nun" (published in The Cabinet, July 1794), "Opie wrote no more novels before she moved to London in 1798 , preferring to concentrate on plays and poems" (Chandler 181). For more on Opie's politics and authorship, see Shelley King's "Politics, Poetics and Propriety: Reviewing Amelia Opie" (Romanticism on the Net, V. 29-30) and "'The Story of the Pineapple': Sentimental Abolitionism and Moral Motherhood in Amelia Opie's Adeline Mowbray" (Studies in the Novel, Vol. 30) by Carol Howard.

${ }^{60}$ This particular work had trans-Atlantic appeal, as demonstrated by the review that appeared in the Unites States Review and Literary Gazette. The Gazette said that Illustrations of Lying "is a book, that we fear few of us can look in the face without blushing" (98). They describe Opie as "a moralist of the most unsparing veracity" (99).
} 
But I beg permission to deprecate the charge of presumption and self-conceit, by declaring that I pretend not to lay before my readers any new knowledge; my only aim is to bring to their recollection knowledge which they already possess, but do not constantly recall and act upon.

I am to them, and to my subject, what the picture-cleaner is to the picture; the restorer to observation of what is valuable, and not the artist who created it. (viiiix)

Opie insists that she is not teaching her readers anything, simply "bring[ing] to their recollection" what they already know — that is, what is already accepted as "moral"; she is not proposing a change to such understandings. Though situated in remarkably different historical moments, Dangers of Coquetry, like Illustrations of Lying, supports normativity and provides female readers in particular with a reminder that their behaviors must be carefully policed. In Dangers, Opie reminds readers that the label "coquette" reflected behaviors, that their behaviors reflected their morality, that their morality was linked to their reputations, and that they alone were responsible for protecting their reputations.

\section{Beyond Salvation: Coquettes in Romantic-Era Culture and Literature}

The evolution of "coquette" as a concept reveals why, by the eighteenth century, linguistic (in)action, what a person says or fails to say, is equal to physical action. It was unnecessary that a coquette physically transgress the boundaries of monogamy (or marriage) to destabilize the notion that feminine desire is directed toward a singular, male object. Flirting women made visible the fact that female desire was not limited to a single subject. "Edward Phillips's definition of 'coquet' in his New world of words, or A universal English dictionary," first published in London in 1685, defines coquette as "An Amorous Courtier, one that makes it his 
business to cause himself to be belov'd, and gain the love of Women. A Lady that strived to win the love of Men... an affected Carriage to win the love of Men or Women; Tattle in Men, Gossipry in Woman, tending to Amorous Intrigue"” (Phillips qtd. in King and Schlick 17). This definition identifies both men and women as coquettes, and as Shelley King and Yaël Schlick point out, this definition of "coquettry" is as much concerned with speech as it is with (sexual) (in)action. ${ }^{61}$ The seventeenth century's focus on the linguistic actions of a coquette remained in the eighteenth century. Dangers indicates that Opie knows that a woman will be perceived as guilty based on speech alone; the final line of Dangers tells readers that "indiscretions" are "as fatal" as "ACTUAL GUILT" (Opie 256). Louisa is certainly thought of as guilty, despite her physical and sexual monogamy. For example, following Louisa's flirtations with Lord Ormington at the ball, Lord Bertie, while talking with another man, remarks, "'Nay,...I do not say [Louisa] is actually guilty, but the woman who is not startled at indulging the adultery of the mind, is not far removed from yielding to that of the body; and the former, I am sure, she is not free from"” (Opie 251). Louisa's linguistic transgressions were enough to threaten her and therefore her husband's reputations. She only had to gesture at the possibility of physical transgression; "indiscretions" and "impropriety" are enough to ruin her reputation (Opie 256).

At the end of the eighteenth century, the label "coquette" indicated a woman's desire for male attention, competitiveness, and/or refusal to commit to a single male admirer-in other words, a desire for change, for inconstancy; such behaviors and desires were beyond the scope of "proper femininity" and in need of correction. If correction seemed beyond the scope of possibility, then a woman became a "finished coquette." The need for such labeling and the

${ }^{61}$ Shelley King and Yaël Schlick challenge our assumptions regarding the now-naturalized gendering of the coquette in their etymological history of the term. For more on this topic see King and Schlick. 
resulting social sanctions indicate anxiety over the existence of such behaviors among women and ultimately raise questions about just how "unnatural” (and uncommon) a coquette's disposition really was. ${ }^{62}$ When a culture locates women's value in their ability to attract and marry a man, it popularizes coquette-like practices. The cultivation of such skills, however, automatically endangers a woman's reputation. Opie is critical of this seemingly-expected (and necessarily careful) balancing act required by women and ultimately discourages women from coquetry entirely, no matter its aim. Early in Dangers, Louisa is aware that her coquetry can get her in trouble. While reflecting on her introduction to Henry, Louisa indicates regret over her behavior for fear of its consequences. After meeting "Mr. [Henry] Mortimer” she laid in bed awake, "seriously...wish[ing] she had followed the advice of her Caroline, to check every propensity to coquetry... she found herself at last punished for her misconduct, in being forced to forego every hope of getting the heart of the only man she now thought herself ambitious of captivating" (Opie 199). Louisa's primary concern is that her "propensity to coquetry" may

${ }^{62}$ In Letter XXIII, “Coquettry,” of Letters on Education (1790), published the same year as Dangers, Catharine Macaulay points out a contradiction in English culture: "whilst the admiration of men continues to be set forth as the chief honour of woman, whilst power is only acquired by personal charms, whilst continual dissipation banishes the hour of reflection, Nature and flattery will too often prevail" (211). As long as gaining "the admiration of men" is the "chief honour of woman," then coquetry "will too often prevail." By placing women's value in their ability to attract and marry a man, Romantic culture made coquette-like practices popular. Later in Letters on Education, Macaulay analyzes Rousseau; she claims that when Rousseau demeans women he does so because of his pride and sensuality: "Indeed [Rousseau] fully avows his sentiments, by acknowledging that he would have young French woman cultivate her agreeable talents, to please her future husband, as with as much care and assiduity as a young Circassian cultivates her's [sic] to fit her for the harem of an eastern bashaw" (Macaulay 213). A woman's "subtlety and... beauty" become the tools of her craft in a culture which encourages the cultivation of both, insisting that she has nothing else to offer the world beyond her ability to increase a man's pleasure, and therefore ought to develop such skills (Macaulay 213). In exchange for developing these tools, women potentially "sacrifice both...decency and....virtue" (Macaulay 213). Women are taught to "cultivate [their] agreeable talents" so that they can "please" their always, already imagined "future husband[s]." The cultivation of such skills, however, automatically endangers a woman's reputation. 
prevent her from winning Henry's heart and becoming his wife; she worries that she is a "finished coquette" and has not carefully enough checked her propensity for pleasing men. Her reputation is in question. Opie's narrative blares its warning: if coquetting women did not conform to expectations of feminine behavior, they would be left without any marriage options at all.

The Disruptive Potential of Coquetry

Coquettes, by revealing that women may desire more than one subject, endanger heterosexual, monogamous marriage. They make readers wonder whether they will, in fact, choose along the lines of cultural acceptability. They do so via their insistence on choices, on inconstancy; by having choices and at times making non-normative choices, they destabilize assumptions about monogamous marriage as a predetermined route for women. If a coquette cannot choose marriage, or if she chooses marriage but continues to be a coquette (like Louisa), then marriage fails to regulate femininity. ${ }^{63}$ Coquettes like Louisa make visible cultural anxieties about women's power, hence Lord Bertie's angry name calling (“'infernal coquette”) when he escorts Lady Jane from the ball. Not only is he irritated with Louisa because of her improper performance of femininity, but also because of her ability to seduce Ormington (with seemingly little effort) reveals her power and marriage's weakness. Marriage is not only a way to manage gender and sexuality, but it is also a tool for building the future of the nation via pregnancy and family, that is, via women's bodies.

By reinforcing the idea that women should direct their attention at a single man who they intend to marry, "coquette" works to limit and pathologize women's choices. Women's

\footnotetext{
${ }^{63}$ While marriage is not the only way to socially manage and limit femininity, it is one of the primary ways. In part this is because it is connected to both the Church and the State.
} 
constancy is expected, and if women failed to direct their attention in such a way and thereby earned the label "coquette," a single woman's reputation was questioned and her value as a potential wife endangered. Coquettes were portrayed as women who lacked morals not only because of their flirting, but also because of their lack of proper feminine traits, especially propriety, sensibility, modesty, purity, and fidelity. The absence of such traits, as well as their flirting, potentially caused such women to remain unwanted and unmarried; this cultural narrative flips responsibility and authority over the decision to remain single so that a coquette's being unmarried is a choice made by men to discard "damaged goods," rather than a choice made by a woman to maintain her independence through single life. ${ }^{64}$ While women's ability to cultivate pleasure for men and themselves by flirting held the potential for reputational ruin, flirtatious, lascivious men did not face such threats. This division points to the ways in which femininity and female sexuality were policed in an attempt to consolidate normativity. In many ways the coquette's analog, the "libertine" in this period commonly refers to "the sexually free behavior and norms of upper-class men"; the label references behaviors that indicate an individual's "free operation of sexual desire against or in delicate negotiation with conventional moral, religious and civil codes" (Cryle and O'Connell 2). A man's libertine behaviors indicated something about his morality, and though detestable to some, unlike the coquette, he had youth and passion as an excuse for his behavior. Throughout the early chapters of Dangers, Henry repeatedly articulates just how indecent he finds coquettes. He insists that Louisa will never be able to capture his attention, let alone his heart because her reputation as a finished coquette is already established. During his discussion with Mrs. Mordaunt, he articulates the function of flirting for men compared to women:

64 The cultural functions of "coquette" are in many ways similar to that of "spinster" (Straub 67). 
"I can excuse nothing... which bespeaks mental depravity, however tolerated by fashion, or glossed by situation. A coquette in your sex is, in my opinion, as detestable as a libertine in ours, and has certainly less excuse for her fault than the latter can boast. The libertine has passion for his excuse, and those who know the force of it, in the bosom of youth, should make some allowances for its effects; but in cool blood to take pains to destroy the happiness of others, to wound an inexperienced heart for the sake of wounding it, as an unwhip'd urchin torments a worm for the pleasure of seeing it writhe about in torture; to seduce lovers from their affianced brides, husbands from their wives, and all to gratify a thirst of admiration, and a despicable vanity, with but a grain of passion to plead her excuse; this is the conduct of a finished coquette, and this is the character, tho' gilded over by beauty and accomplishments, which will ever deserve and meet my abhorrence!"” (Opie 197-8)

Though their behaviors are largely similar, the libertine is driven by "passion" and "youth" while the "finished coquette," with her "cool blood," hopes only to "wound...for the sake of wounding." She is cold, plotting, and manipulative, and has "but a grain of passion." Henry articulates the double standards of Romantic cultural conceptions of morality and sexuality; he is willing to excuse the libertine and eager to condemn the "finished coquette," a woman seemingly incapable of reform. The libertine is understood as embracing an "anti-dogma of inconstancy, understood as freedom from preconceived ideas and emotional attachments" (Cryle and O'Connell 4). Unlike the libertine, the coquette has no excuse; she is a wolf in sheep's clothing, poor "character...gilded over by beauty and accomplishments" (Opie 198). She is not flirting to secure a husband, but to steal someone else's. Henry imagines libertines as individuals whose 
youth and passion plague their productivity, though they are always quite capable of reform. If

libertines learn to properly channel their energies and gain power over youth's vibrancy (in other words, if they grow up and stop challenging authority), their faults (if they would even be characterized as such) would fade away. Coquettes, on the other hand, are not victim to youthful folly or misdirected passion; instead, they heartlessly "[wound]," "[torment]," and "gratify" their “despicable vanity" (Opie 197-8). Coquettes are vain, shallow women who lack the ability to reform themselves. ${ }^{65}$

Throughout the eighteenth century, many tales similar to Dangers warned women of the potential threat that coquetry posed to their future happiness. For example, the conclusion of Memoirs of a Coquet, or the History of Miss Harriot Airy (1765) exemplifies how being a “coquette" endangers a woman's value on the marriage market:

${ }^{65}$ Dangers offers us an example of the cultural contradiction between coquettes and libertines: Lord Ormington's libertine behavior threatens to destroy his potential marriage to Lady Jane. By encouraging (at times even actively seeking) Louisa's attention, he angers his future brother-inlaw, Lord Charles Bertie, and leaves Lady Jane exasperated. On the first night of Ranelagh's opening and Louisa's first "entrance into the gay and fashionable world," Ormington is "[de]composed" by Louisa (Opie 224, 226). Even with Lady Jane on his arm he thought, "To attach such a woman as Louisa was described to be, and rival such a man as her husband, was a task worthy of him" (Opie 226). Ormington threatens his marriage in his desire for conquest and he endangers Louisa's as well. Upon seeing Louisa at the ball without Henry, Lord Ormington's "constancy again vanished at the sight of her ], and sighing deeply, he enquired after the health of her happy husband... Louisa received him with smiles, and transported at this change, the enamoured peer forgot Lady Jane" (Opie 245). Ormington is indifferent toward both Henry and Lady Jane, instead favoring his desire to "[gain Louisa's] affection." Just as much as Louisa engages Ormington's attention, he engages hers; yet, only Louisa is held accountable for such behavior, resulting in Lord Bertie angrily calling her an "infernal coquette." Both Ormington and Louisa are flirts, and their flirtation indicates desire beyond their committed (presumably monogamous) relationships. Their "flirtation is the deviant other which heterosexual love and marriage requires to define itself" (Freedgood). Henry's reaction to both the coquette and libertine is symptomatic of the normative cultural attitude which dictates that women should not seek attention outside of marriage (or from an individual other than whom they intend to marry) because normative femininity does not encompass such desire; normative masculinity, however, encompasses such wavering attentions. 
From year to year, however, [Harriot] went on in pursuit of what she could never obtain - a husband - for who would think of settling with her who behaved with equal freedom to every man she met with, and discovered, by every turn of her eyes, and every movement she made, that the love of admiration was her ruling passion?-Whenever that is the passion, no man can be sure of a domestic companion-For where it is strongly predominant before marriage, it is rarely weakened afterwards: and who would chuse [sic] to be tied to a wife, for the entertainment of the public? - He who could love such a woman is, I own, of a more liberal way of thinking; for I am so narrow as to suppose, that there can be no felicity in the marriage state, where the parties contracted are not wholly attached to each other - and strike out all their happiness at home. (192-3) Because of Harriot's "equal freedom" with "every man," she is no longer marriage material. In many ways, Harriot and Louisa are similar. Like Harriot, Louisa "saw herself surrounded by admirers, whom the fame of her beauty and the report of her expectations, had assembled round the seat where her father resided" (Opie 187). Rather than encouraging the attention of a single suitor, she allowed "vanity and the love of admiration" to take "possession of her heart" and alternatively discarded and encouraged her admirers (Opie 187). Unlike Harriot, though, Louisa is able to marry because she effectively convinces Henry that she has changed. As the passage from Memoirs of a Coquet, or the History of Miss Harriot Airy declares, whenever a coquette is about "no man can be sure of a domestic companion"; for men "freedom" is to be expected, but for women, it is dangerous. In Dangers, Henry explains that one of the most detestable things about a coquette is her desire and ability to endanger marriages, and his observation hits remarkably close to home. He says that coquettes "seduce lovers from their affianced brides, 
husbands from their wives" in order "to gratify a thirst of admiration" (Opie 198). For Henry, blame falls solely on women, on Louisa, for being "seduc[tive]," for remaining a coquette, even after she becomes his wife.

Louisa fails to transform at all; in fact, her coquettish instance on inconstancy is visible in the countless failed resolutions she makes throughout the story. Readers immediately learn that Henry's description of Miss Beaumont as a "finished coquette" makes Louisa "conscious of her resemblance to" Beaumont (Opie 197-8). The narrator tells readers that "at eighteen," Louisa is already "a finished coquette" (Opie 187). There is no history in the narrative that would indicate that she is ever anything but a coquette. Louisa's pattern of making resolutions only to shortly thereafter break them begins immediately: Louisa "was...constantly repenting of her errors and she would retire from the assemblies where she was the idol of the crowd, to lament her broken resolutions, and to form fresh ones for the morrow" (Opie 187-8). Louisa, like her readers, thinks of her behavior as an "error." Therefore, she works to overcome the hurdles of coquetry, traceable in her insistence on making choices only to shortly thereafter change her mind, settle upon a different choice, and alter her behaviors. This pattern emerges because Louisa's “errors [went] uncorrected" throughout her life and "no friendly hand was stretched out to lead her into the path of prudence" (Opie 188). As a child, she wasn't taught "prudence” and so coquetry's multiplicity became part of her early behavioral practices. Though she did have sensibility, Louisa did not have "an exquisite sense of propriety... which led her instantly to condemn and avoid every action which her reason disapproved" (Opie 189). Her impulses go unchecked and she falls "prey to...quick feelings" (Opie 188). Her ability to make "good" decisions and stick with them is never established; she changes her feelings and her choices immediately. As a result of the lack of education and guidance throughout her childhood, Louisa's moral chastity 
(symbolic of her sexual chastity) is undeveloped, and her failure as a wife and mother is therefore pre-determined. Change does not take place from Louisa's early childhood to young adulthood, nor does change take place after her marriage to Henry.

Counter to normative notions of bourgeois femininity, Louisa chooses too much; rather than sticking to the resolutions uttered moments before, as situations unfold and circumstances change, she makes additional choices: to support Mrs. Nelson rather than purchasing something for herself, to treat Lady Jane with kindness, to stay at home or to venture to Almack's. ${ }^{66}$ Her insistence on inconstancy is directly linked to her coquetry. Choices highlight Louisa's tendency to veer from acceptable femininity and support Opie's moral lesson about coquetry. Choices were not afforded to most eighteenth-century women, and Louisa's insistence on them demonstrates her errant femininity. Women had one preferred choice: to be a devoted wife, "which is to say_-given the legal fact of coverture, a system in which a married woman is legally, socially, and economically subordinated to her husband — she should choose to limit her ability to choose" (Braunschneider 99). Louisa's dissolution of resolutions continues throughout her marriage to Henry.

Opie further frames Louisa's version of femininity as an error in Dangers via the contrasting portrayals of Louisa and Caroline, Louisa's long-time friend. The narrative highlights Caroline's progress toward becoming a "successful" wife and mother, a "domestic woman," against Louisa's perpetual coquetry. ${ }^{67}$ During Caroline's betrothal, her father remarks that she "has been

\footnotetext{
${ }^{66}$ Bourgeois femininity requires choices and constant judgment, but it requires constancy following those choices and judgments. Louisa makes a choice only to then change her mind and choose otherwise.

${ }^{67}$ Conduct novels of the eighteenth century portrayed "corrupted desire" primarily as "desire that sought its gratification in economic and political terms" (Armstrong 60). Desire is, in fact, managed by effective domestic economic management.
} 
a good girl, and deserves to be rewarded" (Opie 214). She is a "good girl" because despite her own desires, she has given her life up in service of her father-caring for him after the death of her mother, persevering through the torment of his new wife, and then caring for him again in his old age. Though she loves Edward Mountague she sacrifices his love and seeks contentment with Mr. Conway. Even when Edward, the man she truly loves, shows up unexpectedly and informs her he loves her, she insists that she cannot marry him because she has made promises to Mr. Conway and refuses to lead either man on: "'Stay, most generous of men [Mr. Conway],...and hear me resolve never to unite myself with any one but you, and I here promise to see Mr. Montague no more!"' (Opie 213). Mr. Conway informs her that he cannot marry her due to the "the warmth of affection" she feels for Mr. Montague; this affection would inhibit her ability to give Conway the love "his delicacy demanded" (Opie 214). It is not until Mr. Conway releases her from their marriage contract that she is willing to consider marrying Edward. Characters throughout the narrative endorse Caroline's integrity and morality, demonstrating that she is recognizable as properly feminine. Lady Beaumont declares Caroline "a noble girl" who “deserves to be happy" (Opie 216). For Caroline and Lady Beaumont, Caroline's happiness is located within the context of marriage. The stranger who Lord Bertie speaks to in St. James's coffee-house (where Henry and Lord Bertie decide to resolve their conflict with a duel) is certain that Lord Bertie has misjudged Louisa because she is Caroline's friend, and Caroline "is so amiable, that [he] must doubt the probability of [Louisa] being as [Lord Bertie] describe[s] her" (Opie 251). ${ }^{68}$ Caroline's idealized femininity serves as the model to attract and keep a man.

${ }^{68}$ In The Flirt's Tragedy: Desire Without End in Victorian and Edwardian Fiction (2002), Richard Kaye argues that flirting characters in late nineteenth- and early twentieth-century fiction are essentially used to teach other women how to get a man. He traces such flirting backward in time to the eighteenth-century coquet. The inverse of his argument takes place in Dangers; Caroline attempts to prepare Louisa for marriage. Kaye does not make this claim about 
Louisa recalls Caroline's advice when she fears she will not be able to gain Henry's heart: "Louisa...now began seriously to wish she had followed the advice of her Caroline, to check every propensity to coquetry; and she now saw her error, when it was too late to amend it: she found herself at last punished for her misconduct, in being forced to forego every hope of gaining the heart of the only man she now thought herself ambitious of captivating" (Opie 199). When Louisa's behavior begins to worry Henry he takes solace that Caroline is "expected in a few days," offering Louisa "example and advice" (Opie 240). Shortly before Henry's death, Louisa receives a letter from Caroline informing her of Caroline and Edward's visit. After reading the letter Louisa feels "joy... at the idea of seeing her friend," but her happiness is "damped by the consciousness that she deserved her reproofs" (Opie 247). Throughout Louisa's courtship and marriage to Henry, it is Caroline, the figure of normative femininity, who disciplines and guides Louisa. She is the model for the female reader, not Louisa.

As I've discussed, Opie's narrative shows that coquetry is erring femininity, a cultural phenomenon in need of fixing and a set of behaviors that women should be wary of because behaving as a coquette would endanger their reputations. While it is the case that Opie carefully represented Louisa's behaviors as the stereotypical coquette of the eighteenth century, Opie also made visible in Louisa an alternative femininity, an errant femininity that insists on "both/and" or "neither/nor," rather than "either/or," freeing femininity from a narrowed performance rooted primarily in domesticity. However, such a version of femininity was not viable-- it strayed too far from acceptable femininity. Even in marriage, Louisa embraced the power of her sexuality,

eighteenth-century coquettes, but tracing the development of the figure does lend insight into the way women who flirt were later reincorporated into hegemonic culture so that they are no longer able to transgress and destabilize social institutions, but instead serve as mentors in the process of shaping normative femininity for such institutions. 
continuing to flirt with men other than her husband, and she insisted on inconstancy — on choices - rather than the constancy of domesticity.

Louisa unwittingly foils traditional futurity, a future rooted in progeny. Marriage serves as the primary organizer for the transmission of property, as well as the vehicle through which (proper, culturally acceptable) reproduction takes place. The marital relationship and the family it produced were significant in organizing the distribution of property in the eighteenth century, in many ways due to laws of coverture. A male heir was necessary so that the transmission of property was easily established and maintained, so that the land of the nation could be passed to the next generation of citizens. Marriage works to create citizens by "nam[ing] the terms of legitimacy that render some children citizens" and "announc[ing] a form of kinship relations" that validates (some) individuals as "full citizens," bestowing upon them all of the accompanying rights and privileges (Stevens 66). Any hint at a woman's philandering threw into question the paternity of a child and therefore the transmission of property--hence, the danger of the coquette. Through her inconstancy and decisions to at one moment woo Lord Ormington and at another engage Henry's attention, Louisa raises questions about her child's paternity, about her/his citizenship. Without the organization of this state-recognized, monogamous, marital relationship futurity becomes disorganized. Most conduct books and didactic novels framed the coquette as an error in need of reparation so that she can return to the righteous path toward successful marriage; they echo the laws which forced women into marriages where their rights were forfeit for the benefit of the patriarchal nation-state. As Christian Klesse explains, "From within a Foucauldian perspective on the law a close interrelation exists between legal discourse and sexual identities and the conditionality for the emergence and development of erotic cultures... Some have argued that the particularly enhanced effectivity of the law to construct and 
regulate sexuality rests in its ability to present itself as a superior form of truth" (19). ${ }^{69}$ The British state and culture of 1790 legitimized particular heterosexual relationships and attempted to define normative femininity by making "proper" female sexuality materially non-existent until after marriage and then accepting only monogamous heterosexualities after marriage. Louisa's insistence on being both married and an incessant flirt complicates femininity's cohesiveness as well as the notion that monogamy is always a source of fulfillment.

Coquettes threaten the family through the male desire they attract; they show that marriage's ability to meet the demands of individuals' emotional and erotic energies is socially fabricated. Louisa embodies this; she can't stop being a coquette because Henry isn't enough. She "insensibly flirts with her old admirers," looks to Ormington, her "eyes sparkling with pleasure," because Henry's attention alone is not fulfilling (Opie 241, 227). A coquette's sexual behavior was also subject to cultural discipline because it called attention to women's potential to maintain power over men, to arouse their feelings and desires even when they were in a monogamous relationship. Such is Louisa's power over Ormington; regardless of Ormington's "[alarm] at Lord Bertie's threatening to break off the marriage with his sister," he is constantly drawn back to Louisa, "continu[ally]...giv[ing] [Lady Jane]...cause for jealousy" by engaging Louisa's attention (Opie 241). Coquettes also maintain power over other women, constantly using their beauty, charm, and wit to make themselves the center of attention. According to

\footnotetext{
${ }^{69}$ For the last twenty-five years or so queer theorists have called attention to the ways in which the state legislates against non-heterosexual identities. My focus here isn't sexual identity as we understand it in a $21^{\text {st }}$-century context (as it is for Klesse or $21^{\text {st }}$-century queer theorists), but rather the way in which heterosexuality was managed so that non-normative heterosexualities were displaced. For a greater understanding please see George E. Haggerty's discussion of various forms of deviant desire, particularly female desire in context with kinship relations, in Unnatural Affections: Women and Fiction in the Later $18^{\text {th }}$ Century (Bloomington: Indiana UP, 1998).
} 
Braunschneider, oftentimes cultural discipline for a literary coquette's sexual behavior was delivered "with an urbane and lighthearted....tone" (38). By treating her as only a whimsical girl whose vanity and self-love overcomes her, her significance is dismissed. She becomes less of a threat to marriage and the nation if we all sit back and giggle at her silliness.

The myth of monogamy is that it fulfills all of the desires of the individuals who have committed to one another. In addition to the socio-economic narratives cited above, cultural narratives link marriage and monogamy, making them inseparable from one another so that being married demands monogamy. Both are historically situated within deeply ingrained religious and cultural practices. Marriage is a "wicked [illusion] or ideological [product]" (Birth of Biopolitics 19). Cultural practices tied to religion create the myth of monogamy as an inherent truth, a state which humans have sought for time immemorial. Part of the mythology of affective marriage is that it fulfills the continually regenerating desires of both individuals, leaving husbands and wives emotionally and erotically fulfilled. However, this is impossible. Desire's existence always already insinuates a lack because desire can never be fulfilled and continually relocates. Simply, we do not want what we have; instead, we seek something new. Monogamy and marriage insist this is not the case. They are institutionalized meconnaisance; society maintains that by organizing relationships this way, we are made whole, that our desires are fulfilled. In monogamous marriage one finds one's "other half" or "soul mate." Only this isn't the case; it cannot be because desire is persistent. One way the meconnaisance of monogamy and marriage becomes visible is through the coquette. Recognizing marriage's lack, desire is projected elsewhere. Coquettes function as what Lacan termed the object petit $a{ }^{70}$ The object

\footnotetext{
${ }^{70}$ My understanding of Lacan derives from two essays in particular: "The Mirror Stage as Formative of the Function of the I as Revealed in Psychoanalytic Experience" (1949) and "The
} 
petit $a$ is the symbolic absence that exists because of the constant attempt to fill lack and lack's incessant existence as a result of desire's continual shifting (glissement). While she is the unobtainable object of desire, continually promising and displacing desire's fulfillment, she is also the place where marriage's lack is projected. Through this projection she thwarts marriage's aims, unconsciously endangering the future of the nation.

As a wife and (future) mother, the responsibility of rearing and preparing a future British citizen fell to Louisa. Citizenship was imparted onto children by their mothers, who were "producer[s] and nourisher[s] of new citizens" (Greenfield 80). ${ }^{71}$ Mothers, through their decisions in who to marry, partner with, reproduce with, "[determine] which class and race will predominate in an increasingly integrated society"; they are the "site for controlling human increase" (Greenfield 108). In Henry's final letter to Louisa, composed before departing for an unnecessary duel to defend her honor, Henry chastises her: "[I]f I survive the event of tomorrow, let a sense of the danger your impudence has caused prevent you from erring again" (Opie 252). He expresses his regret at not fulfilling his "“duties of a husband"” to "“awaken [her] to reflection,"” as well as his desire for a normative family: “"Oh, Louisa! a few months would have made me a father, and a few hours may_-," the potential of his own death unutterable (Opie 252). It isn't until this letter that the reader is made aware of a potential child. In the same letter which reveals the existence of this child, Henry orchestrates the transmission of his property in case of his death: "“But I had forgotten — should you give birth to a living child, I leave it to the guardianship of your father and Lord Fitzaubrey"' (Opie 253). Despite Henry's own role in his

Instance of the Letter in the Unconscious or Reason since Freud" (1957) (in Ecrits: "The Mirror Stage..." 75-81; "The Instance of the Letter..." 412-39).

${ }^{71}$ See Susan C. Greenfield's Mothering Daughters (Detroit: Wayne State UP, 2002) for insight into the "cultural obsession with motherly duty and influence" (13). 
demise (by dueling with Lord Bertie and, apparently, by not provoking Louisa's reflection and transformation), the letter places blame on Louisa for his death and the destruction of their family's future. Henry worries that without him she will be left "prey to the malice of a censorious world, which, unacquainted with [her] worth, and ignorant of [her] real goodness of heart, may extend their disapprobation of but one foible so far as to tarnish the luster of all [her] other virtues and accomplishments" (Opie 252). Her coquetry will be her only remarkable trait because for the rest of society, it obscures all else. Henry, of course, dies as a result of the duel and Louisa is devastated:

Louisa suffered herself without resistance to be taken from the body, she seemed insensible to all that passed, and remained for some time with her eyes fixed in one direction. At length she burst into a loud hysterical laugh, and fell into violent convulsions.

Louisa continued in strong convulsions some hours, and the next morning gave birth to a dead child. But though composed and quiet, after delivery, nature had undergone such struggles, that she was pronounced incapable of surviving more than a few days...

Louisa...would utter nothing but execrations on herself for having killed her husband and child. (Opie 254)

Narratives about coquettes commonly ended in death or marriage, but unlike most coquette narratives, Louisa gets married and then dies (Braunschneider 139). Louisa's marriage, followed by her death, was symbolic of her failed femininity and supposed ill-fit as a wife and mother. Louisa's actions echo Lee Edelman declaration in No Future (2004): "Fuck the social order and the Child" (29). The Child is a Symbolic figure that continually defers the rights of current 
citizens for the rights of future citizens, essentially citizens who do not (yet, if ever) exist: "We are no more able to conceive of a politics without a fantasy of the future than we can conceive of a future without the figure of the Child. That figural Child alone embodies the citizen as an ideal, entitled to claim full rights to its future share in the nation's good, though always at the cost of limiting the rights 'real' citizens are allowed" (11). In refusing to continually defer her own immediate desires (Ormington's attention, Lady Jane's jealousy, a night at Almack's) for the desires of the future (Henry's happiness, Lady Jane's friendship, her own mental peace in knowing she maintained her resolution), Louisa kills her fetus and disrupts heterosexual reproduction's futurity, making alternative femininities visible.

Because of Louisa's destruction of her fetus we understand her as a queer literary figure, the sinthomosexual. Sinthomosexual “echoes Lacan's concept of the sinthome, which refers to the unique form that jouissance-ecstatic pleasure that goes beyond desire to engage the Real and the drive - takes in each subject" (Coffman 58). The sinthome reveals the way that subjects place themselves, concepts, and objects within the Symbolic so that the systems of signs and signifiers become recognizable and navigable; "whatever exposes the sinthome as meaningless knot, denying our blindness to its functioning and destabilizing the ground of our faith in reality, effects a disfiguration with possibly catastrophic consequences" (Edelman 38). Louisa's pleasure in flirting as an end in itself, rather than as a means to pleasure, makes visible the empty signification of marriage. She is the narcissistic, child-killing, future-killing figure that Edelman imagines; in refusing the only future she is allowed to imagine, a future based on domesticity, Louisa's alternative femininity has the potential to free future feminine subjects from the 
restrictive gender identity that they always-already occupy. ${ }^{72}$ Marriage's mythology as a way to complete one's self is uniquely located in late $17^{\text {th }}$ - and $18^{\text {th }}$-centuries. It is during this period that affective marriage becomes popular; in Louisa's selection of her spouse based on feelings (of love, attraction, etc.) she works from within heteronormative marriage to deconstruct it. Through her constant flirting, indicative of marriage's lack, she "affirms a constant, eruptive jouissance that responds to the inarticulable Real, to the impossibility of sexual rapport or of ever being able to signify the relation between the sexes" (Edelman 74). According to Lacan, the sinthome is jouissance without an object; "the sinthome refuses the Symbolic logic that determines the exchange of signifiers; it admits no translation of its singularity and therefore carries nothing of meaning, recalling in this the letter as the site at which meaning comes undone" (Edelman 35). Louisa's "symptoms of vanity... and sensibility to praise" do not locate her desire in a heteronormative relationship or polygamous behavior, but in herself - a notion beyond the scope of the Romantic symbolic system (Opie 221). When Louisa "secretly wish[es] to see Lord Ormington" to "engage his attention," she unconsciously reveals that flirting is the pleasure of a coquette (Opie 225). She revels in the flirting process: exchanging looks of "warmest admiration," "bestow[ing]... seducing smiles," and "pursui[ing] her advantage" (Opie 227, 240, 231). Louisa's flirting lacks a sexual end; her goal is not sex (or even marriage), but flirting itself. When Louisa goes to Almack's without Henry (despite her resolution to remain at home) she takes pleasure in her appearance, knowing she will "attract more attention" because of her

\footnotetext{
${ }^{72}$ Edelman encourages us to read many of his sinthomosexual examples as homosexuals (Coffman 58). This is not my intention in reading Louisa as such. I do not wish to elide the historical and cultural differences of Edelman's exemplary characters and Louisa, nor do I wish to propose a particular "type" with beginnings in the Romantic period traceable to $20^{\text {th }}$-century film. Instead, I wish to focus on Edelman's proposal of the sinthomosexual as a "figure produced by—but disruptive of-reproductive futurism" (Coffman 58).
} 
beauty (Opie 244). She expresses her pleasure at the process of flirting with and seducing Lord Ormington: she attracts his attention, "smiles," and then, when "the natural gaiety of her disposition" takes over, flirts throughout the night, taking "glory in [her] conquest" (Opie 245). Her coquettish pleasure again derives not from projecting her desire beyond her marriage (linguistically or physically), but from flirting. Her flirting lacks normative Romantic heterosexual ends: seduction, marriage, reproduction. Her pleasure fails to produce anything except her own jouissance. Because of its masturbatory narcissism, flirting poses a greater threat to the Symbolic order; it cannot be defined against or incorporated within heteronormative, monogamous, marital relationships. Flirting is "the site at which meaning comes undone" (Edelman 35). Recall Braunschneider's claim regarding affective conjugality and female heterosexuality: Coquettes "provide a key site for the culture to worry [about] the matters of female desire and choice," especially worries about women not choosing heterosexual marriage, instead opting for "several men instead of one; ... other women...;...pieces of china, pets, or silk ribbons more than other people;... their own 'freedom' more than wifehood and motherhood; or otherwise fail[ing] to desire and choose in the way affective marriage require[d]" (Braunschneider 12). Louisa's flirting points to the possibility that women get sexual pleasure from things, non-things, or everything; from "both/and," "neither/nor"- that they get pleasure outside of heterosexual marriage thereby usurping masculine power and threatening the patriarchal order. She indicates femininities that are not tied to marriage, that are not defined against and within one's marital and/or reproductive statuses, and that highlight marriage's insufficiency as a system for organizing desire. Through marriage's cultural mythology hegemonic "truths" are created and constantly reinscribed via ritualistic practices (e.g.: wedding ceremonies and receptions, anniversaries, ring wearing) and ties to the State and Church (e.g. 
marriage certificates, legal rights and recognitions). Culture reinscribes such "truths" (of marriage, futurity) in an "attempt to produce a more desirable social order" (Edelman 2) ${ }^{73}$ These cultural "truths" "affirm a structure, to authenticate social order, which [culture] then intends to transmit to the future" (Edelman 3). Louisa, the sinthomosexual, reveals the lie of this "truth" and "exposes the sinthome as meaningless knot" (Edelman 38). By fracturing these regimes of truth, societal "faith in reality" is destabilized: Is the future inevitable? Is marriage sufficient? She shows that marriage is an institution that, despite its mythology as such, fails to organize and contain desire, sex, reproduction, and kinship. Even amidst the height of her flirtation with Lord Ormington, "Louisa's eyes would frequently wander in search of her husband[']s, and having met them, would tell him by a glance of fondness, and an intelligent smile, that she enjoyed the admiration she excited" (Opie 232). She subverts the normative function of flirting (to seduce a man, to get laid), throwing the entire system of social signs into chaos. Her flirting doesn't indicate her desire to have Lord Ormington, just her desire to flirt.

Each of Edelman's sinthomosexuals “are either rehabilitated for reproductive futurism by the stories in which they appear... or expelled from the narrative altogether" (Coffman 58). ${ }^{74}$ Louisa experiences both. The narrative attempts to rehabilitate her for reproductive futurism in her dying breath. After the death of Louisa's fetus, Mrs. Nelson unexpectedly arrives at the door of Louisa's home; in an effort to remind Louisa of her (infrequent) goodness, Caroline (now acting as Louisa's caretaker) ushers Mrs. Nelson and her child to Louisa's bedside. Despite Mrs.

\footnotetext{
${ }^{73}$ Foucault describes this process via "regimes of truth"; regimes of truth "make what does not exist....nonetheless become something, something however that continues not to exist" (Birth of Biopolitics 19).

${ }^{74}$ Edelman's examples of sinthomosexuality include "Ebenezer Scrooge in Charles Dickens's A Christmas Carol; the eponymous protagonist of George Eliot's Silas Marner; Leonard in Alfred Hitchcock's North by Northwest; the birds in Hitchcock's The Birds" (Coffman 58).
} 
Nelson's efforts to convince Louisa that she has "administer[ed] comfort to the unfortunate[,]" Louisa declares that she has "killed [her] own" husband and fetus (Opie 256). In her final moments, Louisa "extend[s] her hand toward Mrs. Nelson and her child" and exclaims, "Father of Mercies, let these plead for me"” and then, she "expire[s]" (Opie 256). She is expelled from the narrative, yet Mrs. Nelson and her child rehabilitate Louisa's sinthomosexuality in similar ways that Tiny Tim rehabilitates Scrooge's in Edelman's reading of The Christmas Carol. In the single instance of her charity and selfless care, Louisa is meant to live on. Her charity toward the Nelsons allows Mrs. Nelson’s child to survive: “"But see! Madam,...but for you she would not have been here now — indeed you have... saved my child's life"” (Opie 256). This final narrative effort to incorporate Louisa's unrecognizable sexuality within the heteronormative and patriarchal is in vain; she is beyond saving - incapable of being incorporated, censured, or fixed. $^{75}$

Opie's didactic Dangers of Coquetry warns women of the deadly consequences of straying beyond the scope of acceptable femininity, of acceptable sexuality, but unknowingly represents an alternative femininity through Louisa, a coquette who, despite narrative tradition, has a chance to marry. Louisa's dead fetus signals a disturbance beyond articulation in the symbolic order. Her coquettish jouisannce is located outside the bounds of the cultural vocabulary. The cultural positioning of the coquette is evidence of this; her figuration as a woman who is cold and lacking passion reflects a cultural inability to understand and organize her jouissance. A coquette's pleasure is not systematizable within any recognized gendered sexuality, a disruption that gives birth not to a child, but to a new (though still unutterable,

\footnotetext{
${ }^{75}$ I mean "fixed" in two ways: Her errors cannot be corrected, and she refuses a singular, stagnant identity. We are unable to articulately mark out her gender and her sexuality based on the available notions and their signifying terms.
} 
deadly) femininity and sexuality. Dangers' emergence within Romantic gender and sexual systems forces the narrative to put Louisa's newly imagined femininity to death, but its interruption remains. Louisa's coquetry deconstructs the symbolic system upholding marriage, heterosexual desire, and normative femininity and it proposes a rather revolutionary remaking of the system wherein women have choices about who to marry, who to fuck, who to flirt with, and the ends of such choices. 


\section{Chapter 4}

"How Idle is Beauty": Interiority, Femininity, and the Queer Gaze

In the 1757 edition of A Philosophical Enquiry into the Origin or our Ideas of the

Sublime and Beautiful, Edmond Burke aligns the ability to love with an attachment that is inspired by beauty. Burke configures beauty as a trait that is primarily visual and material. $\mathrm{He}$ writes, "Beauty is a social quality; for where women and men...give us a sense of joy and pleasure in beholding them,...they inspire us with sentiments of tenderness and affection towards their persons" (18-19). Beauty, a visual experience, elicits an emotional reaction. Because of the "tenderness" and "affection" that beauty inspires, men "enter willingly into a kind of relation" with women who are beautiful enough to inspire love (Burke 1757, 19). By 1801, when Anne Plumptre wrote Something New: or, Adventures at Campbell-House ${ }^{76}$ Burke's text was in its sixth edition; the sixth edition included his introduction titled "On Taste" - a response to critiques of A Philosophical Enquiry, including those written by Mary Wollstonecraft and Hannah More. ${ }^{77}$ Despite Burke's additions to A Philosophical Enquiry, most of the original text, including "Of Beauty," remains unchanged from the 1757 edition. ${ }^{78}$ Burke's philosophy of

\footnotetext{
${ }^{76}$ Something New was published in three volumes.

${ }^{77}$ Burke's alignment of beauty and women was subject to significant critique. See Mary Wollstonecraft's A Vindication of the Rights of Men (1790), A Vindication of the Rights of Woman (1792) and Hannah More's Strictures on the Modern System of Female Education (1799).

${ }^{78}$ In the preface to the 1798 edition Burke writes, "I have been better enabled to discover the imperfections of the work... Though I have not found sufficient reason, or what appeared to me sufficient, for making any material change in my theory, I have found necessary in many places to explain, illustrate, and enforce it" (A2). He goes on to say that he meant not to compose a "dissertation" on the sublime and the beautiful but to discover "the origin of these ideas" (viii). He then reasserts the distinction between the two categories: "If the qualities that I have ranged under the head of the Sublime be all found consistent with each other, and all different from those which I place under the head of Beauty; and if those which compose the class of the Beautiful have the same consistency with themselves, and the same opposition to those which are classed under the denomination of Sublime, I am in little pain whether anybody chooses to
} 
beauty and its connection to love speaks to the interconnected roles of femininity and beauty in Romantic culture. ${ }^{79}$ Women's beauty motivated men to love and to marry. ${ }^{80}$ Beauty's alignment with femininity and women, and Burke's description of it as a trait of "objects" that "are comparatively small" to sublime objects, reaffirmed patriarchal structures that made women secondary citizen-objects. Women, as objects, were signifiers of men's value. Within typical Romantic London and upper-class culture, women who lacked beauty were ostracized and devalued. Potential suitors who invested in cultural narratives about beauty's importance framed women's ugliness as a mistake and one that ought to be avoided or else a suitor's personal reputation was bound to suffer. In my critical reading of Something New, I utilize and build upon the notion of beauty put forth by Whitney Davis. Davis contends that the term beauty "denote[s] a normative communalization of judgments of taste that claims deep aesthetic agreement, gains wide social assent, and relays an entire community's ideals of itself for itself" (27). Lionel Stanhope's way of viewing beauty when he first visits Campbell-House, Olivia's estate, is akin to Burke's. However, Lionel's stay at Campbell-House shifts his view, including beauty's definitive association with feminine value.

A month into his stay at Campbell-House, Lionel Stanhope exclaims the following about Olivia Campbell: "Oh God, how vain, how idle is beauty, when compared with qualities so exalted, so sublime" (Plumptre 122) Lionel's utterance captures a transformation in his way of

follow the name I give them or not, provided he allows that what I disposed under different heads are in reality different things in nature" (viii). He affirms the necessity of a societal standard in "On Taste" (see pg. 3).

${ }^{79}$ Burke claims that the "beauty of the sex" elicits a "mixed passion which we call love" (1757, 18). He indicates that this sort of love is really a necessity because it leads to the propagation of the species, as is necessary with all animals. Sublime objects cause "admiration" $(1757,97)$. Burke does discuss the possibility of beauty of the mind. See "Section X. How far the idea of Beauty may be applied to the qualities of the mind."

${ }^{80}$ See Burke, "Sect. VIII Of the Passions which Belong to Society" (1757): 14-15. 
looking at the world. According to Burke, the sublime "is productive of the strongest emotion which the mind is capable of feeling"; sublime objects "are incapable of giving any delight, and are simply terrible; but at certain distances, and with certain modifications, they may be, and they are delightful" (1757, 13-14). Despite social narratives that train Lionel to align femininity and beauty and to value objects wherein that alignment is visually present, in this utterance, Lionel values the sublime over the beautiful and challenges the status quo. He values the internal over the external as well. Rather than admiring Olivia because of her physicality, he admires her internal qualities. My reading of Something New's narrative reframes ugliness from being a symptom of error that ought to be avoided and reconfigures ugliness as an indicator of internal value (e.g. morality, sensibility); in this configuration, a woman's ugliness is an indication of her errancy because her morality does not align with her physicality, signaling a break from literary tradition wherein beauty signifies internal value. Lionel's way of looking shifts and he begins to devalue beauty as the elicitor of love. In this chapter, I argue that Something New is a critique of Burke's objectification and commodification of women. Plumptre's purposeful use of Olivia, the ugly heroine of Something New, and what I will call Olivia's queer gaze critique the alignment of femininity with beauty, as well as the cultural narratives that establish "taste" as a collective consensus. Like other queer, errant figures, however, Olivia's revolutionary potential is unsustainable. Olivia's queerness is viable only at Campbell-House, a heterotopia that "represent[s], contest[s], and invert[s]" normative society (Foucault 3). Though the specter of queerness is not viable outside of Campbell-House or Something New, its emergence alters "the national imaginary" and demonstrates the possibility of difference (Freccero 8).

Something New is not only a text engaging with current political issues surrounding Plumptre's readers, including the cult of beauty, but is also an oeuvre against literary standards 
reinforced by mainstream British literature. Plumptre's intention to challenge behavioral norms in Something New is first indicated in the prologue. A three stanza poem, the prologue is central to understanding Plumptre's overarching goals for Something New. The first stanza indicates Plumptre's love of French culture and her political position in relation to the English monarchy: “The man who oft turns o'er th' historic page...though, while aw'd by pow'r's superior force, / States, empires, cities, provinces remain / Supinely yok'd by Tyranny's fell chain, / That love of freedom in ev'ry breast / Resistless rules, nor e'er can be suppress'd, / Indignant bursts its bond, or soon, or late, / When despots in their turn must yield to fate" (Plumptre 3). Readers, according to Plumptre, of "th" historic page" cannot ignore, despite being "aw'd by pow'r's superior force," that power is impermanent and "despots in turn" will be forced to "yield to fate" (Plumptre 3). Plumptre, known socially as a Francophile and Napoleon-supporter, gestures to the political tumult taking place in France and its impact on England. However, by the time Something New is published in 1801 most British citizens questioned Napoleon's tactics and motives ${ }^{81}$ Associated with Plumptre's allusions to the French Revolution, the first stanza of the prologue calls attention to the fall of existing powers. In the second stanza, Plumptre shifts her attention to "Britons" and their ability to "proud[ly] boast that we indeed are free" (Plumptre 3). In pointing out the "fair Liberty" and "choicest blessings" experienced by Britons, Plumptre rhetorically aligns herself with British readers. It is only after pointing out that Britons are free, except for where they are "Restricted...by the law's decree," that she invites readers to question their freedom. She asks, "Are free indeed?" and declares British freedom "an empty boast!" (Plumptre 3). Instead, she says, that Britons, "deep within [their] sea-encircled coast," are still

\footnotetext{
${ }^{81}$ For a detailed discussion of Napolean's effect on British Romanticism, see Bainbridge. For understanding of Plumptre's feelings toward Napolean and his influence on her later writing, particularly A Narrative of a Three Years' Residence in France (1810), see Cracium.
} 
subject to "one branch of tyranny." This tyrannical force "h[o]ld[s] o'er Learning's sons imperial sway, / From earliest times till e'en the present day" (Plumptre 3). Despite Britain's “wideextended bound" there is not a single "soul," or author, "who dar'd magnanimously spurn these chains, / And rearing Freedom's staff on Learning's plains, / Invite thy more enlighten'd vot'ries, Sense, / Resistance' task tremendous to commence" (Plumptre 3). Instead, beauty remains a tyrant:

No! still, in spite of ever-varying Chance, Has BEAUTY held o'er Novel and Romance, One undivided, unmolested rule, And was the Heroine, witty, wise, or fool; Still she was lovely, still in form and mien, The rival e'en of fair Idalia's Queen.

The hapless female, who irradiant eyes Ne'er struck beholder's heart with soft surprise; Who shew'd no symmetry of form, or face, Though richly stor'd with ev'ry mental grace; Nor in the Novel's or Romance's walk, Has dar'd presume as heroine to stalk, But far from wounding observation flown, To live retir'd, unnotic'd, and unknown. (Plumptre 3) Despite Britain's apparent development, the outlawing of "Slavery" and the nation's imperial expanse ("our Island's wide-extended bound"), one thing has not changed: literature still values beautiful heroines over all else. Even "female[s]" who possess "ev'ry mental grace" have no 
place in British literature. Instead, they go on to "live retir'd, unnotic'd, and unknown." Plumptre concludes the prologue by challenging readers further. She asks, "But shall our breasts, by love of freedom warm'd, / Still bow to laws by Despotism form'd?" (Plumptre 3). Wisely, Plumptre uses Britain's current political climate and questions about despotic rulers (particularly in France) to influence readers' perception of her own text, as she wants them to read her story about a heroine whose primary trait is not beauty, but also to point out the ways in which literature is underscoring and upholding beauty norms that particularly impact women's lives. Plumptre positions herself in conflict with such norms and declares, "No, we'll the RIGHTS OF AUTHORS here defend, / And in these pages place before your view / An UGLY heroine-Is't not SOMETHING NEW?” (Plumptre 4). Plumptre immediately politicizes Something New and her ugly heroine, Olivia Campbell. ${ }^{82}$

All of Something New follows the lead of the prologue by questioning conventional cultural assumptions about beauty and its value. ${ }^{83}$ Plumptre's novel initiates such questioning through several strategies. First, Something New uses the recognizable literary motif and story

\footnotetext{
${ }^{82}$ Despite Plumptre's labeling of her ugly heroine as "something new," other authors have featured ugly heroines in their narratives. See, for example, Sarah Scott's Millenium Hall (1762). ${ }^{83}$ The copyright page of the 1801 edition of Something New, printed by A. Strahan for T. N. Longmas and O. Rees, features a quote from the third act of Dryden's Cleomenes, a tragedy concerned with the personal effects of Revolution and centered on love, rejection, and (failed) rebellion. In Dryden in Revolutionary England, David Bywaters explains that "Cleomenes, however, was very nearly banned from the stage - its performance was twice prohibited because of its supposed Jacobitism - and perhaps in response to this episode Dryden abandoned his effort to conciliate the court. He did not, however, return unchanged to his attack on the Revolution. He grew even more emphatic in reminding us of his place in literary tradition and in elevating the literary above the political" (7). The copyright page quote highlights the "inconstant[cy]" of "man," preparing the reader for the "various"-nature that characters in Something New take on. The lines: "Perhaps the atoms rolling in his brain / Make him think honestly the present hour, / The next a swarm of base ungrateful thoughts / May mount aloft" foreshadow the change in thinking that Lionel will experience under Olivia's influence at Campbell-House (Dryden 3.1.1821).
} 
elements of "Beauty and the Beast," but Plumptre's version of "Beauty and the Beast" is based primarily on internal characteristics. Second, Plumptre's novel indirectly critiques Burke's alignment of beauty and femininity by featuring an ugly heroine and making that ugliness the central theme of the story. And finally, Campbell-House is a queer heterotopia that enables Olivia and the other characters who live and visit there to escape the despotism of the upper classes and establish their own culture and associated values. Campbell-House's stark juxtaposition with main stream British society makes visible the ways in which aligning beauty, femininity, and exteriority breed gender inequity.

$\underline{\text { A "Proverbially Plain" Beauty }}^{84}$

While Plumptre seeks to challenge literary conventions as they relate to genre and representations of women, as she outlines in the text's prologue, her use of "Beauty and the Beast" aligns with literary tradition. It is a timeless tale because authors constantly rewrite and retell it; the archetypal tale is "a vehicle for... social and political messages or the popular ideas of [an author's] time" (Swain 107). ${ }^{85}$ "Beauty and the Beast" and its archetypes offer Plumptre a

\footnotetext{
${ }^{84}$ Plumptre, 5

85 The first version of the published tale "The Beauty and the Beast" can be traced to the 1740 publication of "a French novel for young adults by Gabrielle-Suzanne Barbot de Villeneuve" (Swain 104). Villeneuve's story was quickly revised by others, including by Jeanna-Marie Leprince de Beaumont in 1756. Beaumont's version of the tale was "a concise didactic tale for children" which emphasized "Beauty's humility, patience, generosity, kindness, and hard work"; "moral commentary round[s] out the tale, as in the final statement that perfect happiness is "founded on virtue"' (Swain 105). Beaumont's version of the tale was then translated into English and disseminated throughout Europe; it was included in The Young Misses Magazine, Containing Dialogues between a Governess and Several Young Ladies of Quality, Her Scholars (1761). Beaumont's version is the story most individuals reference when they talk about "Beauty and the Beast." Plumptre, a Francophile through and through — so much so that she insisted people pronounce her name with the French accent rather than the English-would have been most familiar with Beaumont's version of the tale. "Beauty and the Beast" scholars argue that the first tale to follow the traditional "Beauty and the Beast" story is actually the story of "Cupid and Psyche." See Jerry Griswold's The Meanings of "Beauty and the Beast” (Broadview, 2004) and
} 
way into her tale about ugliness. ${ }^{86}$ Like the traditional "beast" in the "Beauty and the Beast,"

Olivia's external features are her determining characteristic and make her a cultural outsider.

Olivia, as a rich, upper-class woman, is marked by her "plain" features as an "Other" within

British culture, and as an ugly heroine, she is also an "Other" in British literature. Olivia's

otherness urges readers to consider how standards of female beauty align with social values and

"permits an investigation of our own reactions to otherness in all its various forms" (Griswold

24) ${ }^{88}$ Plumptre illustrates a common reaction to female ugliness as a form of Otherness prior to

Lionel's arrival at Campbell-House. While travelling to Campbell-House, Lionel stops at "the

Campbell Arms at Maxstead" to wait for Henry (Harry) Eagerton and Harry's valet Arthur

Williams so that they can arrive and meet Olivia together (Plumptre 10). While there, Arthur

Marina Warner's From the Beast to the Blonde: On Fairy Tales and Their Tellers (New York: Farrar, Straus, and Giroux, 1995).

${ }^{86}$ It also offers her an archetypal narrative structure that challenges normativity. As Swain explains, "In its original outlines, 'Beauty and the Beast' may have delighted audience with its image of a potentially open society in which middle-class daughters could marry aristocratic husbands who respected them and women could choose to enter into marriages more or less freely...the original 'Beauty and the Beast' reflects the eighteenth-century emphasis on individual rights and freedoms - and tentatively suggests that they might even be extended to women" (107).

${ }^{87}$ The figure of the beast varies; according to Marina Warner women tend to make the beast into a "creature traditionally classed as lower than mammals" - toads, fish, and lizards, for example - and the "beast" is also often a bear, snake, pig, monkey, lion, or bull (Warner 300, Griswold 16).

${ }^{88}$ Saxena also discusses Beauty's traditional Otherness: "By reinforcing the cultural codes of matrimony and gender, the tale suppresses the monstrous potential of the relationship between a woman and a beast. This potential is circumscribed by the notions of virtue and goodness: in being a girl, Beauty stands for an 'otherness' rendered unthreatening by her education and initiation into womanhood during the course of the story. Beauty, a father's girl right from the beginning in the versions of Beaumont, Lang, and others, agrees to marry the Beast to save her father. Eventually she falls in love with the Beast and finally accepts his transformation in an unselfconscious and serene manner" (Saxena 197). Saxena also points out that Otherness might ultimately be what connects Beauty and Beast: "The otherness of Beauty, the state of womanhood as it embodies deviance from the male ideal, links her closely to the Beast, the monstrous Other of the manly ideal" (195). 
shares that "the folks at the inn at Doncaster" told him that Olivia is "damned ugly." In response to Olivia's otherness, Arthur expresses "anxiety for [his] master's credit” being ruined by his marrying a woman who is "damned rich," but "damned ugly" (Plumptre 10-11). Arthur's anxiety captures the value of women's beauty on the marriage market and in general: to support a man's reputation. Furthermore, an ugly wife, an "object" indicative of a man's cultural "credit," devalues his worth. Like other "beasts," Olivia is externally monstrous and, because of this, she is a social outsider.

Olivia's ugliness, her "difference," is the central theme of Something New and is remarked upon by nearly every character, even those who hold her in the highest regard. Lionel's effort to "overcome" her "difference" drives the plot. Historically, "Beauty and the Beast" is a story about heterosexuality and the (supposed) allure of the other sex because the story is "about courtship, about differences overcome and the rise of love" (Griswold 17). It is, indeed, also a story about "difference"- - hence its popularity in the gay community; it often features characters "who do not conform to the "mainstream's sexual mores"” and their subsequent portrayal "as monsters" because of such difference (Griswold 17). ${ }^{89}$ The premise of Something New is, in fact, heterosexual marriage. An archetypal element of the tale is that "a parent" serves "as [the] initiator of the actio[n]" (McLeod xv). ${ }^{90}$ Lionel's father, Sir Francis, and Olivia's deceased

\footnotetext{
${ }^{89}$ See Michael Ford's Once Upon a Time: Erotic Fairy Tales for Women (New York: Masquerade Books, 1996) for more on the connection between fairy tales and the queer community.

${ }^{90}$ Plumptre also maintains the use of an "enchanted castle" (McLeod xv). Working in cahoots with Olivia, the servants of Campbell-House share the (false) story of the house's ghost with Arthur who shortly after "sees" the ghost and, terrified, reports the experience to Lionel (Plumptre 57). Lionel, determined to find an explanation, seeks permission from Olivia to investigate the "old wing which appeared uninhabited" (Plumptre 61). On the appointed night, as Lionel settles in to read "Young's Night Thoughts," he is disrupted and a sublime experience ensues. According to Burke, "whatever is fitted in any sort to excite the ideas of pain, and danger, that is to say, whatever is in any sort terrible, or is conversant about terrible objects, or
} 
father, General Campbell, both "initiated" and encouraged their children's marriage to one another. Olivia and Lionel's meeting is organized by Lord Stanhope (Lionel's father). It is his wish that Lionel meet and marry Olivia. Sir Francis wishes desperately for his son to marry so fine a woman as Olivia, but he also believes Lionel is "unworthy to possess such a treasure"; though Lionel is "a fine, handsome, spirited young fellow," he is full of "folly" (Plumptre 6). According to the ideology of Something New (and Sir Francis Stanhope) that "folly" is Lionel's internalization of hegemonic cultural expectations about women's worth based on their beauty. Lionel writes to Harry when he finally succumbs to his father's wishes, "Lift your hands and eyes in astonishment, if you please, my good cousin [Harry], yet 'tis even so. I have this very moment solemnly pledged myself to Sir Francis to pay my respects to my long-destined wife, Olivia Campbell" (Plumptre 5). Of course, Lionel has no desire to marry Olivia; he only visits Campbell-House and meets Olivia to silence his father's "importunity" (Plumptre 5).

In addition to using "Beauty and the Beast" archetypes to illustrate typical responses to otherness and difference, Plumptre's reinvention of "Beauty and the Beast" emphasizes the value of interiority. Typically, "Beauty and the Beast" features a "Beast" who is as inwardly monstrous

operates in a manner analogous to terror, is a source of the sublime; that is, it is productive of the strongest emotion which the mind is capable of feeing... at certain distances and with certain modifications, they... are delightful" (1757, 13-4). Lionel's investigation of the seeminglyabandoned portion of Campbell-House "excite[s his] ideas of pain, and danger." After being "satisfied that [he] was safe from the intrusion of flesh and blood and not apprehensive of other visitors," Lionel "hear[s] a violent crash" and then encountered "standing directly before [him], a figure in a long white garment, in whose features [he] instantly recognized, oh God! the perfect resemblance of [his] father" (Plumptre 64-5). The ghost, in "a voice...deep, solemn, and emphatic," said 'IMPOSTER, TREMBLE!!!"” (Plumptre 65). Lionel notes that his "feelings are not to be described"; his reaction to "a sight so awful, so unexpected...petrified [him] with horror" (Plumptre 65). Once he learns that the scene was manufactured by Olivia, the servants, and his father he marvels at Olivia's ability to "conduct [her]self so well...under circumstances equally embarrassing" (Plumptre 83). Olivia welcomed Sir Francis into her home so that he could “expose” Harry and Lionel's "treachery and villainy" (Plumptre 80). 
as his physicality indicates. "Beauty," on the other hand, possesses both physical attractiveness and virtue. In Griswold's comprehensive account of the various ways in which the "Beauty and the Beast" narrative is adapted by authors, he chronicles what he calls "cross-gender versions of 'Beauty and the Beast" wherein "the female is beastly or unattractive because of issues of class; then, instead of the female rescuing the male..., the male rescues the female by 'raising her up' to social acceptability" (21) ${ }^{91}$ Deborah McLeod, the editor of Broadview's version of Something New, subscribes to Griswold's "cross-gender version" in her critical introduction to Something New. McLeod figures Olivia as the traditionally masculine hero of the "Beauty and the Beast" narrative while Lionel Stanhope is "a stereotypically feminine heroine: he "blushes like a "fair maiden" and feels "silly and abashed"”, (McLeod xviii). Like my reading, McLeod's interpretation of Lionel and Olivia's roles are rooted in interiority. Lionel's "blushing" is a signifier of his internal feelings of being "silly and abashed." However, McLeod's reading of Olivia and Lionel maintains traditional gender roles by "reversing" them so that the story has a masculine woman and a feminine man; gender roles remain coherent if not heteronormative. Certainly readers can understand Olivia as "Beast" since she is "proverbially plain" and "damned ugly" (Plumptre 5, 10). Usually in "Beauty and the Beast"-type tales, "the representation of the Beast...is one in which the outward appearance of a monster conflicts with his inner nature," but because Something New's value system is based on the heroine's "mental graces" it is Olivia's "inner nature" that makes her Beauty, not Beast (Crew 75, Plumptre 3). I posit a new reading of Olivia and Lionel in relation to "Beauty and the Beast" archetypes; they do not "reverse" their genders in relation to their sexes. Rather, using the value system established in the Prologue to

${ }^{91}$ This variation on the tale does not fit Plumptre's adaptation; in fact, Olivia is far from needing "raise[d]... up"--she is the owner of Campbell-House. She is, however, easily read as "the beast" because she is "unattractive." 
Something New and following the tradition of the "Beauty of the Beast" tale "to emphasize the unreliability of outward appearances," they ought to be read against the traditional Beauty and Beast roles based on their interior life, rather than external appearance (Warner 299). ${ }^{92}$

Therefore, Olivia is Beauty and Lionel is Beast.

Lionel, though he is traditionally beautiful, is "monstrous" in his treatment of Olivia. Like many of the "Beasts" in other iterations of the tale, Lionel learns to be a new man through Olivia. Plumptre's choice of name, "Lionel," is no accident. The etymology of his name links him to one of the most common beasts in "Beauty and the Beast" stories: a lion. While Lionel is physically attractive and wealthy, he is morally bankrupt without Olivia's influence. After finally agreeing with his father that he will travel to Campbell-House to meet Olivia Campbell, he immediately proposes a plan to Harry: “An idea suddenly strikes me! — You, Harry, are in want of a fortune-I want to get rid of one. Why then should we not accommodate each other, and by making this visit together, under an exchange of names and characters, accomplish our reciprocal aims" (Plumptre 6). Lionel wishes "to get rid of one" fortune-Olivia's. Lionel's inclination toward deceit and self-interest is evident from the start of the tale. Harry agrees to Lionel's plan: "Be your plan then pursued! - it was surely the inspiration of heaven itself!" and the two arrive at Campbell-House pretending to be the other (Plumptre 8). When Olivia first greets Lionel and Harry, she assumes Lionel to be Lionel because his "strong resemblance...to the worthy Sir Francis, speaks [him] at once his son" (Plumptre 18). Harry clarifies that it is he who is Sir

\footnotetext{
92 My reading of the "Beauty and the Beast" trope in Something New aligns with Vandana Saxena's understanding of how Beauty and Beast are positioned against and in context with one another. In her essay "Beauty and the Beast: Reclaiming the Monsters" she writes: "Rather than serving as binaries, Beauty and the Beast emerge as two sides of the same coin. Embodying femininity and monstrosity, Beauty and the Beast stand as two signifiers that simultaneously support and contest the structure of Western patriarchy and its celebration of the masculine ideal" (Saxena 196).
} 
Francis's son and goes on to pay Olivia compliments in a way that she reads as boastful and empty, referring to her as "a lady so highly and so justly celebrated" (Plumptre 18). Lionel, like Beast "in the literary fairy tale of the ancient regime," is not able to "meet Beauty [Olivia] as a social and intellectual equal"' (Warner 299). Olivia's ability to see through Lionel and Harry's deception is foreshadowed in this scene when she declares: "Can this really be the son of Sir Francis Stanhope? What a contrast are his manners to those of his father! If the latter may sometimes appear to want a higher degree of polish, yet how far preferable is his blunt unvarnished honesty, to this florid fulsome strain of compliment"” (Plumptre 18). Olivia evaluates "Sir Frances Stanhope" on his interior qualities as well as his exterior qualities. Because "his manners" contrast so greatly with "those of his father," she is immediately able to identify Harry as an imposter. She allows Lionel and Harry's ruse to continue for nearly a fortnight. According to upper-class assumptions about a woman's ugliness, Olivia’s “outward appearance" conflicts with the kindness that she directs toward these men who continue their attempts to deceive her. She offers Lionel multiple opportunities to confess his deceit, and each time he fails to do so, displaying his Beast-like nature. Simultaneously, Olivia's patience and attempts to allow Lionel and Harry to confess their true identities demonstrate her "Beauty"-like traits. Olivia's benevolence is best demonstrated in her ability to forgive Harry and Lionel for their deceit after all is finally revealed. Olivia is the Beauty archetype because she possesses what every Beauty has: a reliable moral compass.

Lionel's transformation is essential to the shift in values that he experiences as his stay at Campbell-House continues — a shift that enables him to "resee" Olivia and revalue her based on her upstanding ethics rather than her facial features. Many versions of "'Beauty and the Beast' [emphasize] the animal qualities of the groom and his ultimate transformation from a monster 
into a human being" (Swain 106). Like other "Beasts," Lionel is transformed by "Beauty." Plumptre dispenses with the traditional gendering of the "Beauty" and "Beast" characters and leads the reader to question who is monstrous and who is beautiful by challenging the notion that feminine beauty is an indicator of morality. As Plumptre points out in the prologue to Something New, in most courtship stories (including "Beauty and the Beast") feminine beauty functions as a signifier for virtue and upstanding morals; those without beauty lack virtue. Something New insists on an alternative value system by highlighting Olivia's value as a moral and ethical role model, despite her external ugliness (Plumptre 10). Olivia fulfills the role of "Beauty" because of qualities that are interior rather than exterior. Olivia, while "damned ugly," is Beauty-like in her morality and serves as an ethical role model for other characters, as well as readers. Evaluating Beauty: "Both sexes are capable of beauty, but the female of the greatest" 93

While Olivia is "Beauty" in relation to "Beauty and the Beast" archetypes, she is not "the beautiful.” One of the primary ways that beauty was understood while Plumptre was writing Something New was through Burke's Enquiry. Burke argues that beauty is the elicitor of love and that women are the most beautiful of the sexes. ${ }^{94}$ According to Burke's philosophy then, Olivia's life is predetermined: she can't be loved because she is not beautiful. Plumptre's novel expands critique of the social order by interrogating the ways in which aesthetics, particularly female beauty, limit women's roles and potential futures.

\footnotetext{
${ }^{93}$ Burke 1757, 80

${ }^{94}$ Most Englishmen were familiar with Burke's A Philosophical Enquiry Into the Origin of Our Ideas of the Sublime and Beautiful (1757) and his ideas were influential. More than ten editions were published by R. and J. Dodsley alone between the years 1757 and 1793. Boe explains that "when T. Cogan wrote the introduction to his English translation of The Works of the Late Professor Camper (1794), he...omitted "Essays on the Principles of Beauty" because "this essay would have conveyed the same information to the English reader...as Mr. Burke; with which we may suppose every Englishman of taste to be familiar"” (Boe 351).
} 
Olivia's characterization challenges Burke's claim that beauty is a signifier of taste. According to Burke, taste is universal and "that bodies present similar images to the whole of the species, it must necessarily be allowed, that the pleasures and the pains which every object excited in one man, it must raise in all mankind, while it operates naturally, simply, and by its proper powers only" $(1770,8)$. Whether objects are beautiful (or sublime), then, is a shared cultural experience. Burke's theorization of the senses assumes a particular type of normativity that erases and marginalizes those who perceive the world and the objects in it otherwise, as well as those who do not sense them at all. For Burke, identifying the beautiful must be based on established social standards, otherwise chaos will ensue because societal structure and hierarchy will collapse. Burke claimed that "man, who is a creature adapted to a greater variety and intricacy of relation, connects with the general passion, the idea of some social qualities, which direct and heighten the appetite which he has in common with all other animals" (Burke 1757, 18). Contrastingly, Beauchamp, one of Olivia's closest friends, believes that "Tastes are various; nor can any thing be more absurd than for one person to pretend to judge for another in these matters" (Plumptre 21). For Beauchamp, taste is individual, not societal. Burke's insistence that taste is societal has potentially dangerous implications for individuals whose tastes do not align with mainstream notions of what is, for example, beautiful. Burke places "man," and his tastes and "passion[s]," within a "social" context. He goes on:

[A]nd as he is not designed like them to live at large, it is fit that he should have something to create a preference, and fix his choice; and this in general should be some sensible quality; as no other can so quickly, so powerfully; or so surely produce its effect. The object therefore of this mixed passion which we call love, is the beauty of the sex. Men are carried to the sex in general, as it is the sex, and by the common law of nature; 
but they are attached to particulars by personal beauty. I call beauty a social quality; for where women and men, and not only they, but when other animals give us a sense of joy and pleasure in beholding them, (and there are many that do so) they inspire us with sentiments of tenderness and affection towards their persons; we like to have them near us, and we enter willingly into a kind of relation with them, unless we should have strong reasons to the contrary. (Burke 1757, 18-19)

Not only does Burke establish beauty as a quality determined by social norms and cultural reinforcement, he also inherently connects beauty, something material, with love. In order for a man to love a woman, he must be "inspire[d]... with sentiments of tenderness and affection towards [her] person" (emphasis mine). It is not a woman's character (or even her wealth) that inspires a man to love her, but her beauty; the "sense of joy and pleasure" that he gains in "beholding [her]" is necessary to "make the social order possible" (Boe 349). ${ }^{95}$ Prior to their arrival at Campbell-House, Lionel advises Harry (pretending to be Lionel) to "weigh the matter well" because if he pursues Olivia, "the pursuit of beauty must be relinquished forever" (Plumptre 9). Harry's attraction is to Olivia's wealth, an option that Burke fails to consider, and he plans, as Arthur puts it, "to make love to the fortune" (Plumptre 46). As a result, Harry is not concerned with Olivia's beauty, let alone loving her. Before even meeting her, he remarks:

Now, half my future bride's fortune is mortgaged for the payment of my debtsin idea at least, which is to me the same thing as though it were done in realityhave her I must, therefore, by some means or other. And believe me, I intend to

\footnotetext{
${ }^{95}$ Mary Wollstonecraft's A Vindication of the Rights of Men (1790) and A Vindication of the Rights of Woman (1792) "pointed out the antisocial consequences of the fetishizing of women's beauty;" Wollstonecraft's "critiques... advanced" her "visions of women's place in society," and highlights the ways in which "aesthetics were central to [her] critiques of the social order" (Ana de Freitas Boe 348).
} 
make her a most excellent husband. She shall have one thousand pounds a year entirely at her own disposal; and with that I shall leave her to follow her own inventions, while I, with the rest of her fortune, follow mine. (Plumptre 14) Olivia is a means to an end for Harry. His goal is to be "a most excellent husband," but only so that he can possess her fortune and then "follow" his "own inventions." Harry's treatment of Olivia as a means to his own personal ends is a small example of larger societal trend wherein women are, in general, a means to an end.

Women are primarily objects for looking at because female beauty is necessary for the social order. Female beauty elicits "passion" among men and inspires them to develop "a kind of relationship with" women. Beauty is the impetus for love, the organizer of the social order, particularly of marriage. Burke creates a standard of beauty constructed entirely upon a male gaze objectifying the female body (Burke 78). ${ }^{96}$ Though Burke begins his discussion of proportion and bodies by saying that such traits can be found "in many subjects," some "very beautiful" and "other[s] very remote from beauty," rebuking the notion that beauty is based on proportion, he nonetheless spends time sharing methodologies for measuring the beauty of bodies, encouraging readers to be aware of pseudo-scientific ways they might look at and evaluate (women's) bodies (Burke 1757, 79):

The neck, say they, in beautiful bodies should measure with the calf of the leg; it should likewise be twice the circumference of the wrist. And an infinity of observations of this kind to be found in the writing, and conversation of many....others take other methods of estimating the proportions, and all with equal success. But are these proportions exactly the same in all handsome men? or are

${ }^{96}$ See the section titled "Proportion not the cause of BEAUTY in the human species" (78). 
they at all the proportions in beautiful women? nobody will say that they are; yet both sexes are capable of beauty, but the female of the greatest, which I believe will hardly be attributed to the superior exactness of proportion in the fair sex. (Burke 1757, 79-80)

Burke's attention to body parts known in particular for their "feminine allure," including "the neck," "the calf," and "the wrist," indicate that despite his wondering aloud about whether these measurements are meant as evaluators for "handsome men" or "beautiful women," it was clear to the reader (and to Burke himself), that the proportions are meant solely in relation to women's bodies. In the eighteenth-century, women's bodies are, after all, the primary bodies at which one is meant to look and judge. The passage quoted above also reflects "the eighteenth century['s]...progressive shift away from defining beauty according to the male figure and its proportions towards associating beauty with the female, eventually reserving sublimity or more active qualities for the male" (Bindman 54). Burke's declaration that "the female" is "capable... of the greatest beauty" placed women as "the paragons of a socially productive beauty" that "fetishiz[ed]...their loveliness," without "advanc[ing] society" by keeping female bodies passive objects for male consumption (Boe 349). Lionel and Henry Egerton are exemplary practitioners of Burkean beauty philosophy. In part, this is because of their upperclass background and acquiescence to London's culture and social standards.

Contrary to literary tradition, Something New's protagonist is sublime, rather than beautiful. According to Burke, "the passion caused by the great and sublime" is "astonishment," and "astonishment is that state of the soul, in which all its motions are suspended, with some degree of horror" $(1757,41-2)$. The "inferior effects" of the sublime include "admiration, 
reverence and respect" $(1757,42)$. In Lionel's September 12 letter to Orlando St. John detailing Olivia's refusal following his proposal he writes:

I grow more and more enchanted with Olivia's manners and conversation...'Tis not mere esteem or respect...; it is in short a feeling only to be experience in contemplating a heart like hers. Can there be on earth a spectacle more sublime than a person with powers so extensive, employing them to the noblest purposes. (Plumptre 146)

Like the sublime objects that Burke describes, Olivia inspires "admiration, reverence and respect" in Lionel. Unlike beautiful objects that elicit emotion due to exterior qualities, Olivia inspires a sublime experience for Lionel because of internal qualities: "her heart" and "powers...employ[ed]...to the noblest purposes.

Looking Queerly: Sublimity and Heterotopia

Plumptre's characterization of Olivia and Lionel destabilizes reader's assumptions about gender expression and social use of gender to structure norms and beliefs. Lionel arrives at Campbell-House as a rather typical upper-class, $18^{\text {th }}$-century man. One indication of this is that he considers himself "a devoted slave to beauty" (Plumptre 5). He insists that "the woman who could fix [his] roving affections must be lovely as an angel" (Plumptre 5). Should Lionel ever marry, it will be because of a woman's beauty, a most Burkean position on beauty and its value. However, Lionel's stay at Campbell-House and his relationship with Olivia initiate a shift in him, and the value that he maps onto beauty decreases. Rather than valuing external beauty as an elicitor of love, as he did when he first arrived at Campbell-House, he learns to value interiority through observing and imitating Olivia, developing his own queer gaze through this process. 
Olivia sees the world differently through what I call a queer gaze. The queer gaze challenges heteronormative values and undermines cultural institutions that are based on those values. As Laura Mulvey argues, "Freud... associated scopophilia with taking other people as objects, subjecting them to a controlling and curious gaze" (8). She goes on to argue that visual pleasure, particularly the mode of looking in film, is indicative of patriarchal power structures and further oppresses women (in particular). Following Mulvey, critics have utilized her notion of the gaze to theorize other ways of looking that result in, as Mulvey claimed, pleasure and narcissism. ${ }^{97}$ Like these theorists, I take up Mulvey's notion of the gaze, and I do so to argue for a counter-cultural way of looking. Unlike Mulvey's gaze or Ann Kaplan's “imperial gaze,” the queer gaze challenges notions of beauty, taste, and acceptability. This way of looking resists narratives of correction and insists on instability and alteration as an acceptable, even desirable, way of existing. Olivia's queerness is a disruptive tool that interrogates the gender binaries of Romantic England and "names a non-identity-based critical cultural and political practice that seeks to resist...claims of collective identities" (Freccero 15). Olivia's queer gaze has particular aims; it works to challenge class divisions, gender roles, and aesthetic norms by shifting focus to interiority rather than exteriority. The queer gaze is a critical strategy for making looking material. It links an immaterial concept, in this case aesthetics, and the viewer's perception of an object — her/his mental image — with the object of the viewer's gaze. Olivia's queer gaze, then modeled by other characters, privileges interiority. Adopting a queer gaze has significant effects,

\footnotetext{
${ }^{97}$ Mulvey's essay is demonstrative of typical 1970s "white feminism" in that it fails to consider that the mode of looking and pleasure that she describes is based entirely on white, heterosexual, middle-class experience and identity. What other critics have done to make Mulvey's theory intersectional shapes my understanding of "the gaze" in ways that are now intuitive. See, for example, Teresa de Lauretis's Alice Doesn't: Feminism, Semiotics, Cinema (Bloomington: Indiana UP, 1984), which considers what happens when women do the looking.
} 
even if temporary. For example, it alters the perception of characters like Lionel who were previously invested in beauty as a signifier of value. Since Lionel is the primary letter-writer in Something New it is most often his voice that guides readers' understanding of Olivia and the events at Campbell-House, thus when I trace the shift in his gaze, I do so using his first-hand account. As Lionel adopts Olivia's queer gaze, he experiences her as a sublime object and his emotional attachment to her follows. He believes he is in love with her and pursues the ritualized traditions associated with love, namely marriage. Olivia's queer gaze is narrated primarily by Lionel Stanhope.

In Lionel's October 12 letter to Henry Egerton, Lionel explains the latest happenings at Campbell-House. He provides a detailed account of his exchange with Beauchamp. Lionel's letter reveals that not only has he adopted Olivia's queer gaze, but others at Campbell-House have as well. When Lionel expresses fear that most "persons" would have "sense enough to think that Miss Campbell's heart would...be much more valuable if associated with a lovely face," Beauchamp replies:

'Such persons are surely very unreasonable.'

'Are not the majority of mankind unreasonable?'

'Some surely might be found who think otherwise.'

'We are said commonly to judge of others by ourselves; may I suppose that the case now?'

'Assuredly! —Mr. Ryder, not long after I came hither, from a sudden impulse of admiration at hearing some particular instance of her benevolence, I exclaimed that I did not think the brightest eyes, or the loveliest form, could add one ray of luster to such a soul as hers; and with my hand here solemnly laid upon my heart I 
can declare, that every hour I have since passed under her roof, has more and more strongly confirmed me in this opinion.' (Plumptre 195)

Like Beauchamp, Lionel has learned from Olivia to take up her queer gaze and revalues women's bodies. He no longer thinks that "the brightest eyes, or the loveliest form" are the most valuable qualities a woman can possess. In an earlier letter dated September 12, Lionel warns St. John of the dangers that Olivia must be aware of as she considers a husband:

No, St. John, she must beware a man of the world, one who is anxious that public admiration should sanction his taste in the wedded partner of his heart. Her husband's breast must be guarded by a thick coat of mail, impenetrable to the senseless sarcasms a face like hers will unavoidably excite in the gay world, or all her virtues and accomplishments could not ensure him from many painful moments of disgust and repentance. She must be all to her husband, public opinion, nothing, or woe to them both" (Plumptre 147).

Lionel thinks himself the sort of man who can "guard" his "breast" from the "senseless sarcasms a face like her hers will...excite." Because he has accepted the value system at work at Campbell-House he has forgotten, or thinks himself rid of, the societal pressures of London and other upper-class spaces.

Campbell-House and those that reside in it manifest Olivia's gaze. It is what Foucault calls a "heterotopia" (3). According to Foucault, a heterotopia is a "real place" that "represent[s], contest[s], and invert[s]" mainstream culture (3). They are "places...outside of all places...because [they] are absolutely different from all the sites that they reflect and speak about" (Foucault 4). Campbell-House is a heterotopia because it "represent[s], contest[s], and invert[s]" the value systems at work in upper-class London, for example, a "site" that captures 
most of the mainstream values circulating in Britain. ${ }^{98}$ The people of Campbell-House, and their behaviors, make it a heterotopia "of deviation: those in which individuals whose behavior is deviant in relation to the required mean or norm" exist (Foucault 5). Olivia fills Campbell-House with individuals who would otherwise be judged and discarded by society, with objects that would not be deemed "tasteful" by the upper-class, and she does so despite her immense wealth and understanding of "good taste and behavior."

Olivia's disregard for the fixity of cultural value systems, her errancy, leads her to do away with archaic gender and class divisions that are meant only to uphold upper-class ideology. She treats her servants with respect, often seemingly regarding them as her equals (though their status as servants indicates otherwise). She views her wealth as a tool for helping those less fortunate than herself, and she advocates on behalf of numerous women and children throughout the course of Something New. ${ }^{99}$ Additionally, she is quick to satirize stereotypical ideas of femininity. She is aware of the standards regarding female interaction with a man she hopes to marry, but pokes fun at the expectations by over-performing the expected role. In part this is because she is trying to make Harry, who is pretending to be Lionel, uncomfortable. She is aware that she is his mark and through her own wit and understanding of what "Lionel" expects from a woman with as much wealth as her, leads him into a dialogue that highlights the ridiculousness of the courtship process. After "Lionel" tells Olivia that she is "worthy" of "be[ing] mentioned

\footnotetext{
${ }^{98}$ For more on how sites have changed throughout history see Foucault 1-3.

99 Though little is known about Plumptre's life, one thing that is certain is her alignment with radical politics. Henry Crabb Robinson labels her an "old [Jacobin]" and highlights her radicalism through an anecdote of their first meeting in 1810: "I met [her] at a dinner-party at Gamaliel Lloyd's. She said, "People are talking about an invasion-I am not afraid of an invasion; I believe the country would be all the happier if Buonaparte were to effect a landing and overturn the government. He would destroy the Church and the aristocracy, and his government would be better than the one we have" (Robinson 191). Like Plumptre, who disregards the typical English position, Olivia is also quick to make fun of the status quo.
} 
with a Bradamant, or a Marphisa, and Erminia, or a Clorinda," all heroines of romance, Olivia replies:

'I feel but too sensibly how little I merit such a compliment. Supinely educated but to those frivolous occupations, which, have alone of late years been allowed to my sex, the thimble and the needle are the only weapons I have ever been permitted to brandish. My unaspiring fingers know not to gird on the polished sword, or adjust the plumed helmet; my nerveless arm is unaccustomed to poising the might spear, or hurling the well-aimed javelin. My trembling foot shrinks from the manly spur and well-suspended stirrup; and if I dare to mount the mettled courser, I vault not, alas! with vigorous stride into rich caparisons that valour claims, to traverse shapeless mountains and trackless deserts, regardless of the howling tempest's fierce assail, encountering beasts, and still more savage monsters in the human form - but tamely seat myself in the tame side-saddle, canter my steed for an hour or two over the smooth-shorn lawn, or along the even gravel-road, and then return home dull and indolent as I went out, again to betake myself to my paltry feminine employments. Thus must I crawl through life, at the end of which I shall not have performed one exploit worthy to hand down my name to far-removed posterity.' (Plumptre 37-8)

Olivia knowingly speaks in this most absurd manner to demonstrate to "Lionel" her upper-classness and worthiness of his pursuit. In the heterotopic-space of Campbell-House, she utilizes the language of upper-class society to mock it. In part, her performance is successful only because she is mocking him and he fails to be properly upper-class in the first place- he is after all a poor man who is pretending to be someone else so that he can eventually run off with her wealth. 
Lionel, on the other hand, is astonished. Olivia's remarks lead Lionel to note that he was "scarcely [able to] refrain from laughing at a rhapsody so nonsensical," yet refrained because Olivia "wore an air of such perfect seriousness, and seemed so absolutely entranced by her subject" (Plumptre 38). Olivia's ridiculous performance continues as she goes about listening to declarations from "Lionel" as absurd as her own.

Olivia welcomes individuals who are outsiders in British mainstream-culture into Campbell-House. For example, Beauchamp is an upper-class man who fails to see the value in wealth; he is regularly made fun of by Mrs. Stapleton, a devotee to upper-class mores. Within Campbell-House, it is Mrs. Stapleton who is seen as out-of-step and archaic rather than Beauchamp. Lucy is another example of Campbell-House's enchanting character; after she was seduced and ruined by her lying, villainous lover, Olivia saves her and her mother, Mrs. Morgan, from the workhouse. Oliva employs Lucy as a teacher in the school house at Campbell-Housea role that sets her up as a mentor and role-model to children in the community, a role that would be entirely unsuitable for a woman with her reputation outside of Campbell-House. Understanding Campbell-House as heterotopia aligns with Plumptre's goals for the text in purposefully making Olivia an ugly heroine. Both of these narrative features apply pressure to mainstream English values and put forth an alternate narrative of what English society might look like if adherence to gendered norms was less strict.

Olivia's gendered errancy is central to her ability to thrive, despite her external ugliness, in a world where beauty is a defining feminine trait, and Campbell-House is full of characters who follow Olivia's queer lead. Beauchamp, who is described by the hostess at the inn in Dorchester as "sort of squire like," is "independent" (Plumptre 12, 54). Unlike the upper class individuals like Mrs. Harrison and Stapleton who randomly pop in and out of Campbell-House, 
Beauchamp does not prefer the attendance of servants. When Mrs. Harrison arranges for an outing to the Cotton Mills at Gresley, she suggests that "Mr. Beauchamp shall take Mr. Egerton in his wiskey, and Mr. Stanhope shall drive me in Miss Campbell's phaeton"” (Plumptre 53). Beauchamp, however, doesn't see any reason to use the wiskey, as it will occasion the attendance of a servant; Beauchamp suggests that "the two gentlemen...accompany Mrs. Harrison in the phaeton" and he will "mount [his] horse" (Plumptre 53). Beauchamp, like Olivia, is unconcerned with demonstrating his access to wealth through the use of servants and material goods, like the phaeton and wiskey.

By establishing a heterotopia, Olivia undermines the regime of truth regarding class, aesthetics, and femininity. Olivia prioritizes interiority over exteriority; a person's character is more important than his/her wealth or beauty. Olivia's errancy is most often displayed when she speaks with other characters from the upper class. During a heated discussion with Mrs. Stapleton, Olivia says: "II always regulate my conduct by what I think is right to be done, not by considering what others would be likely to do"' (Plumptre 97). This is certainly Olivia's maxim throughout her life at Campbell-House. While visiting Olivia at Campbell-House, the "lecturing" Mrs. Stapleton confronts Olivia about what Stapleton believes is poor behavior for a woman (Plumptre 97). In Stapleton's estimation, Olivia has behaved in a way "very improper in a young woman who has any regard for her character" because Olivia did not immediately "kick [Lionel and Harry] out of doors" once discovering their imposture (Plumptre 97). Olivia, though, is only concerned with what she "think[s] is right to be done" and has little regard for "what others would be likely to do." Olivia replies that "kicking them out of doors" would be "unbecoming" to her "sex and situation" and informs Stapleton that "the gentlemen to whom [she] allude[s], are with [her] still, and [she] hope[s] will continue [at Campbell-House] some time longer" 
(Plumptre 97). According to Stapleton and upper-class rules of decorum, Olivia's behavior is improper for a woman of her standing because she betrays the "laws of hospitality and humanity” by treating “cheats” as guests in her home (Plumptre 97). In Lucy’s case, Mrs. Stapleton reports that she must "tell a thousand lies on [Olivia's] behalf, and protest that [Olivia] did not know what sort of a woman Lucy Morgan was when she came into the parish" (Plumptre 98).

Lucy and her mother, Mrs. Morgan, "are the widow and daughter of a poor curate in Wales" (Plumptre 32). They found their way to Campbell-House through a rather tragic chain of events; Beauchamp shares these events with Lionel after they assist the Morgan women by removing Owen, the source of Lucy's destruction, from their small home. Owen "holds it as a principle article of his creed, that women were created only as toys for the men to sport with, and cast from them at pleasure" (Plumptre 32). He made promises of marriage to Lucy, which she believed, and "he never intended to fulfill" (Plumptre 32). They remained together for almost a year and a half, Owen continually delaying their marriage, and eventually Lucy returned to her parents' home, but it was too late. "Lucy's disgrace” deeply hurt her father and while her return home "was a balsam that soothed," it was too late and he died with the knowledge that his daughter was home, but "his unhappy daughter was delivered of a still-born son" (Plumptre 32). Lucy's father may have been able to forgive her mistakes, but "it could not be forgiven by the world. Lucy, recovered from her confinement, first to get into service, but her virtuous neighbours $[$ sic] unanimously agreed that it would be an impeachment of their own characters to admit such a woman into their houses" (Plumptre 32). ${ }^{100}$ All of her efforts to find work and earn

${ }^{100}$ Beauchamp has adopted the queerness of Campbell-House. In his articulation of Mrs. Morgan and Lucy's experience he repeatedly demonstrates a sort of disgust toward the individuals who turned Lucy away. When he explains that even Lucy's family refused her, he says, "but among 
money were met with refusal. When Olivia learned of their story, "she instantly sent for both" of them "and has proved a ministering angel of comfort to them. She established them in the cottage" and after being certain that Lucy's mistake was an outlier, "she made them mistresses of a little school, to which they have paid the most unremitted attention; and the children have improved rapidly under their hands" (Plumptre 33). Because Lucy had a rather scandalous past, Mrs. Stapleton believes that Olivia has concealed from " "the world...the nature of [Lucy's] misfortune" to protect her own "credit," rather than Lucy's (Plumptre 98). Olivia, however is quick to respond that she "“is not ashamed of having rescued a penitent from too severe contumely, and restored a valuable member to society"”; she continues: "I would by no means wish for my own sake that the nature of her misfortunate should be concealed. Delicacy to her alone, would prompt such a wish"” (Plumptre 98). Olivia, again, is not concerned with exteriority, with how things appear on the surface; rather than taking the position of most upperclass women on a woman such as Lucy, public opinion is of no concern to Olivia; instead, she is focused on Lucy's future and her positive contributions to the environment and community at Campbell-House.

Mrs. Stapleton, not yet satisfied with how little Olivia cares about public perception, goes on to attack and critique Olivia's behavior with Ryder: "'Every body says you are going to be married to him, yet you shew no indignation at the report, and encourage him still to come to your house. 'Tis in vain therefore for me to say that I think I know Miss Campbell too well, to fear her degrading herself so far as to marry a little shop-keeper's son; while he's still suffered to

them also she found too nice a sense of virtue, to concern themselves about one whom they regarded as a disgrace to her family" (Plumptre 33). Though not explicitly stated by Beauchamp, he has a sense of disgust toward individuals who claim virtue, but meanwhile allow a young woman and her mother to starve. 
come after you in this way, how can people disbelieve the report"' (Plumptre 98). Again, Olivia is unconcerned with "'the report"”: "As Mr. Ryder is a man of the highest worth and talents, I should certainly not think an alliance with him degrading to me, therefore the idea really does not excite indignation in me, and the reports to which you allude, believe me, will not in the smallest degree either accelerate or prevent the match"” (Plumptre 98). Many women would be concerned with the public's opinion, concerned that her romantic affections are being paid to a man below her social class and therefore hurting her own social standing; Olivia says that she would "be very sorry to deprive them of such a source of pleasure" if they "find any gratification in believing" the reports of her affection for Ryder. She is not concerned with maintaining her class performance through romantic affiliations, real or imagined.

Campbell-House and Olivia's mode of seeing the world make visible alternative value associations. Olivia's queer gaze leads Lionel to reconsider how femininity relates to exteriority and beauty and through my reading of Olivia and Lionel's gazing, I identify a unique function of the sublime. By aligning femininity with the sublime, with the soul-moving experiences that are the realm of men and poetry, the sublime destabilizes beauty as a signifier of feminine value and insists on the multiplicity of taste. By revaluing the sublime in this way, readers and other characters, like Olivia, take up a "queer gaze" and alter the normative way of "seeing" in Something New.

Because Olivia has largely deconstructed the coherence of gender by demonstrating its emptiness, her behaviors and management of Campbell-House demonstrates that gender roles are errant, class-based divisions are unstable, and interiority can take precedence over exteriority. Like the heterotopias that Foucault describes, this is an inversion and destabilization of the widely held cultural views and behaviors that shape normative culture. The ideology circulating 
at Campbell-House demonstrates Olivia's belief that the rest of the world is erring by insisting on a singular "normal."

Olivia's queer gaze, and Lionel's transformation at Campbell-House into a queer-seer, enables both of them to see subjects as always-transforming rather than static. They resist seeing spaces and people as singular and stable. As a result, Lionel's and Olivia's narration of objects and subjects throughout Something New (1801) make errancy visible in the text. This errancy is a resistance to Burke's philosophy. Burke's response to criticism of Enquiry, because of his alignment of women with "beauty" and his insistence on consolidating normativity, was "On Taste" and he argues for the necessity of a standard of evaluation: "For if Taste has no fixed principles, if the imagination is not affected according to some invariable and certain laws, our labour is like to be employed to very little purpose" $(1793,3)$. In order for Burke's Enquiry to have any purpose, his readers must invest in the necessity of a shared and established societal taste. He insists that "if we suffer ourselves to imagine, that their senses present to different men different images of things, this sceptical proceeding will make every sort of reasoning on every subject vain and frivolous, even that sceptical reasoning itself, which had persuaded us to entertain a doubt concerning the agreement of our perceptions" $(1793,7)$. According to Burke's rationale, anyone who perceives beauty where others do not, who identifies darkness where others identify light, or who do not agree "to call vinegary sour, honey sweet, and alloes bitter" is mistaken - is committing an error of taste $(1798,8)$. Burke's methodology for categorizing and experiencing the world is one based on notions of erring; an individual either properly perceives the world and is in line with the status quo, or mistakenly perceives the world otherwise and is in need of correction. For Burke, the world is based on “either/or.” Olivia, like Burke's critics, refuses to succumb to such a worldview and insists on "both/and" ways of looking and 
understanding. This is evidenced by her queer gaze, articulated by and later manifested in Lionel. Their gazes destabilize the relationality between feminine/masculine, exteriority/interiority, beauty/intelligence, and beautiful/sublime. Olivia refuses Burke's insistence that the sublime is masculine, and therefore normally the realm of men, and beauty feminine and the realm of women. Instead, Olivia demonstrates the potential of errancy in her queer space at CampbellHouse.

As Lionel's tenure at Campbell-House continues, his imagination becomes entirely occupied by Olivia. Lionel “cannot entertain any other" object but Olivia (Burke 1757, 41). His "mind is so entirely filled" by her; he writes obsessively to St. John about her, time and again recounting why he "admir[es], revere[s], and respect[s]" her. According to Burke, these are symptoms of "passion caused by the great and sublime" $(1757,41)$. In letter after letter, Lionel accounts for Olivia's every action, reaction, and movement. His mind and pen are occupied by few others, and even when he writes of his concerns for Harry, he does so with reference to Olivia. Lionel is overcome with the "great power of the sublime" (Burke 1757, 41-2). Lionel believes that his "admiration, reverence and respect" for Olivia—effects, according to Burke, of her being sublime - is reason to marry her, but Olivia worries that these emotions will fade and she will find herself without a husband who truly loves her or is committed to her (Plumptre 147). She is able to anticipate the temporary astonishment that Lionel experiences; she worries that this will wear off and lead to an unsustainable marriage.

Olivia is able to queer gender and class roles at Campbell-House because she fosters such an environment. Her dismissal of traditional roles leads those who live and work at CampbellHouse to participate in the maintenance of this gender-queer, class-queer space. Her influence at Campbell-House is so omnipotent that even her guests begin to adopt her queerness. Lionel 
experiences Olivia as a sublime object, leading to admiration and a singular focus on her. Lionel conceives of admiration as love and seeks Olivia's hand in marriage; in a letter to Orlando he proclaims: "Oh God! how vain, how idle is beauty when compared with qualities so exalted, so sublime! The one is fleeting and transient, adored for a while, then regarded no longer; but a soul like Olivia's is an inexhaustible mine of attractions, ever varying, ever new" (Plumptre 122). Olivia's "qualities" are "sublime"; in contrast with beauty, they are timeless and transcend measurement. Unlike the women that Lionel expected to fall in love with, Olivia is a sublime object. In this letter to Orlando he makes reference to her being "sublime" because he holds her in such high esteem, but in doing so he also articulates that he is in love with her, a terrible, terrifying experience that fills him with awareness of the potential dangers of loving Olivianamely, the loss of his reputation. The potential damage to his reputation by loving Olivia is an indicator of queerness' danger — a danger because it threatens the foundational logic of British society. Later, Lionel tells Olivia that "he was so blind...henceforward [he] shall...consider beauty as... secondary" (Plumptre 130). Lionel claims "blind[ness]" prior to learning to see differently at Campbell-House. According to Burke, beauty elicits love; ${ }^{101}$ the sublime, on the other hand, provokes a "delightful horror" in the viewer (Burke 1757, 52). Lionel's experience of Olivia as a sublime object is an "irrational and a violent aesthetic experience" (Boulton $\mathrm{xl}$ ). Lionel's viewing of Olivia triggers a violent, painful shift in him that does not lead him to love, but awe. Even though Lionel mistakes his awe for love, Olivia is less convinced and refuses his declarations and proposals on multiple occasions. Like the sublime, Lionel sees Olivia not as "smooth and polished," but as "great" and "mak[ing] a strong deviation" (1757, 52). Just as

${ }^{101}$ See Section X: Of Beauty and Section XVIII: The Recapitulation of Burke. 
sublime landscapes inspire poets with admiration, Olivia inspires Lionel to think that he could love a woman so "great" and virtuous, yet so ugly and "terrible" $(1757,96)$.

\section{$\underline{\text { Unsustainable Queerness }}$}

Lionel must continue looking queerly in order for Something New to result in Lionel's marriage to Olivia, and while such change seems possible within the queer space of CampbellHouse, once Lionel returns to London it is evident that change is impossible. His return to the "gay world" of London squashes the possibility of queerness and he is unable to continue looking queerly as he did at Campbell-House (Plumptre 233). When Olivia leaves the space where her gaze and aesthetic prevail, queerness is erased and she is once again subject to hegemonic determinations of feminine value. In London she is aware that Lionel begins to once more cherish traditional feminine beauty. He again becomes "a slave to beauty" and recognizes that he is unable to romantically love Olivia, instead falling for fair Charlotte (Plumptre 5). In other words, once "the beautiful" is available to him again and is threatened, he adopts normative modes of looking and sees "the sublime" as awe-inspiring, not love-inspiring (Plumptre 233).

Though Orlando shared information about Charlotte in many of his letters to Lionel while Lionel was at Campbell-House, Lionel's focus remained on Olivia. Once Lionel meets Charlotte in London, however, he is less resolute in his love for Olivia. He is finally moved to action when "Charlotte's life [is] in imminent danger from an overturn in a curricle"; once he sees that he may "be torn from" her "for ever," he recognizes "the excess of [his] passion" (Plumptre 335). He tells Harry of the episode in a letter wherein he declares:

Harry, I am awakened. Various causes have combined to disperse the mist which lately obscured my senses, to restore me to a proper sense of my own interest, and to impress my soul with the deepest and most unbounded gratitude for the kindness I have 
received...[T]ell Olivia that I think of her no more but as the guardian of my honor and happiness...[T]ell her I speak the pure effusions of my soul when I declare that I consider her as something superior to mortality. (Plumptre 334)

Lionel is "awakened” by Charlotte's near-death experience. Queerness, "the mist that lately obscured [his] senses," is removed and he is "restore[d]...to a proper sense of [his] own interest." The signifiers of queerness - Olivia and her gaze — no longer threaten to ruin him by destroying his reputation because he loves Charlotte. Lionel tells Harry that he has proposed to Charlotte: "I laid open my whole heart to Charlotte, told her all that has passed with Olivia, and asked whether she could accept the hand of a man so circumstanced? And she did accept it, and I am blessed" (Plumptre 335). By confessing his temporary queerness and being forgiven for it, he can return to normativity with Charlotte as the signifier and savior of his return. Lionel's engagement to Charlotte illustrates the impermanence of queerness; it is impossible to maintain outside of spaces like Campbell-House and within hegemonic, upper-class Romantic culture, the disruptive power of queerness is but temporary. Nonetheless, he is forced to confess it. Campbell-House, and the temporary effects of it and Olivia, indicate that there is another way of seeing, even if that way is not sustainable outside of queer spaces. Plumptre's narrative demonstrates that despite Olivia's best efforts, she and Campbell-House (like the readers of Something New) are almost always subject to the normative pressures of society. There is little escape.

Olivia is queer because she develops a counter-narrative which applies pressure, through her queer gaze and the environment she fosters at Campbell-House, to upper-class notions of value associated with exterior beauty and femininity. Because of Olivia's influence, errancy, rather than fixity, is the status quo within Campbell-House. She fosters an environment where individuals with potentially ruinous histories have a second chance. Plumptre uses Olivia and the 
environment at Campbell-House to imagine an alternative reality that contradicts hegemonic culture and puts forth an idyllic cultural environment that does not privilege an individual's gender, beauty, and/or wealth, but his/her interiority. Something New concludes by returning to London where the more common cultural narrative, beauty alone as an elicitor of love and signifier of feminine value, reemerges. Despite what seemed to be Lionel's adoption of a queer gaze at Campbell-House, he is unable to maintain such a mode of looking upon his return to London. He ends his engagement to Olivia and marries "the beautiful" Charlotte. The novel concludes by Lionel wishing for Olivia's happiness and grateful that her kindness spared him from a life marred by her ugliness. Outside of the heterotopia of Campbell-House, Lionel is unable to maintain the queer gaze and readopts mainstream ideology about beauty's importance. Despite this loss, the emergence of queerness and the heterotopic space of Campbell-House serve as examples to readers of alternate, viable realities. While there isn't space for queerness within mainstream culture, as it must be corrected and/or eradicated, its emergence unharnesses a new narrative that disrupts the status quo and leads to questions about what one perceives as "normal" and as "error." 


\section{Chapter 5}

Erring Populations \& Population Debates as Prophylactics

Inherent in Romantic population debates is the problem of sexuality—or the passion between the sexes - after all, to discuss population one must discuss reproduction and sex. Romantic debates about population emerged as a way to discuss sexuality through a "new regime of discourses" (Birth of Biopolitics 27). Underlying debates about population is a debate about how female reproductive capacity should be managed by larger, patriarchal societal institutions and how mismanagement of that capacity leads to superfluous, erroneous populations. In History of Sexuality, Volume 1: An Introduction, Michel Foucault argues that sex must enter discourse; it is hidden without language. ${ }^{102}$ During the Romantic population debates, sexuality certainly entered discourse. Sexuality was also written onto bodies, usually female bodies and even more particularly, female bodies with the ability to reproduce. Reproductive, female bodies represented all that the population discourses addressed: concerns about population growth, poverty, availability of subsistence and finally, concerns about modes of female sexuality. Such discourse was a narrative about populations that were mistakenly enlarged and methods for correcting their growth. The power to control female sex was the power to control such populations, and therefore control the growth of the social body. Should management of the female body fail, the state and its upper-class citizens were, in their opinions, held responsible for a grievous error.

Sex and power are intrinsically linked. The Romantic population debates are power negotiations - primarily between men — about the way that the female body, sexuality, and

\footnotetext{
${ }^{102}$ I refer to this text as The History of Sexuality throughout the remainder of the text. Citations appear in the text.
} 
reproduction, should be managed to keep it in check — that is, to avoid error. The population debates were a discussion of how to control and eliminate populations that theorists perceived as erroneous. In particular, the population debates framed superfluous population as an error that needed a practical methodology to control its growth, and this is the role of population theorists such as William Godwin and Thomas Malthus. Primarily, the populations thought of as erroneous consisted of impoverished people. To control the exponential increase of population, political economists developed strategies for managing the female body. The management of the female body takes place through multiple strategies. Such strategies support the patriarchal, classist, social order, including making the individual female body subordinate to the British social body. This means prioritizing the masculine whole (the social body) over the feminine individual (the female body). Foucault argues that "sexuality is not the most intractable element in power relations, but rather one of those endowed with the greatest instrumentality: useful for the greatest number of maneuvers, and capable of serving as a point of support $[\ldots]$ for the most varied strategies" (History of Sexuality 103). Foucault cites the location of sexual "repression" in the Victorian period, and while it may have come to fruition during this time period, the seeds were planted earlier as evidenced by Romantic discussions of controlling what they considered excess population. ${ }^{103}$ Harriet Martineau challenges the subordination of the female body. Her narrativization of political economy demonstrates the subordination of every individual body, rather than just the female body. Rather than holding women solely responsible for preventing erroneous birth and population increase, Illustrations holds all citizens responsible. More importantly, Martineau's Illustrations forges a specific domain for women in the population

\footnotetext{
${ }^{103}$ Foucault argues against the idea of a simple repression of sexuality and notes the vast expansion of discourses on sexuality; see The History of Sexuality, 17-35.
} 
debates. While men may theorize about population, it is women who put it into practice. Despite Martineau's emphasis on women's effect over population control, she still invests in population theories that disempower poor people. Ultimately, Illustrations is complicit in the master discourse of (masculine) population theory and frames impoverished English citizens as an error in need of correction.

Romantic population theory asks the public to consider how its bodies and sexualities are working for the national body - that is, how one's decision to have sex and possibly to reproduce may change the availability of resources and the ability of the nation to produce for every citizen. In this chapter I first outline Foucault's theories of power, particularly those focused on the body and sexuality; then, I employ Foucault's "strategic unities" to analyze William Godwin and Thomas Robert Malthus' population theories. Godwin and Malthus were the leading voices in the population debates and heavily inform Martineau's Illustrations. I continue my analysis to argue that throughout the end of the eighteenth and beginning of the nineteenth centuries, population theory was used as a corrective ideology and rhetoric to maintain power over the female body and sexuality. Finally, I conclude that Martineau's Illustrations of Political Economy offers a new approach, via narrative, to the appropriation of population theory that makes women active agents in British culture. First impressions of Martineau's text highlight her support of women, but additional analysis makes clear that Martineau is complicit in the middleclass vision of society that frames poverty as error, thereby disenfranchising poor women in particular. ${ }^{104}$ Martineau's narrative supports an errant understanding of gender but rejects class errancy.

${ }^{104}$ Illustrations of Political Economy is referred to as Illustrations throughout the remainder of the text. References come from Broadview edition, 2004. Citations appear in the text. 
The historical differences of the population texts and Foucault's terminology can lead to confusion concerning vocabulary; as a result, the definition of a few key terms and concepts will help to clarify their uses throughout this chapter. Sexual identity categories are beyond articulation for Malthus and his contemporaries because their language focused on acts. "Sex" has two definitions; first, the physical sex of a person, as rooted in their biology. ${ }^{105}$ The second definition of "sex" refers to the physical practice of bodies; in this chapter, this definition is linked primarily to Foucault's language in History of Sexuality. ${ }^{106}$ For the Romantics, phrases like "the passion between the sexes" referred to sexual acts. As a result of the historical period, reference to sex as a physical act is most often restricted to sex between a man and a woman and commonly in the context of marriage. The social construct of "homosexual" did not exist for the Romantics as it did for Foucault. When Malthus writes that "there are individual exceptions [to the passion between the sexes] now as there always have been," he adds that "these exceptions do not appear to increase in number" so one should not "infer [...] that the exception would, in time, become the rule, and the rule the exception" (Malthus 71); though Malthus is referencing men who have sex with men and women who have sex with women, he is unable to name " the exceptions" based on an identity, such as "homosexual." Rather Malthus's "exceptions" point to sodomites or "acts contrary to nature," terms that identify a set of behaviors that can be isolated from a person's identity. Foucault articulates this difference clearly: "Sodomy was a category of

105 Though, the stability of a biological category is questionable; for more on this topic see Judith Halberstam's Female Masculinity (Durham: Duke UP, 1998). For an in-depth understanding of Romantic conceptions of sex and gender, see Thomas Laqueur.

${ }^{106}$ Foucault switches between the terms "sexual practices," "sexuality," and "sex" throughout the text to refer to the physical practice of bodies; see, for example, page 3 of History of Sexuality, "At the beginning of the seventeenth century a certain frankness was still common [...] [s]exual practices had little need of secrecy [....] But twilight soon fell upon this bright day, followed by the monotonous nights of the Victorian bourgeoisie. Sexuality was carefully confined; it moved into the home $[\ldots]$ On the subject of sex, silence became the rule." 
forbidden acts: their perpetrator was nothing more than the juridical subject of them," but the "homosexual became a personage, a past, a case history, and a childhood, in addition to being a type of life, a life form, and a morphology" (43). ${ }^{107}$ "Sexuality," then, refers to those physical practices (of sex) as indicators of an individual's preferred or culturally forced sexual practices and desires. I often use the phrase "female sexuality" in reference to reproduction; I use this term to signal to the reader that visible pregnancy is an unavoidable signifier of a woman having had sex, an aspect that even the most prudish society was (is) unable to erase. ${ }^{108}$

It is helpful to view the political texts of population theorists such as Godwin, Malthus, and Martineau through the theories of Foucault because Foucault allows consideration of how discourse shapes individual and social bodies, and he also permits us "to account for the fact that [sex] is spoken about, to discover who does the speaking, the positions and viewpoints from which they speak, the institutions which prompt people to speak about it and which store and distribute things that are said" (History of Sexuality 11). Foucault's theories open up methodologies for consideration of the ways in which sex enters discourse, an analysis of the speaker, the speaker's position in society, the influence of societal institutions, as well as the silenced voices of the text. Much like Foucault, Godwin and Malthus both leave women on the periphery of their theorizations; women are only considered when they discuss the passion between the sexes or the role of children in society, and even then women are usually discussed in relation to men. Unlike Foucault, Godwin, and Malthus, Martineau creates a specific space for women by narrating population theory through fiction and also by crafting feminine characters

${ }^{107}$ See pages 42- 43 of History of Sexuality for a thorough understanding of Foucault's theory about the formation of "the homosexual."

${ }^{108}$ Again this reference is historically framed since contemporary reproduction/pregnancy gives no indication of an individual's sexual practices or desires. 
that naturally embody the practices of population control. It may initially seem counterintuitive to analyze the discourse of Romantic sex in relation to women using a twentieth-century philosopher who virtually ignored women altogether, but Foucault's theorization provides a helpful lens for analysis.

Foucault ignored issues specific to women; he almost never directly acknowledges that women have any place in the power/knowledge structure. ${ }^{109}$ Foucault's focus on the body (social and individual) can be readily applied to the female body. In The History of Sexuality, Foucault relies on historical bodies to trace the origins of sexuality to modern practices (such as the evolution of "sodomite" to "homosexual"). Such an approach invites theorists and critics to take up his work in unique ways, including adapting it for use throughout alternate historical periods and applying it to bodies and peoples that Foucault ignored. He reminds readers that "there is no single, all-encompassing strategy, valid for all of society and uniformly bearing on all the manifestations of sex," thereby acknowledging the inability of one theorist to address all facets of a society, highlighting the importance of historicizing cultural practices and phenomena, and encouraging his readers to use his ideas as building blocks to their own ideas (History of Sexuality 103). Just as there are multiple texts one might use to develop theories of sex and sexuality, there are multiple texts that address theories of population in the Romantic period.

109 Though, he implicitly does so by arguing that everyone, even those who are seem to have no access to freedom, such as enslaved peoples, have access to power. It would be logical to argue, then, that even though Foucault doesn't directly address women's implications and "roles" in the power-knowledge structure, women do, in fact, have a place in such a structure. Powerknowledge refers to the reciprocal relationships between power and knowledge; "power and knowledge directly imply one another; there is no power relation without the correlative constitution of a field of knowledge, nor any knowledge that does not presuppose and constitute at the same time power relations" (Discipline and Punish 27). 
I've chosen Godwin's Enquiry Concerning Political Justice and Malthus' Essay on the Principle of Population and A Summary View of the Population Principle for analysis because the texts are in historical dialogue with one another. Godwin wrote Political Justice in 1793 and Malthus wrote Principle of Population in 1798, partially in reply to Godwin. ${ }^{110}$ Political Justice and Principle of Population stand in philosophical opposition to one another and represent the two primary discussions of population theory. Godwin represents what one might call an "optimistic" approach to population control while Malthus represents a "pessimistic" approach; one is rooted in achieving perfectibility during earthly life - that is, the removal of error through careful self-evaluation and alteration — and the other in achieving perfectibility in an after-life. Both Principle of Population and Political Justice are foundational population debate texts. Traceable through the voices of these two individuals is the evolution of the population debates, which make them ideal for an analysis of discourse surrounding the female body, sexuality, and the power relationships involved in both. Martineau published Illustrations of Political Economy, a set of twenty-five short narratives, from 1832 until 1834. Martineau's Illustrations translated the political theories of Malthus, and other theorists such as David Ricardo and Adam Smith, into narrative which enabled all British citizens to access population theory and educate themselves without the "boring and obscure" jargon of political theory (Roberts 15). While her writing is a bit later than that of Godwin and Malthus, her stories are set in the past, amidst the implementation of the Corn Laws (1791), the Speenhamland System (1795), and the Combination Acts (1799). ${ }^{111}$ Additionally, Martineau's Illustrations were published the same

${ }^{110}$ Enquiry Concerning Political Justice hereto referred to as Political Justice and An Essay on the Principle of Population hereto referred to as Principle of Population. Citations appear in the text.

111 The Corn Laws kept domestic grain prices high by placing high taxes on imported grain which was good for landowners because plots of land that were previously unfarmed had to be 
year that "Parliament passed the First Reform Bill"; issues of population were still on the national mind (Logan 9). To understand how Martineau's Illustrations shifts the population debates away from treating women as those making mistakes via their actions - sexual and otherwise - and toward women as agents of change, it is first necessary to establish an understanding of the two key voices in the debates: Godwin and Malthus.

$\underline{\text { Godwinian and Malthusian Theorizations of Population as Error }}$

Godwin argues for population control based on the power of man's reason, and he believes in the perfectibility of society; through the exercise of reason, humanity will reach a state of perfectibility where resources will be equally distributed, labor will be equally rationed, and therefore minimized, and immortality will be attainable. He believes that through the use of reason, which consists of removing error to find truth, mankind will overcome the challenges of population. Political Justice is an argument for the removal of error to attain perfectibility. As Mark Philp declares, "William Godwin (1756-1836) is one of the earliest advocates of anarchism" (1). Godwin argued that government was only necessary to regulate human error and should humans be capable of applying reason throughout every facet of their lives, then government would become unnecessary. Because humans continue to make mistakes in their logic, we are destined to press on and apply logic to the errors we discover: "Our grasp of moral and political truth necessarily develops because errors involve us in contradictions, confusions and paradoxes - and these are sufficiently discomforting to prompt further reflection" (Philp 3). Because of Godwin's reliance on reason, truth has an overwhelming power; it is capable of leading men out of ideology. Reason disempowers what one might call "group-think" by asking

farmed to produce enough domestic grain. The Speenhamland System established a system of poor relief based on family size. The Combination Acts illegalized trade unions and similar acts. 
each individual to think for himself and then navigating society based on individual thought (i.e. reason). Godwin heralds the power of truth; he claims, "If there be any force in the arguments of this work, we seem authorized to deduce this much from them, that truth is irresistible. Let then this axiom be the rudder of our undertakings. Let us not precipitately endeavor to accomplish that today which the dissemination of truth will make unavoidable tomorrow" (789). Godwin's belief in the reliability of truth allows him to theorize about "the prolongation of human life" (Godwin 770). While his reliance of truth questions social ideology, it simultaneously asserts a find-able truth that exists when reason is applied. Such logic implies that "proper reasoning" will lead to a single truth. Therefore, those who are not capable of properly applying reason and discover alternate truth are mistaken.

Godwin argues that if we use our minds properly, we will rid society of the errors created by emotion which cause "the heart to palpitate, and the limbs to tremble"-bodily signifiers of love and/or desire. Reason, for Godwin, stands in contradiction to and in conflict with emotion. According to Godwin, the passion between the sexes is extinguishable because "one tendency of a cultivated and virtuous mind is to diminish our eagerness for the gratifications of the senses" (776). Godwin explains that through the work of "a cultivated and virtuous mind" mankind will be able to "correct certain commencing irregularities of the system, and forbid, in circumstances where those phenomena would otherwise appear, the heart to palpitate, and the limbs to tremble" (774). Godwin's argument is based on the idea that "if the power of intellect can be established over all other matter," then it can also be established "over the matter of our own bodies" (Godwin 771). The immaterial - the mind - is capable of controlling and correcting the materials - the body. Godwin believes that it is mind over matter when it comes to our bodies: "Every time that our mind becomes morbid, vacant and melancholy, our external frame falls into 
disorder" (Godwin 772). If we do not properly manage our minds, our bodies will follow suit. According to Godwin, because of our minds' power we will be able to master our bodies: we'll be able to control the blood in our veins, the palpitations of our hearts, and so on. Godwin extends this line of argument so far as to lengthen human life to the degree of immortality. He believes that the power of our minds (reason) is so strong that we will be able to live forever. ${ }^{112}$ Godwin's arguments revolve around what seems to be an always-evolving, optimistic view of humanity's potential. His belief system gives human beings unbridled power if only we can harness the potential of our minds and check the pleasures of our bodies. Malthus' theories, on the other hand, argue against such an outlook.

Malthus, in contrast to Godwin, argues that surplus populations-errors in production according to his view_ can be avoided through vice and misery. Malthus' argument concerning population is based on "two postulata. First, That food is necessary to the existence of man [and second], [t]hat the passion between the sexes is necessary and will remain nearly in its present state" (Malthus 70). Malthus believes that population increases geometrically and food increases arithmetically (Malthus 71); the difference in this mathematical equation reveals that man's population will always be greater than the amount of food available, and since "food is necessary to the existence of man," Malthus believes that we must control the population to keep food shortages at bay. ${ }^{113}$ The best way to control population is through vice and misery because they

112 For a full articulation of Godwin's beliefs concerning health and the prolongation of life, see "Of Health, and the Prolongation of Human Life" (770- 777).

${ }^{113}$ William Cobbett passionately challenges Malthus' theorization by pointing out fallacies in his argument. Included in Cobbett's argument is the fact that Malthus focuses this population increase to Britain. Cobbett wonders why continental Europe would not experience a similar increase in population (see p. 71 of Cobbett's Weekly Political Register Vol. 46, No. 2, 12 April 1823). He also identifies the fact that the enumerations, what we would today refer to as a census, which Malthus used to do his math were not standardized. The 1801 enumeration 
serve as checks for population. For example, when people are struggling to provide themselves with enough food or when they are overworked, they are miserable and less likely to reproduce. Malthus' theory opposes Godwin's in that for Malthus the body's senses (hunger, in this case) are dominant. Vice prevents population by decreasing available sexual resources, as I'll explain later. According to Malthus, vice and misery are necessary to stop the mathematically predicted population explosion. Malthus breaks from tradition when he argues for an unhealthy social body — one entrenched in vice and misery—rather than a healthy social body based in reason and virtue (like the social body imagined by Godwin).

The female body, including the ability to reproduce, represents the hope and danger of the future; the female body is subject to external (state) regulation because women are thought of as incapable of managing such a responsibility on their own. Management of the female body is a theoretical attempt to better the nation and to prevent women. Foucault's identification of "great strategic unities which, beginning in the eighteenth century, formed specific mechanisms of knowledge and power centering on sex" offer insight into the management of the female body (History of Sexuality 103). One of Foucault's strategic unities is the "hysterization of women's bodies," a process that includes the analysis of the female body "as being thoroughly saturated with sexuality" which led to the medicalization and "pathology intrinsic to it," and finally, and perhaps most importantly, the female body "was placed in organic communication with the social body (whose regulated fecundity it was supposed to ensure), the family space [...], and the life of children" (History of Sexuality 104). The female body was linked to the healthy, wealthy, British social body because of the female ("regulated") power to produce the next generation.

measured persons, but the 1811 enumeration measured families (see pp. 1045-1046 of Cobbett's Weekly Political Register Vol. 34, No. 33, 8 May 1819). 
The female body becomes a representation of the British social body and all of its intrinsic anxieties about the potentiality within the female body capable of reproduction. Romantic theories of sexual reproduction and potency were based on the resource of sexual fluids. Both men and women had sexual fluids and both fluids were needed to procreate, but since women were often thought of as individuals "whose desires knew no bounds" men believed that their "resources" were in demand and this generated male anxiety about women's abilities to deplete precious male resources (Laqueur 4). ${ }^{114}$ Hence, female desire (to which there are no bounds) needs male regulation via population theory.

For Malthus, the key to population remains in the relationships between the sexes, primarily through marriage. Malthus' definition of vice is based on the concept of sex outside of marriage, as well as early marriage. There are two concepts that underlie Malthus' beliefs: sex outside of marriage and marriage late in life. According to Romantic notions of the body, persons who take part in sex outside of marriage or are married late in life are barren or less fertile than individuals who only have sex in the context of marriage because people who have sex outside of marriage have overused and depleted the fluids of reproduction, leading not to reproduction, but to a check of it. For Malthus, the overuse and depletion of sexual fluids is a mistake, but the check on population is a positive outcome of that mistake. For example, if an individual engages in sex with prostitutes throughout his twenties and then gets married at the age of thirty-five, he has overused his sexual fluids through sex outside of marriage (with the prostitute, who is commonly perceived as barren), which is framed as error because of his overabundant sexual appetite. However, the check on population is desirable; because he is less

114 These beliefs about male-resource demand stand in direct contradiction to contemporary beliefs, which emerged in the late nineteenth century, that women are the "resource in demand." 
fertile, he is less likely to abundantly reproduce. This complicates error in society because while one might argue for the correction of unleashed sexual appetite, one might also simultaneously praise the population check that results from that unleashing.

In contrast to this deceptively easy relationship between oversexed and fertility, one man's error may well be praised for keeping population in check. Such a view contrasts with other versions of error discussed in earlier chapters. Instances of error in the narratives discussed throughout this chapter are both in need of correction and in service of the nation. Additionally, the fact that such a man did not get married until age thirty-five furthers his positive influence on society because it leads to a check on population since earlier marriages result in a greater number of children. Malthus also believed that early marriage encouraged sex at an earlier age, without the depletion of sexual resources on barren individuals such as prostitutes. The alternative to sex outside of marriage is early marriage; when marriage occurs early in life, procreation occurs earlier and more frequently, which is, for Malthus, bad. Early marriage is positive because Malthus believes that "there is scarcely a man who has once experienced the genuine delight of virtuous love, however great his intellectual pleasure may have been, that does not look back to the period as the sunny spot of his whole life [...] and which he would most wish to live over again" (Malthus 146). Here, virtuous love refers to marriage early in life, and therefore, having children early and often. And here lies the contradiction: early marriage is framed as culturally desirable but population, which occurs more frequently in early marriage, is a drain on the health of the social body. So, for Malthus marriage late in life and sex outside of marriage are socially problematic, but the check on population is desirable.

Contradictions found in Malthusian population theory drew attention to the management of the female body and sexuality. Malthus cannot, as a man who believes himself to be writing 
social theory, approve of women having sex outside of marriage or without the intent of reproduction, so he must chastise those who practice such behavior and commend the practice of marriage early in life. Malthus is unable to mend the rift between beliefs about female sexuality and his argument about population and must leave the contradiction in place. In a brief attempt to account for the contradiction, Malthus acknowledges that "a sensual pleasure not attended with the probability of unhappy consequences [i.e. over-population] does not offend against the laws of morality, and if it be pursued with such a degree of temperance as to leave the most ample room for intellectual attainments, it must undoubtedly add to the sum of pleasurable sensations in life" (147). Sex is an enjoyment of life, but he urges that "it be pursued with [...] a degree of temperance"; however, its pursuit is only justified if it "leave[s] [...] room for intellectual attainments" (Malthus 147). There is less room for "pleasurable sensations" in the lives of Romantic women. ${ }^{115}$

The lives of Romantic women are dictated by an economy of sexuality which is both financial and political and calls upon responsibility for the social body. Outside of marriage, men were often free from any fatherly responsibilities. Social pretenses held that child care was a responsibility of women; that is, women were responsible for the care and development of the social body. Foucault also identifies "a socialization of procreative behavior" as a strategic unity which involves "an economic socialization via all incitements and restrictions, the 'social' and fiscal measures brought to bear on the fertility of couples; a political socialization achieved through the 'responsibilization' of couples with regard to the social body as a whole" (History of Sexuality 104-105). Foucault's “"responsibilization” of couples” might as well be read as “female

\footnotetext{
${ }^{115}$ For a reading of Malthus' use of the body as "an absolute social problem," see Catherine Gallagher.
} 
responsibility" instead; a gendered double standard around sex held women responsible for their sexual behavior. ${ }^{116}$ Godwin best illustrates the portion of the debate about "a socialization of procreative behavior" by proposing a society of perfectibility in which procreation ceases to exist. The implications of Godwin's concept of immortality on sexuality are direct; if mankind ceases to die, then the need for additional generations becomes obsolete. Immortal men "will probably cease to propagate. The whole will be a people of men, and not of children. Generation will not succeed generation" (Godwin 776). Social institutions relegate "appropriate" female sexuality to matrimony and reproduction, but since there is no need for reproduction and there is no need for matrimony, "the abolition of the present system of marriage appears to involve no evils" (Godwin 763). Because sex is acceptable (for women) only within the bound of marriage and marriage will be unnecessary if there isn't a need for future generations, sex will become obsolete.

Such a view aligns with Godwin's championing of reason over emotion; Godwin relies on the individual to reason critically to the benefit of the nation. Godwin claims matrimony to be "the worst of monopolies" and proposes that marriage is a truly selfish act; it forbids human beings "to follow the dictates of their own mind" because the institution implies monogamy. Since acceptable female sexuality is limited to reproduction and marriage, an "appropriate" female sexuality would cease to exist in Godwin's estimation, leading women to become either asexual or hypersexual. ${ }^{117}$ The system that Godwin theorizes, leading to mankind's immortal

\footnotetext{
${ }^{116}$ For more on the bastardy clauses of 1834 and their relationship to gender hierarchy, see Lisa Forman Cody. Cody argues that the bastardy clauses of 1834 freed men from their fatherly responsibilities and women were held solely responsible for their sexual behaviors.

${ }^{117}$ Godwin never specifically addresses what will happen to female sexuality; both extremes are feasible since the removal of marriage would lead to the expectation that women wouldn't have sex or that sex would be uncontrolled without the regulation of church and state that marriage supposedly provides.
} 
perfectibility, results in the removal of female sexuality from society; this is a system that completely alters Romantic concepts involving "socialization of procreative behavior." This removal of female sexuality (and procreative behavior) also leads to the removal of male anxiety about overpopulation and female ability to deplete resources (both male sexual resources and food resources). In this view of society, the economy of sexuality is removed; it is removed because it benefits the social body. Responsibility rests on individuals to employ reason and virtue to such a degree that immortality is attainable; the social body benefits from the individual's ability to regulate errors in reasoning and find truth, leading to immortality.

Foucault's "strategic unities" are traceable throughout Godwin's and Malthus' population theories. Each author makes an effort to colonize the female body for the use of the social body and to propose social policy that indirectly authorizes what is appropriate for female sexuality and procreation. Sex became "a thing one administered. It was in the nature of a public potential; it called for management procedures; it had to be taken charge of by analytical discourses" (History of Sexuality 25). The management of female sex was theorized by men of privilege and prestige, men who managed to carry on discussions of population to discuss the management of female sexuality and reproduction without ever including the voice(s) of the female population of Britain, but when Harriet Martineau published her Illustrations of Political Economy, a female voice of population theory emerged.

Martineau's Narrativization

Other scholars focus on ways that Martineau helps to shape the discourse of political economy in Victorian Britain and even more give attention to her autobiographical works and 
their possible influence on Illustrations. ${ }^{118}$ It is impossible to write about Martineau without gesturing to this body of critical work, but unlike scholars who consider how Martineau's own experiences with poverty encouraged her realistic representation of poverty or her beliefs about poverty, I focus on the ways in which Martineau forges a specific domain for women in the population debates by revealing that British women practice population control without ever reading population theory. Unlike Malthus and Godwin who believe that British citizens must alter their behaviors and engage in particular and intentional ways of existing to enact population theory, Martineau's Illustrations demonstrate that population control is something that middleclass British women do naturally. For Martineau, population control is sometimes inherent in women's behavior, as she illustrates through her characters. Martineau also challenges the subordination of the female body by arguing for a subordination of every individual body. She does this by pointing out that no one is free; Martineau "welcom[es] dependence on certain laws which control the lives of both women and men" (David 45). And while Martineau's dependence on laws that control everyone's lives makes Martineau uninteresting for critics like Deidre David, it is precisely what makes Martineau's Illustrations unique. Caroline Roberts argues that David "relegates [Martineau's] work to the status of 'auxiliary usefulness' to a patriarchal culture because she does not originate meaning" (Roberts 13, David 31). David makes the same

118 See Harriet Martineau's Harriet Martineau's Autobiography (2 vols. London: Virago, 1983) for the autobiographical text. Critical biographical texts include Diana Postlethewaite's "Mothering and Mesmerism in the Life of Harriet Martineau (Signs. 14.3 [Spring 1989]: 583609); Margaret G. O'Donnell's "Harriet Martineau: A Popular Early Economics Educator" (The Journal of Economic Education. 14.4. [Autumn 1983]: 59-64); and, Ann Hobart, "Harriet Martineau's Political Economy of Everyday Life" (Victorian Studies. 37.2 [Winter 1994]: 223251). Scholars that focus Martineau's shaping of political discourse include Elaine Freedgood ("Banishing Panic: Harriet Martineau and the Popularization of Political Economy." Victorian Studies. 39.1 [Autumn 1995]: 33-53); Max E. Fletcher ("Harriet Martineau and Ayn Rand: Economics in the Guise of Fiction." American Journal of Economics and Sociology. 33.4 [Oct. 1974]: 367-379.) 
argument about Martineau's theories that Godwin made about the feminine fields of art and literature. Eighteenth- and nineteenth-century ideas regard science and its theories as masculine, and literature and art are generally seen as feminine. ${ }^{119}$ Godwin dismisses the idea of the arts as perfectible; things such as ensemble music and theater involve the re-use of others' ideas and hence, have no value in a society based on reason. Theater and music [seem] to include an absurd and vicious co-operation. It may be doubted whether men will hereafter come forward in any mode formally to repeat words and ideas that are not their own? It may be doubted whether any musical performer will habitually execute the compositions of others? We yield supinely to the superior merit of our predecessors, because we are accustomed to indulge the inactivity of our faculties. All formal repetition of other men's ideas seems to be a scheme for imprisoning, for so long a time, the operations of our minds. It borders perhaps, in this respect, upon a breach in sincerity, which requires that we should give immediate utterance to every useful and valuable idea that occurs. (Godwin 760)

The arts are never, in his British society, original; instead, they are always based on the repetition of others' ideas and collaboration. This includes writing, music, and theater-all of which fall into the "feminine" category of arts and literature. ${ }^{120}$ That is, the feminine is never capable of producing anything original or useful to Godwin's society. This offers a gesture to the feminine and women's inability to be part of this perfected race of immortals; Godwin excludes

\footnotetext{
${ }^{119}$ The division of literature and art as feminine is subject to debated; for example, poetry was seen as masculine in comparison to the art of fictional narrative which was feminine. For more on the division between science and literature, see Roberts, especially p. 14.

${ }^{120}$ Godwin explains that reading doesn't fall into this category because it enhances the intellect; the underlying reason is because reading is linked to education, a facet of society available almost exclusively to men.
} 
women entirely. Godwin's society is one built solely on the perfectible ideas of science, of men. ${ }^{121}$ Because Martineau is using Malthus's, Ricardo's, and Smith's ideas as a beginning for her own version of a political economy, according to David, she is simply reproducing "other...ideas," or "indulg[ing] the inactivity of [her] faculties" (Godwin 760). In David's theorization of Martineau's text, the feminine again falls victim to the patriarchy; Martineau is far more complex than David's reading allows. She uses the "boring and obscure" political theory of the aforementioned men to craft fiction, evidence of her education and rebellion against proscribed gender fields (Roberts 15). Her education allows her to write for the public sphere and escape the private sphere, the designated space for women. ${ }^{122}$

Martineau also exhibits her understanding of political theory, even though it is within the masculine sphere of science and its theorizations and, therefore, inappropriate for women. She adapts political theories to decrease male, patriarchal management of the female body, and to call attention to society's responsibility for the social body—including men and women. Martineau's narrativization makes population theory comprehensible for the everyday reader. Her female characters always practice population control, but are unable to articulate their practices as population control until hearing about the science of population theory. In "Weal and Woe in

${ }^{121}$ Percy Shelley challenges Godwin's assertion that the arts are beyond a society of perfectibility. In the Preface to "Laon and Cythna" Shelley says, "I have considered Poetry in its most comprehensive sense, and have read the Poets and the Historians and the Metaphysicians whose writing have been accessible to me, and have looked upon the beautiful and majestic scenery of the earth as common sources of those elements which it is the province of the Poet to embody and combine" (Shelley 134). In a note to this portion of the text Shelley adds, "In this sense there may be such a thing as perfectibility in the works of fiction, notwithstanding the concession often made by advocates of human improvement, that perfectibility is a term applicable only to science" (Shelley 725).

${ }^{122}$ Here public sphere refers to the portions of society which (help to) dictate social laws and practices. The private sphere is the space of the home, and spaces that allow women to be a part of the community, without wage compensation (i.e. volunteers). 
Garveloch" Martineau tells of the struggles of an impoverished fishing town in Scotland. Ella, who is considered "one of Martineau's best-drawn characters," is married to her husband, Angus, and they have nine children (Logan 55). Ella and Angus struggle to provide for their family and along the way begin to articulate some of Malthus' theories of population, with the help of the local magistrate, Mr. Mackenzie. This tale is perhaps the best illustration of Martineau's use of political theory and her belief that British women naturally practice population control in their homes without knowledge of public conversations and debates on the topic. Martineau uses socially responsible male characters to argue for the subordination of every body to the social body. She does so not only through some of her male characters but also by creating a feminine sense of community to hold both men and women responsible, unlike Godwin and Malthus who imply female responsibility exclusively. In this context "feminine" refers to a social definition instead of a definition (mistakenly) linked to human bodies. "Feminine" focuses on the collective, rather than the individual, and takes an affective approach to population theory rather than a strictly political one. Finally, Martineau's decision to use the genre of narrative fiction impresses a sense of femininity on traditionally masculine population theory, and thus on the rhetoric of population.

In a conversation with Angus and Ella, Mr. Mackenzie explains population theory. Martineau is not exactly subtle in her use of theory, but she doesn't outright label it either; the narrative envelopes the theory making it comprehensible and relevant to the reader's life through the lives of the characters. After one of Ella's brothers, Fergus, discovers his nets are destroyed by a local busy-body (Rob), Mr. Mackenzie explains why resources are so precious and the destruction of property such a concern for the magistrate's office: “"The number of people doubles itself for ever, while the produce of the land does not, the people must increase faster 
than produce. If the corn produced corn without begin wedded to the soil, the rate of increase might be the same with that of the human race"” (Martineau 81). Angus adds:

"If the number of producers increased only in proportion to the increase of food, there would be no distress of the kind our islands were formerly afflicted with, and may be afflicted with again....And all this time...these very quarrellers go on marrying early, and raising large families - that is, they bring offspring into the world while they are providing as fast as possible for their future starvation.” (Martineau 81)

And Ella concludes, "“I think not indeed...It seems a thing to be checked, rather than encouraged"' (Martineau 82). Ella is an active agent in her understanding of population theory; after this conversation, Ella is able to give voice to her lived practices in her home. Ella has been naturally practicing Malthus's population theories all along; she simply did not realize that this was a conversation taking place in the public sphere. For example, she and Angus "knew enough of comfort to see the necessity of providing room and ventilation if they wished to keep their large family in good health and good habits" (Martineau 58). Ella and Angus are framed as individuals with a family which their income allows them to support, even if they struggle at times. After Ella's conversation with Mr. Mckenzie, she has a new found ability to articulate population theory, and she goes to talk with her neighbor, Katie.

Katie, a widow and mother, makes nets to support herself and her children independently. Katie is well-born and educated, adding to her independence. Ella tells Katie, "Children are born whose youthful parents have neither roofs to shelter, nor clothes to cover them; and the more widely poverty spreads through the multitudes of labourers, the faster that multitude is doubled" (Martineau 111). Ella is referring to the families in the community who continue to reproduce regardless of their inability to care for their large families — primarily poor families. She and 
Katie lament the decisions made "in the name of Providence" (Martineau 111). They rejoice in their ability to use judgment and power to "limit [their] numbers to agree with the supply of food” (Martineau 111). Here Martineau applies Godwin's notion of reason and judgment to check population. Martineau further shows women's home practices as embodying public conversations through Katie. Katie exemplifies an alternative to pauperism; even though she is a widow, she does not collect public funds to support her family. She supports her family and refuses to take part in the public system or to increase the size of her family through marriage. Martineau fictionalized Malthus's idealized deployment of population theory, but she did so in a way that makes management of the female body an act of women rather than men. For Martineau, women aren't citizens in need of correction, but are already enacting population control through the management of their households. Malthus imagines that families do not need to know the theory, per se, but just by using common sense, population control should take care of itself. "Common sense," of course, is rooted in patriarchal notions of right and wrong, including traditional notions of femininity. Ella, her family, and Katie are perfectly Malthusian in that they do naturally intuit Malthusian theory. The connection between marriage and population increase is further addressed through Katie, who is loved by one of Ella's brothers, Ronald.

Ronald takes responsibility for population control; even though he is in love with Katie and would like to marry her, he does not. Ella tells Katie that Ronald will not marry her because “"it is not for himself only, but for you [Katie] and your children, and for us and for society, that he thinks and acts as he does....he sees that prosperity can never last among us, while we make no provision against the changes that must ever befall, while seasons are sometimes stormy and our commerce liable to variations"' (Martineau 110). According to Ronald, he can't marry Katie because doing so would inevitably increase the population; population increase must be avoided 
because commerce isn't reliable enough and therefore poverty is always a potential. Katie understands Ronald's decision but laments that “ “it is hard...that he must deny himself because his neighbors are imprudent"' (Martineau 110). Ronald sees the care of the community as part of his responsibility; he tells his brother, Fergus, "“I have only myself to work and care for...and whatever is left over is the natural portion of my kindred"' (Martineau 107). Through Ronald, Martineau subordinates the individual body in favor of care for the social body; it is not just the responsibility of women, like Katie, to monitor population growth. Lisa Forman Cody claims that Martineau "assert[s] that poverty arose from overpopulation and that women more so than men were responsible for demographic growth. By the mid-nineteenth century, Liberal political economists and their acolytes viewed these gendered assumptions as natural laws, arguing that a sexual double standard was reasonable and natural" (Cody 135). But Ronald's choices in "Weal and Woe in Garveloch" demonstrate that Martineau advocates for the responsibility of each person in society, regardless of sex. Her narrative demonstrates that all citizens are capable of checking the potential errors associated with population growth and administering to the care of society through their individual choices. For Martineau, each individual is responsible for the whole.

Martineau further removes women from exclusive responsibility over population by creating a feminine sense of community. The household represents Romantic and early-Victorian ideals of femininity; part of this ideal is the concept that mothers sacrifice themselves for the betterment of their families. In such a configuration, the feminine is responsible for the care and nourishment of the whole. Martineau extends this mode of feminine living to the entire community, not just the household. Martineau's characters exhibit, as I explained above, that the individual should sacrifice for the community. Each individual should take on a feminine mode 
of care for others. The best example of feminine (and coincidentally, female) sacrifice for the community occurs in "Cousin Marshall." The story begins with the death of Widow Mary Bridgeman, and the orphaning of her four children: Jane, Ned, Sally, and Ann. Mrs. Marshall, a woman with a household of her own, takes in two of her nieces (Sally, who is going blind, and Ann, the youngest). The Marshall family does not collect parish funds and manages by planning ahead and investing in a Benefit Club. Mrs. Marshall contrasts Mrs. Bell, the sister of the deceased; Mrs. Bell takes parish money even though her husband is employed (and earns a better wage than Mrs. Marshall's husband), and refuses to take any of the children, forcing Jane and Ned to the workhouse. Mrs. Marshall and her family re-ration their family income and food to care for Sally and Ann; by accepting them into their household "they must give up one dish of meat a week, and make some other reductions of the same kind" (Martineau 225). Mrs. Bell suggests that Mrs. Marshall ask for help from the parish, but Mrs. Marshall refuses: "'We will try what our own charity can do before we ask it from those who have less concern in the matter'” (Martineau 226). Mrs. Marshall isn't sacrificing for her immediate family; in fact, she is sacrificing her family for the Bridgeman children. Mrs. Marshall gives up what little comfort the family has to avoid placing all four children in the workhouse, leaving them to the public system. She takes in the two children that she knows her family's wages can manage to care for and adapts her budget to care for them and to relieve the community of the burden. This illustrates a feminine mode of living extended to the entire community because Mrs. Marshall refuses to allow all of the Bridgeman children to become responsibilities of parish funds and restructures her own family to care for the Bridgeman children. Martineau does not stop here in her alteration of masculine political theory, however. 
Martineau's narrativization illustrates political economy and immediately alters the genre; it moves control of the female body from the masculine genre of theory to the feminine genre of narrative fiction. Her stories "[taught] readers political economy by exhibiting its principles 'in their natural workings in selected passages of social life"' (Roberts 10). Not only did the stories alter genre, but they also moved political theory from public debate to the private familial space of the home, again from the masculine to the feminine. As readers we are welcomed into Ella's and Katie's homes in "Weal and Woe in Garveloch," in "Cousin Marshall" Mrs. Marshall urges us to see the truths of poverty in her home and in the homes of her neighbors, and finally in "Sowers not Reapers" Mrs. Margaret Kay and her sister-in-law Mary show us what female sacrifice, care, and love look like in their impoverished homes. It is often middle class, male characters who discuss political theories and play the role of population "theorists" in the narratives and are capable primarily of theorization instead of application. In "Weal and Woe" it is the magistrate, Mr. Mackenzie; in "Manchester Strike," one could easily mistake Mr. Wentworth, a man who was "rich as a young man, had failed through unavoidable misfortunes, and had worked his way up again to a competence, after having paid every shilling he owned" for Malthus (Martineau 156-157); in "Cousin Marshall” the educated, handsome surgeon, Mr. Burke is the center of political theory; and finally in "Sowers not Reapers" it is Mr. Ferguson, the landlord, and Chatham, a hard-working, single man, who readily engage the jargon of political theory. While these men spout their theories, working class men and women actually embody population theory: Ella and Katie in "Weal and Woe," William Allen in "Manchester Strike," Ned and the Marshall family in "Cousin Marshall," and Mary in "Sowers not Reapers." Each of the characters run their household according to the laws of population theory (a la Malthus, Ricardo, and Smith) before speaking to the middle class "theorists"; upon speaking to 
the "theorists" they realize that population control is something they've been practicing all along. The characters who display what living according to population theory means aren't just women, but men as well. Each of these characters values work, community responsibility, and individual sacrifice for the betterment of the community, but perhaps most importantly none of these characters take advantage of the public system for poverty relief that Martineau so despisesdoing so would contradict their support of the community, and instead would focus on individual care. Martineau crafts responsible male characters that care for their families by returning home with their earnings rather than squandering them away at the alehouse, like many impoverished male characters. ${ }^{123}$

Martineau's Illustrations brought characters to life who demonstrated poverty in Britain under the reign of the Corn Laws, Combination Acts, the Speenhamland System, and Elizabethan poor-laws. Population theory developed because of anxiety about the expansion of the human race and the resulting lack of resources. The British "government understood that they were not dealing simply with subjects, or even with a 'people,' but with a 'population,' with its specific phenomena and its peculiar variables," specifically the poor population (History of Sexuality 25). The poor population was believed to threaten those who held property, and destabilized the middle and upper classes as they grew in number and dependence. This belief was supported by the appearance of an increasing number of impoverished people dependent on parish funds. ${ }^{124}$ Popular belief sustained the idea that the poor of Britain threatened the entire

${ }^{123} \mathrm{Mr}$. O'Rory in "Weal and Woe" and Clack in "Manchester Strike." Sobriety alone does not make for a "good man" in Martineau's narratives, but in the context of the stories, men who avoid drowning their sorrows of poverty in a pint of gin are regularly used as examples of responsibility.

${ }^{124}$ Cobbett points out that if parish support sharply increased the poor population then this phenomenon would have started when poor relief started, which is not the case. Cobbett believes that the increase in people receiving parish support was not actually an increase in number but 
nation because they continued to reproduce even though they were unable to provide for their offspring, which would result in a continuing increase in the poor rates and a continuing decrease in the wealth of the upper and middle classes. Population theorists tried to lessen the threat of the poor through what Foucault identifies as "a socialization of procreative behavior," which is "achieved through the 'responsibilization' of couples with regard to the social body as a whole" (History of Sexuality 104-105). They did so by theorizing how one might stop the poor population from increasing - the problem was not the wealthy population (after all, they were able to provide for their children). Martineau's characters were "imagined as free agents because they controlled their [physical,] sexual bodies, Martineau's citizens were to take responsibility for themselves reproductively and, by extension, economically" (Cody 142). Characters such as Robert and Katie take care of themselves sexually and economically, and therefore care for the entire community. In this way Martineau is like Malthus and Godwin; her Illustrations support "a socialization of procreative behavior" by writing a narrative that supports characters that do not receive parish funds and by degrading characters who do. ${ }^{125}$

\section{$\underline{\text { Limits of Martineau }}$}

Malthus and Godwin argue for a society entrenched in vice and misery or rooted solely in reason, respectively. Martineau frees individuals from vice and misery by allowing them to obtain individual happiness. In fact, she argues that vice and misery only create more vice and

rather an increase based on the location of people. The surge of individuals from the rural areas of Britain to the cities increased the need for parish funds in certain areas, which increased the poor rates for middle and upper-class people in that region.

${ }^{125}$ For example, Martineau frames each individual who does not receive parish funds (characters like Katie and the Marshalls) as heroic, while simultaneously framing characters who do receive parish funds as dangerous to the growth of society (Mrs. Bell). She does so because her underlying argument is that parish support is bad and only promotes poverty and laziness in Britain. 
misery. The parish rates exemplify this for Martineau; for each individual who begins to accept parish funds, parish rates increase and eventually those who are rate payers become rate receivers. ${ }^{126}$

I've shown how Martineau forges a specific domain for women in the population debates by revealing that British women, as illustrated by Martineau's characters, naturally practice population control. I've also shown how Martineau relieves women from sole responsibility for caring for the British social body by creating responsible male characters in her tales. But, Martineau's acknowledgment of women's enactment of population control is overshadowed by her investment in population theories that disempowered the poor. Population theories that disempowered the poor often had greater effect on women. As Cody explains, "Because many Liberals accused women in particular of sexual immorality that was believed to cause demographic growth, engineers of the new Poor Law [of 1834] argued that women should bear the financial responsibilities for out-of-wedlock pregnancies...to discourage them from imprudent premarital sexual relations" (132). ${ }^{127}$ Cody's detailing of the logic behind the Poor Law of 1834 aligns with Malthus' and Martineau's notion that misery checks population. Additionally, "under the new legislation, single mothers would no longer be able to expect the parish to extract money from the father...If a woman could not support her child, she would have to enter a workhouse" (Cody 132). Poor women were left with the burden of family care, unlike men who sometimes had the ability to relinquish their family burdens and care only for

\footnotetext{
${ }^{126}$ See the story of the Dale family in "Cousin Marshall," pp. 281- 289.

${ }^{127}$ Cody also explains that the Poor Law of 1834 was enacted by a Whig government that the working class had been disappointed in since the Great Reform Bill of 1832 (133). For more on the intersections of policy and social class see Cody.
} 
themselves. Martineau's decision to support the upper-class master narrative that endorsed the ultimate demise of public funds left women without the ability to care for their families.

As the British government enacted laws that "conjunction[ed] a whole set of practicesfrom the moment they bec[a]me coordinated with a regime of truth — [the government] was able to make what does not exist, nonetheless become something, something however that continues not to exist" (Birth of Biopolitics 19). That is, simultaneously Britain feared that an increased population might make sources scarce and created laws that made resources scarce, and then was able to place all responsibility for the declining state of the nation on an impoverished, captive population - captive because they were a class of people who did not exist (the ignored, the degraded, and the refuse of society), yet were responsible for many of Britain's troubles. The impoverished population wasn't worth considering when Parliament passed laws that made it more difficult for the poor to obtain food, to maintain safe working conditions and so on, but the impoverished had to exist; they had to become the scapegoats of society, the symptom of behavior ruled by error, in order for population theorists to warn about the dangers of overpopulation. Parliament created laws that limited the power of individual bodies to care for themselves (whether because food prices were increased or because they were not able to assemble in labor unions to fight for better wages and conditions ${ }^{128}$ ); they become the problem of human capital, "which links generations together," because "their problem is the formation and transmission of human capital" (Birth of Biopolitics 244). While facets of Martineau's narratives empower women by making all of society responsible for the care of the entire British social body, and by creating female characters that embody the theory of population naturally, Martineau ultimately abandons impoverished women by narrating in support of laws that

128 Though, Martineau opposed the regulation of unions. 
disempower them and treat them as a mistake in need of correction. Her narratives are gender queer, but fail to queer economic class in any way. For example, in Chapter VIII of "Cousin Marshall", titled "What is Charity?," Mr. Burke tells Mr. Effingham that the best plan to reduce early marriage and reproduction among the poor is to abolish the poor rate. Mr. Burke believes that "the best plan" is "to enact that no child born from any marriage taking place within a year from the date of the law, and no illegitimate child born within two years from the same date, shall ever be entitled to parish assistance" (Martineau 287). Martineau's inclusion of this philosophy, which is actually Malthusian, is evidence of her support of halting parish assistance. The halting of parish assistance increased poverty and therefore increased misery, serving as a supposed check on population. So while Martineau queers the genre of population theory by inserting feminine modes of care and empowered female characters into masculine discourse, her reason for doing ultimately supports a class-based ideology about poor-relief. Martineau maintains the status-quo by placing the female body "in organic communication with the social body $[\ldots]$, the family space $[\ldots]$, and the life of children" to support a patriarchal institution that sought to take away the financial support system upon which many women depended (History of Sexuality 104). A final reading of Martineau reveals that while her population theory integrates every individual in British society into the necessary sacrifices for the betterment of the larger social body, she ultimately argues that the poor (women) should sacrifice the most.

Despite Martineau's attempts to empower women by making them the agents of population control, she falls into a familiar trap. She is, as $21^{\text {st }}$-century feminists would say, a White Feminist; even though she has women's interests in mind, she is only concerned about progressing the plight of (white) middle- and upper-class women. She makes poor women the sole individuals upon which the troubles of England rest and frames them as incapable of 
checking their desires, supporting themselves and/or their children, and portrays them as lacking any of the self-reflective behaviors that she attributes to middle- and upper-class women. Though Martineau's narrativization of population theory marks a moment of gender deviance-like Wollstonecraft, Plumptre, and Opie — she is sure to reinforce class stereotypes and hierarchy. In doing so, Martineau ultimately fails to queer femininity or produce an errant representation of women. Her insistence upon class divisions aligns her firmly with normative culture. 


\section{Epilogue}

"Manternity": Gender Errancy, State Power, and Discourse

In the preceding chapters, I analyzed texts from the late-eighteenth and early-nineteenth century to destabilize "collective[ly] misrecogn[ized]" understandings of identity as truth/error and "either/or" (Bourdieu 81). I deployed error as a provisional and tactical strategy to argue that identities are, at times simultaneously, errant and erring. My use of error worked to destabilize notions of identity as organized and recognizable and demonstrate identity's potential for queer errancy. In my consideration of Godwin's portrayal of Wollstonecraft, Plumptre's version of the coquette, Opie's imagining of an ugly, queerly seeing heroine, and Martineau's gender queerness and class normativity, I focused on the productivity of error as a lens for analyzing identity precisely because error, like queerness, is polysemous and versatile. I utilize queer errancy as a critical tool for deconstructing the coherency of identity. While the majority of this project focuses on seeking out the effects of queer errancy in the Romantic period, I also seek to demonstrate the usefulness of this critical approach beyond these historical boundaries by applying pressure to the discourse of gender and sexuality in the $21^{\text {st }}$-century.

In April 2008, Thomas Beatie announced his pregnancy. ${ }^{129}$ Public responses included outrage and disgust; one commenter said, "II would like to say that this is not a miracle but a hoax. It is the end of the world manifesting just like it says in the [B]ible"” (Beatie 286). ${ }^{130}$ Others offered support: “"Mr. Beatie sounds like one of the least confused people on the planet.

129 The news was released via Beatie's personal statement on Advocate.com; you can view the original story here: http://www.advocate.com/Society/Commentary/Labor_of_Love/. Many believed that the story was an elaborate April Fool's joke since the news appeared in late March, around April $1^{\text {st }}$.

${ }^{130}$ In text citations for Labor of Love: The Story of One Man's Extraordinary Pregnancy are cited as Beatie; in-text citations for Beatie's article in The Advocate are cited as "Labor of Love." I've made this particular distinction since the author and text titles are the same. 
He and his wife wanted to have a baby, and they used the body parts available to them as a couple to create a new life—nothing 'confused' about that! I'll reserve 'confusion' for those minds that can't keep up with modern times"' (Beatie 287). Beatie's decision to carry a child after legally (i.e. recognized by the state) transitioning from woman to man endangers the perceived stability of sex, gender, pregnancy and parental roles. ${ }^{131}$ Beatie does not fit the hegemonic definition of man or father because he was not born with a penis, male testosterone levels, (fertile) sperm, and he carried his child in his womb. Because of his identity as trans, pregnant, and father, he visibly and rhetorically alters the fixity of sex, gender, pregnancy, and parenthood. ${ }^{132}$ His narration of his experience as a pregnant man in Labor of Love: The Story of One Man's Extraordinary Pregnancy offers an opportunity to apply pressure to queer theory's ability to account for individuals who live outside of and between the binaries. In many discussions-including discussions from the queer community, Beatie is rhetorically framed as an "error," a deviation from what is "right" or "correct," a mistake. ${ }^{133}$

To discuss concepts of error in relation to Beatie, I look to Michel Foucault's 1978-79 lectures at the Collège dè France. "The Birth of Biopolitics" lectures address liberalism and

\footnotetext{
${ }^{131}$ As J. Jack Halberstam notes in Gaga Feminism, Beatie was not the first trans man to carry a child, despite his claims otherwise on the Oprah show.

${ }^{132}$ A simple Google search using the terms "Thomas Beatie or pregnant man" reveals the horrifying response to trans individuals in general and Beatie in particular. Reading comments that users have posted to articles or blogs that discuss or even reference Beatie display the acceptance of transphobia in our culture; many people have commented that Beatie's child should die, or is the spawn of Satan.

${ }^{133}$ Halberstam discusses the public reaction to Thomas Beatie in "Gaga Genders"; while I am not sure that I have "stumbled across the very symbol [I] needed to prove the end of everything or the beginning of something else," I am sure that Thomas Beatie's story, as he told it, reveals the extent to which narratives of fixity comfort us (Halberstam 33).. The idea of errancy, of "wandering," is scary; it means that change is constantly on the horizon, that we can be both "feminine" and "masculine" simultaneously without ever undergoing an alteration in how we understand our "selves," and that self-development and definition is never quite complete.
} 
political economy to explore ways that particular forms of governmentality regulate citizens' bodies and create regimes of truth that dictate true and false, genuine and erroneous. ${ }^{134}$ Foucault seeks to uncover the ways in which "that which does not exist becomes something." Foucault resists "showing how it was possible for an error to be constructed—or how an illusion could be born" in favor of focus on the ways that "a particular regime of truth, and therefore not an error, makes something that does not exist able to become something" (Birth of Biopolitics 19). Error is created via cultural practices and beliefs that validate established norms and oppose deviation from those norms. Analyzing Beatie's experience using this Foucauldian methodology shows how a set of accepted cultural beliefs, which popular opinion considers truths, are not truths at all. Beatie's experience, as he narrates it in his autobiography A Labor of Love, reveals the regime of truth at work in the creation of cultural truths, particularly homonormativity. ${ }^{135}$ Beatie's supposed errancy reveals an instance when "that which does not exist," a pregnant man, “becomes something.” Thomas Beatie's identity as a pregnant man triggers numerous attempts to deconstruct the supposed cultural truths of sex, gender, pregnancy, and parenthood; his deconstruction of these categories leads to mainstream framing of his identity as erroneous. Additionally, the prevailing notion of error predetermines error even in the gay, lesbian, bisexual, trans, and queer communities' debates about Beatie, supporting a homonormative community identity and casting Beatie as an outsider harmful to homonormative goals.

\section{$\underline{\text { (De)Constructing Error }}$}

\footnotetext{
${ }^{134}$ Foucault's discussion of liberalism and political economy is rooted in the population debates throughout eighteenth and nineteenth century Britain. He goes on to discuss German neoliberalism, American neo-liberalism and the concept of "homoeconomicus."

135 I've attempted, not always successfully, to preserve Beatie's trans voice in this analysis as it is problematic to revise Beatie's text to suit my needs for analysis without acknowledging the power dynamics and cultural processes at work in such a revision; that is, my ability as an academic to "remove" his voice from the narrative to suit the needs of my analysis.
} 
Beatie's experience isn't illusionary or constructed since it is defined by a set of cultural beliefs and practices that are coded and upheld as inherent truths. ${ }^{136}$ These truths define cultural perception(s) and the power-knowledge structure at work within them. Power-knowledge refers to the reciprocal relationships between power and knowledge; "power and knowledge directly imply one another; there is no power relation without the correlative constitution of a field of knowledge, nor any knowledge that does not presuppose and constitute at the same time power relations" (Discipline and Punish 27). Foucault explains that "it is not the activity of the subject of knowledge that produces a corpus of knowledge, useful or resistant to power, but powerknowledge, processes and struggles that traverse it and of which it is made up, that determines the forms and possible domains of knowledge" (Discipline and Punish 27-8). Beatie affects the relationships between power and knowledge because he arrived at his sex through bodymorphing surgeries and technologies but retained his female reproductive organs. Furthermore, he identifies as a man during pregnancy — a bodily state that is perceived as limited to women only. He challenges the authority of power-knowledge's domains of knowledge and begins to create new knowledges. He reveals the power-knowledge relationships in the construction of sex, gender, pregnancy, and parenthood as well as the failures of cultural truths because of an "error" that fractures the inherency of truth and absolutism. Beatie's transition from woman to man offers the first example of Beatie's life as erroneous and reveals the first fracture in the regime of truth that defines error.

${ }^{136}$ Arguing for identity as social construction is helpful to expand discourse, political goals, and so on but is not particularly helpful for a man who is told that he "is just a bearded woman who should be thrown in a crazy bin, sterilized, and lobotomized! We [society] need to have laws for basket cases like this"' (Beatie 285). 
Until Beatie's transition in 2002, his name was Tracy. Beatie's transition, and in particular the transitionary phrase of his life, makes visible the failure of language for individuals who exist between and/or beyond the traditional binaries. ${ }^{137}$ Hawaii, Beatie's birth state and home in 2002, has only two requirements for legal recognition of sex confirmation: ${ }^{138}$

First, they must produce a letter from a therapist or medical doctor attesting that they're living full-time as the gender they intend to switch to, and that they're undergoing treatment...The second requirement is that a person undergo some sort of irrevocable surgery to alter their gender; in [his] case, that would be the surgical removal of [his] breasts. (Beatie 153-54)

The state inherently connects sex and gender; it is given the power to and is responsible for recognizing someone's sex/gender and creates a system that mandates the requirements for altering sex/gender from that recorded on one's birth certificate. State power is expected to

${ }^{137}$ Other identity groups traverse this gray area as well; groups such as bisexual peoples, interracial peoples, and somewhat-disabled peoples reveal the failures of binary systems that demand we check one box or another when asked to testify our identities. For a discussion centering around issues of legality that individuals face please see Ruth Colker's Hybrid: Bisexuals, Multiracials, and Other Misfits under American Law (New York: New York UP, 1996).

${ }^{138}$ The trans community maintains a lively debate about which term is appropriate for discussing the process that claims an individual's gender and/or sex, whether it is recognized by the state or not. Terms in the debate include "sex reassignment," "gender assignment," "sex confirmation," "gender confirmation," "genital reassignment" and "sex and/or gender congruence surgery." Please see Jason Cromwell's text titled Transmen and FTMs: Identities, Bodies, Genders, and Sexualities, particularly "Words Spoken about Transsexuals," pp. 20- 21 for further understanding (Urbana: Univ. of Illinois Press, 1999). Based on my reading of Beatie's autobiography, I've chosen the term "gender confirmation" in this instance because it best explicates his experience, I believe. In his biography he says "My gender is constant-I am a male. Even when I was a female, I identified with the male gender" this terminology along with other indicators in the text highlights Beatie's experience as constantly male, as his surgery as confirming a part of his existence, rather matching his body with his gender (Beatie 308). Beatie's language doesn't reflect a theoretical understanding of gender and sex, let alone a queer theoretical understanding. For Beatie, these two things are highly connected. This understanding aligns with that of the state wherein sex and gender and always conflated. 
regulate who is allowed to jump the binary since there is no way to escape the binary in the state system. No matter the paperwork, trans identity is considered "erroneous" by the state; even if all of the state mandated "proof" is provided, individuals are forced to occupy either side of the gender binary. ${ }^{139}$ Intersubjectivity is impossible. Government documents do not alter cultural construction of fixed gender binaries; deviation demands reconsideration of "absolute truths" about human existence - that female-bodied people always have a sense of femininity, that fathers always have fertile sperm and mothers always have a uterus which is capable of bearing children. The government's response to trans individuals is to police the process of sex/gender alteration, a system created to avoid allowing errors to enter the system. One can choose "an erroneous life" in the eyes of the state, but even that has to be state approved.

The goal of state power is to prevent people from roaming or wandering around the sex/gender binaries and to fix them in one place or another. In his narrative, Beatie emphasizes the need for a state-regulated system for legally recognizing transition to prevent people from making a "rash or impulsive" decision about legally changing their gender (Beatie 154). The goal of state-regulated systems that allow for gender confirmation is to encourage individuals to "blend into the 'normal' world around them, to avoid sensationalism, and to have private relationships with others away from public scrutiny" (Rubin 2). The problem with a system that encourages, perhaps even forces one to "blend into the "normal," whether related to trans experience or not, is that the system and the "individual rely upon historically variable categories

${ }^{139}$ One example of trans identity as erroneous, even with the required "proof" is thoughtfully discussed in Paisley Currah's article "Expecting Bodies: The Pregnant Man and Transgender Exclusion from the Employment Non-Discrimination Act" (WSQ: Women's Studies Quarterly 36:3\&4 [Fall/Winter 2008]: 330-336). Currah explains that "while so many people now know that a man can get pregnant, relatively few people outside queer communities are aware of the ENDA debacle." (Currah 331). Currah goes on to explain the implications of trans identity and the ENDA, evidence of state power and the regulation of trans bodies and identities. 
in their search for intersubjective recognition. All experiences must be situated within the flow of history" (Rubin 12). "Intersubjective" directs us back to the regime of truth that mandates singular identity categories; fixed practices and categories, such as gender "show how the set of practices and a regime of truth...marks out in reality that which does not exist and legitimately submits it to the division between true and false" (Birth of Biopolitics 19). Intersubjectivities straddle different sets of practices and the division between true and false; they must be relegated to the realm of error in order for the hegemony to sustain power and for information about persons, their bodies, and their identities to be readable. Beatie narrates his personal history and gender experiences throughout his autobiography, often pointing toward an intersubjective identity.

Beatie's overarching narration in Labor of Love paints his gender experiences as though he always had an interior sense of masculinity even if he did not always express that sense outwardly; he announces, "My gender is constant_-I am a male" (Beatie 308). Here Beatie references his "gender" using the language of the body: "male." Despite Beatie's proclamation, his narration of his life indicates that his gender identity is actually rather winding and flexible. He explains that as a (girl-identifying) child "part of [him] wanted to be more like [his] feminine mother, while [he] preferred to act like [his] masculine father. [He] wanted to be beautiful like her, but became comfortable with a body that looked like his" (Beatie 80). He articulates a desire to be both masculine and feminine - to embody masculinity but to perform femininity. His decision to transition was supported by Nancy, now his wife, who empowered and supported him; he recalls: "For years I had been drifting away from my birth gender — female — and toward an identity that felt more right. I cut my hair short and had moved from my tweener phase straight into wearing exclusively men's clothes. I began working out and building up my body, 
and I felt more masculine than feminine" (Beatie 153). In both instances, Beatie points toward an "intersubjective" identity. As a child, Beatie felt a sense of femininity and masculinity that he derived from observing his parents. As a transitioning adult, he feels that he is shedding his femininity in favor of masculinity, but what underlies this statement is a remaining sense of femininity, hence his need to rid of it. ${ }^{140}$

Beatie could not occupy an intersubjective space that allowed him to identify as both masculine and feminine, or allowed him to identify as a man while still embodying both feminine and masculine experiences - the binary system forces him, and all of us, to choose one or the other. Beatie believes that:

genderwise, our society is dimorphic - it insists on two, and only two, categories. There are men and there are women, and that's all there is. If you are a woman who prefers to live as a man, you simply don't fit into this unvarying gender paradigm. You aren't allowed to be on the fence about your gender - it is strictly an either/or proposition. Thus, society forces you to choose one or the other, even if you don't feel the need to do so.

(Beatie 249)

Cultural myths frame Beatie as an "error" because his gender experiences do not confirm the common American gender narrative which insists that one must be either male/masculine or female/feminine, voice one's experiences as solely that of a man or a woman, and further emphasizes the need for sex and gender to be congruent. Conversely, Beatie's narrative refuses ideas of gender as inherent based on one's body (despite his use of "male" and "female" to

${ }^{140}$ The focus of my commentary isn't to dislodge Beatie's transition or even to doubt his identity. In fact, I think a line of argument that attempts to do so not only exemplifies transphobia in our culture but also insists that individuals can't excavate their identities, and instead must stick to the cultural script that is always already written for us, an insistence that is wholly limiting, essentialist, and ridiculous. 
discuss gender), and reveals our culture's inability to see gender identity as fluid and individual. Beatie restructures power-knowledge; he helps to re-"determine the forms and possible domains of knowledge" by publicly fracturing gender's fixity (Discipline and Punish 27-8). Beatie forces us to question what being a gender means in a society that leaves us no room to define ourselves without fear of ostracism, violence, and rejection if our gender performance fail to align primarily with a singular, readable gender. Beatie's pregnancy and role as a father offer the second example of Beatie's life being perceived as erroneous and a second fracture in the regime of truth that defines error.

When Beatie's pregnancy story reached mainstream news, the public almost instantly voiced concerns about the legality of Beatie, his family, and his child; the public called upon state power and the state's ability to regulate bodies and lives. If the state is the body of power which regulates and dictates gender and sex, if sex and gender are "thing[s] one administered," then "it was in the nature of a public potential; it called for management procedures; it had to be taken charge of by analytical discourses" (History of Sexuality 25). One online discussion board commenter said, "“There is no way this child will be able to lead a normal life. Oregon is a strange state, but they cannot seriously allow this to happen. It is unethical, immoral, and disturbing"” (Christensen); another commenter supported the Beatie family, "'The people of Oregon are proud of Thomas and Nancy. They have done nothing but create another beautiful, happy, and loving family on earth. To me, it's pretty simple: love knows no bounds and does not judge"” (Beatie 288). In both of the comments, individuals gesture to Oregon; implicit in their statements is the idea that the state has some ability to control what goes on within it, what its people are and are not allowed to do, and who is and who is not allowed to reproduce. State power is an inherent part of American life (perhaps it even defines American life); the clearest 
example is our reliance on government for the penal code and its upholding. Many American citizens agree that the state's involvement in crime-definition and prevention, as well as countless other issues, is necessary to maintain order (which we might also term "freedom" or "democracy"). ${ }^{141}$ When someone fails to uphold order, we expect the state to get involved; we expect the state to police us. Beatie's decision to "go public" with his pregnancy led to some citizens demanding the state's immediate action because they viewed Beatie, his family, and his body as disturbing order; citizens framed Beatie's pregnancy as impossible and inappropriate. The state was largely unable to react because Hawaii's laws (as well as the laws of many other U.S. states) do not force individuals to give up their reproductive organs; ironically, laws which are meant to prevent "binary jumpers" (thankfully) encourage intersubjective lives and identities in this way, rather than forcing individuals to have both "top" and "bottom" surgeries. ${ }^{142}$ Beatie reveals "that possibility of error inherent in life," the possibility of perceived mismanagement and misadministration by the state. He defies popular conceptions of pregnancy and stretches the limited definitions of maternity and paternity, asking us to redefine the terms based on his experience.

When Beatie's gender was "officially recognized" as "male" by the state of Hawaii, he gained the right to marry his wife, Nancy, and to sign a marriage certificate as her husband, as a man. His decision to retain his female reproductive organs had no effect on his transition to a man in his eyes or in the eyes of the state; it neither voids nor reduces the validity of their

\footnotetext{
${ }^{141}$ Such issues include national spending, education services, international affairs, health organizations, and so on.

142 "Top surgery" refers to the removal or addition of breasts; "bottom surgery" refers to the alteration of the penis or vagina. Jason Cromwell's Transmen and FTMs: Identities, Bodies, Genders, and Sexualities (Urbana: Univ. of Illinois Press, 1999) explores the troubles of terminology for FTM and transmen. See pages 23-24 for a thoughtful discussion of the limiting terms such as "pre-op" and "post-op."
} 
marriage, his legally recognized sex, or his experience as a man. Beatie is a man with a womb capable of bearing children, and therefore also a man with the capability to deconstruct the regime of truth surrounding child-bearing. Beatie's decision to carry his and Nancy's baby was not an easy one. Nancy, after having two children in a previous marriage and experiencing medical problems, was forced to have a hysterectomy many years earlier. They considered a surrogate, but using a surrogate meant "turning over the responsibility for carrying [his] child to someone else, a stranger - and hoping this person would be as diligent about taking prenatal vitamins and protecting the baby as [he] knew [he] would be. Instead, [he] chose to be [his] own surrogate - to use [his] body... and not someone else's" (Beatie 305). Even after deciding to carry their child, Nancy and Beatie faced the criticism and denial of the medical community; one doctor told them that "the ethics committee met... and...came to the consensus that this situation is just too different. It's never been done before. We have nothing to refer to. There are just too many outstanding questions and concerns"” (Beatie 205). Some of these questions and concerns focused on their child: what would they tell the child about his/her birth, would Beatie be the mother or would he "insist" on being the father? Beatie neither considered himself a mother, nor did he believe that the act of carrying a child in his womb was a maternal one. The ethics committee was concerned with the rhetoric surrounding pregnancy and parenthood, with the roles shaped by the rhetoric in particular, while Beatie was concerned with the health of Nancy and his child.

The exclusivity of child-bearing to ciswomen supports the gender binary by fixing essential notions of femininity (nurturing, passive, emotion-driven, family-oriented) to the female body; cultural notions of female-ness and femininity as biologically rooted are part of the regime of truth. Structures of (medically-based) power/knowledge reinforce the narrative that 
individuals who are men can't carry and birth children, that the female womb, in a woman's body, holds exclusive rights over the birthing of the next generation, and that the pairing of maternity, female-ness, and womanhood are biological truths that simply can't be fractured. ${ }^{143}$ "The opposition" of male and female and man and woman, "the values that are attributed to one or the other," including the ability to birth children, "the power effects that" American society and medical institutions "link to that division—all this may be nothing but the most belated response to that possibility of error inherent in life" (Life: Experience and Science 15). Facing the "possibility of error inherent in life" often invokes hegemonic fear and hatred, rather than forcing critical reflection about how error is constructed and possibly challenged.

Beatie's gender and parental identities remained fixed throughout his pregnancy: he was a father and a husband. His identity as a man allowed him to hold claim to fatherhood even as the medical community questioned, and sometimes insisted on, his status as female and mother. Beatie's decision to fight for the title of "father" affects contemporary definitions of motherhood and fatherhood by dislodging the act of child birth from female-ness. Beatie's article in The Advocate articulates his experience as a pregnant man:

Despite the fact that my belly is growing with a new life inside me, I am stable and confident being the man that I am. In a technical sense I see myself as my own surrogate, though my gender identity as male is constant. To Nancy, I am her husband carrying our

\footnotetext{
143 Josephine Johnston ("Field Notes." Hastings Center Report 38.3 (May-June 2008): c2), a bioethicist who was consulted for several articles concerning Beatie and his pregnancy, addresses how we might discuss Beatie's pregnancy without simply asking, "Is this bad/good?" and "Can we really call this male-pregnancy?" in her "Field Notes" for the Hastings Center Report (38.3 [May-June 2008]: c2). Instead, she suggests that we consider the fact that "difference is damaging only because we insist on it" (c2).
} 
child -- I am so lucky to have such a loving, supportive wife. I will be my daughter's father, and Nancy will be her mother. (Labor of Love)

Beatie says that "[he] see[s] [him]self as [his] own surrogate"; there is a separation between him and his womb. He is able to keep his identity separate from child-bearing; his "self" is separate from his “acts." Beatie's concept of identity separates his acts from his identity, similar to Foucault's theorization of homosexuality's emergence as an identity. ${ }^{144}$ For Beatie, pregnancy is a temporary state, not a signifier of his identity, similar to Foucault's explanation of the sodomite as act-based rather than identity-based. Beatie rearticulates this separation of momentary act and constant identity while narrating his labor: "'Your uterus is really tired,' the midwife tells me, and I think, 'That makes two of us'" (Beatie 3). Again, his uterus is separate from himself, a momentary act or space. Beatie’s return to separating identities and acts confuses most individuals involved in his pregnancy, and many refuse to even acknowledge such a separation.

Individuals in the medical community assumed that because Beatie was carrying a child, he would experience a change, or lapse, in his gender identity: "Dr. M. had other reservations as well. Would I, as a male, be able to get insurance that would cover my pregnancy? How would the birth certificate read — would it say that 'Thomas' was the mother?" (Beatie 199). Beatie assured them, "I was a man before the pregnancy, and I would be a man after the birth, which made me the baby's father" (Beatie 252). The concern about an important state-document, the birth certificate, was constant. It reiterates fears about "error" entering into government without notice. The birth certificate offers Beatie another way to validate his life as a man through government documentation. For individuals who see identity as fixed and biological, the chance that an individual with a uterus, not just capable of producing and bearing children but actually

${ }^{144}$ See Foucault, The History of Sexuality, 42-43. 
doing so, might sign a birth certificate as a man is threatening and troublesome: "Everyone we talked to was worried about the birth certificate. Who would be the father, and who would be the mother? We knew what we wanted-I wanted to be listed as the father, even though I was giving birth. I did not at all feel like what I was doing was maternal” (Beatie 252). But Beatie immediately points out the fractures in state regulated definitions of motherhood and fatherhood in relation to birth certificates: "I am our baby's father, and Nancy is her mother. It's that simple...I was the one who gave birth to our child, and existing definitions equate 'birth parent' with 'mother'...By those same definitions, all mothers are female_ - and I am legally and unequivocally male; therefore, I can't be a mother'(Beatie 310). While one definition of motherhood is linked to the act of birth, the other definition is linked to one's legal gender identity; so, if Beatie signed the birth certificate as a mother, he would still fracture the regime of truth that dictates definitions of motherhood and fatherhood. The doubts of the medical community were not, however, limited to concerns about titles of mother and father, but extended to Beatie's individual gender experiences.

Other questions from the medical community focused on Beatie himself; doctors were unable to understand how Beatie would carry a child without identifying as female; they worried that he was not "psychologically capable of going through this difficult process" (Beatie 199). Beatie was clear and confident: "Through the pregnancy I would still be a man, not least because that's what it says on my driver's license, social security card, birth certificate, and passport"; he wondered "how would [he], a legal male, [could] be listed as the mother" (Beatie 252). He relied on state documents to retain his legally-recognized gender within the questioning medical community. He used the power that states mobilize to regulate gender to subvert the biologybased medical system. One doctor had concerns whether his "staff [would] be comfortable 
working with [Beatie]" and suggested that Beatie shave his facial hair before returning for another appointment (Beatie 200). All of these concerns frame Beatie and his childbearing as a biological mistake and even as a moral or ethical wrong-doing in the eyes of the medical community. First, the medical community doubted his authenticity as male because of his desire to carry a child and because he is trans, but they also doubted the morality of his decision. Beatie illustrates how "the coupling of a set of practices and a regime of truth form an apparatus (dispositif) of knowledge-power that effectively marks out in reality that which does not exist and legitimately submits it to the division between true and false" (Birth of Biopolitics 19). A pregnant man can not exist in the medical imagination; he must become an individual whose psychological stability is questionable and whose identity must be returning to female to desire a child. The expectation is that Beatie is either/or rather than both/and. Beatie responded to these claims by explaining that "the desire to have a child is neither a male nor a female desire — it is a human one" (Beatie 197). He destabilizes the association of wanting a child with femaleness or femininity and, unfortunately, claims it as a universal part of human existence.

\section{Reinforcing Normativity}

Beatie's claims about the universal desire for children problematically reinforce a regime of truth which dictates the meaning of "family." Later in his autobiography he says that having a baby is "more than just the American dream. It is a fundamental imperative of families everywhere to procreate and bring children into this world" (Beatie 304; emphasis added). $\mathrm{He}$ and Nancy "both...wanted the same thing — a big house with a white picket fence and maybe a deck where [they] could snuggle under the stars, and a lawn [they] could mow and a chime outside and a bird feeder in the back. You know, the classic American dream" (Beatie 180, emphasis added). They decided to have children because they "were secure in [their] relationship 
as husband and wife, and now [they]'d be parents_-and have the classic nuclear family. The only difference would be that [Beatie] — the male and the father-would be the one getting pregnant and giving birth" (Beatie 197, emphasis added). Throughout my analysis of Beatie's experience as a pregnant man, I've pointed to all of the instances in which he has helped to reveal the regime of truth as an illusion, but here he reinforces it. As an individual who was once actively engaged in the lesbian-rights movement it is surprising that Beatie assumes the definition of family to be singular and stable. ${ }^{145}$ He doesn't acknowledge any alternative definition of family that doesn't include children, and he even supports a conservative definition of family that invokes images of husband and wife. He assumes that to be a family one must have children, a mother, and a father. Most troubling is the assumption that all people want children, that it is a "fundamental imperative."

Beatie implies that the decision to have children is supported because he is in a stable relationship and able to be a part of a classic nuclear family. There seem to be two possibilities for such an essentialist line of argument about family. The first possibility is that Beatie has transitioned so seamlessly to being a man that he has no doubt about his ability to assimilate as a father. Therefore, he sees himself and his family as "classic" (i.e. one man, one woman, 2.5 children) and believes that others will see them as "classic" too. This seems to be a reasonable belief system; he and Nancy moved to Oregon and the community there had no idea that Beatie was a trans individual. As Beatie explained in his article in The Advocate, "To our neighbors, my wife, Nancy, and I don't appear in the least unusual. To those in the quiet Oregon community where we live, we are viewed just as we are -- a happy couple deeply in love. Our desire to work

145 Thomas and Nancy were once well-known activists in Hawaii's lesbian community; for the details of their experiences see chapters "Love Story" (133-150) and "The Decision" (particularly pages 171-176). 
hard, buy our first home, and start a family was nothing out of the ordinary" ("Labor of Love"). Throughout most of his pregnancy, in fact until Beatie decided to write his letter to The Advocate, many individuals in his Oregon community did not realize he was pregnant. Beatie's identity as trans does not require him to break all of the rules, regardless of liberal public expectations to do so.

The second possibility for Beatie's essentialist argument is that Beatie is in complete denial about American progress regarding the definition of family. Individuals and organizations that fight to expand the narrow definition of family at work in America can only hope that one day a family such as Beatie's could be considered a "classic nuclear family"; this is not the current state of family-politics in America. "Purity of identity is essential to modern-day identity politics, wherein membership is only permitted after proof of a pure identity," and while we can debate what "pure identity" might be or if such a thing even exists, it is certainly the case that trans identities do not fall into Western conceptions of "pure identity," even if the individual has fully assimilated into his/her "new" gender (Bornstein 105). Beatie made the decision to go public with his pregnancy, and through public exposure and debate, he engaged a discourse about identity and family. Beatie's experience may help progressive groups, such as the queer community, open conversations that seek to redefine "family," but his essentialist statements about family prevent him from being a singular example of what new definitions of family might be. It seems, however, that Beatie isn't the only one halting progress.

\section{The Homonormative Regime}

The response by the lesbian, gay, bisexual, trans, and queer communities to Beatie's April 2008 article in The Advocate was immediate; some members of The Advocate's readership responded with support and praise for his visibility, while others worried how a pregnant man 
might stall gay and lesbian progress in politics (particularly, the battle for gay and lesbian marriage). Beatie's decision to announce his pregnancy in The Advocate allowed him to "control how [his and Nancy's] story was made public" and avoid appearing in tabloids and other media sources that wouldn't allow them to "[tell] people about the challenges [they] were facing" (Beatie 306). The Advocate revealed his story to a community that he felt he was a part of, and to a readership familiar with trans lives and experiences-- at least, in theory.

Two articles appeared on The Advocate's website after Beatie's original article was released. The first, "In Response to 'Labor of Love,"” was written by Robert Haaland; above the byline The Advocate clarified Haaland's role in the debate: “An FTM activist responds to the media coverage of Thomas Beatie after his article appeared in The Advocate." Haaland explains the range of responses to the Beatie story and ultimately concludes that "it is difficult but not impossible to talk about this story in thoughtful, nuanced, and sensitive ways." He continues: "I would argue that we must all come together as a community and do our best to do so. The entire LGBT community needs respect and support for our lives and our families. We need to be prepared to grant respect and support to others who are different from our own particular configuration." The second article, titled "Trans Positions," appeared in May 2008, nearly a month into the media frenzy. Jen Christensen outlines several positions the trans community has taken on Beatie, including “[concern] specifically for Beatie's family" in which "transgender activist Jamison Green...says he's thrilled Beatie's pregnancy is healthy and that he knows other transgender people who have had children, but none have been so vocal about it" (Christensen). Green wonders if the public attention will hurt Beatie and his family, and Christensen concludes that the media attention has already done so and goes on to consider "that this story has a high 'ick' factor for the general population." She discusses worries about mainstream responses to 
Beatie's life and sudden trans visibility. Christensen concludes that though there may be some concerns about the effects of the media, "if the audience at the Oprah show is any indication, perhaps there is hope." Beatie appeared on the Oprah show to discuss his pregnancy, and "after hearing Beatie's story, things quickly changed"; the audience seemed supportive (Christensen). The Advocate published stories in support of Beatie, but the public discussion boards reveal a different response. It is important to consider who might author comments on The Advocate's online discussion boards: The Advocate is a U.S. magazine whose readership consists primarily of gays, lesbians, and members of the queer communities. Many of the comments on the discussion board reveal a homonormative concern about public perception of the gay and lesbian community and Beatie's potential to harm homonormative political agendas. ${ }^{146}$

Homonormativity attempts to resemble heterosexuality by focusing on long-term, monogamous relationships, identity stability, a desire for children and familial relations, and by minimizing a diverse community in favor of a heterosexual aesthetic. This often means leaving butches, bois, trans individuals, and others who don't maintain the cultural script that streamlines sex and gender (including individuals like Beatie) on the periphery. The image of community stability is essential in order for homonormativity to be a successful political tool. According to Lisa Duggan, homonormativity "does not contest dominant heteronormative assumptions and institutions, but upholds and sustains them, while promising the possibility of a demobilized gay constituency and a privatized, depoliticized gay culture anchored in domesticity and consumption" (Duggan 50). Homonormativity, as Duggan's definition clearly points out, works

\footnotetext{
146 There are other comments that support Beatie and his family; my analysis of the homonormative argument isn't meant to void the support and care that some members of the community offered. Instead, my analysis seeks to highlight a particular form of homonormative response to Beatie, and the dangers that homonormative response might reveal.
} 
to mimic heterosexuality, but its continual, inevitable failure to do so results in homonormativity's "joking inauthenticity” (Roof 5). Homonormativity must constantly adapt to its failures, attempting to "mend and mask its gaps" to perform an acceptable heterosexual-based replication (Roof 5). As a result, there is constant homonormative concern about individuals who reveal homonormativity as fraudulent, vigilant surveillance of the LGBTQ community by the homonormative regime, and immediate disavowal of individuals who fail to meet the definitions and needs of the homonormative political agenda. This practice is blatant on The Advocate's discussion boards.

The homonormative community automatically adopts the prevailing notion of error in their community, rather than questioning how concepts of error are formed in the first place, a political strategy that would be significantly more fruitful for the entire LGBTQ community. The homonormative response accepts Beatie as erroneous and attempts to displace him from the community. Tom, who positions himself as a gay man, questions Beatie's trans identity: "It just [adds] the 'freak' fuel to the fire. While I am trying to show my life as just as normal as my neighbors['s,] along comes someone attached to the [GLBTQ] movement who takes it away. Heck it takes away from the tran[s] rights movement as well...I think it is appalling, and even degrading to call this person transgendered [sic]" (Tom). Tom's comment gestures back to concerns articulated by Christense: Beatie's "story has a high "ick" factor for the general population." Such concerns and comments highlight a homonormative political approach that focuses on pacifying hegemonic worries about the "abnormal" LGBTQ community, rather than one that asks the hegemony to see the diversity of our community. One commenter, Novelli, to an article on The Advocate's website said, "Changing external features does not change the gender one was born. Beatie was born a lesbian woman...How can Beatie have it both ways: to 
be male enough to marry a woman yet female enough to give birth?" (Novelli). Novelli seems to believe in an absolute sense of gender and sexuality at birth and while this is extremely problematic, his comment speaks to public questions about how an individual can legally alter his/her gender and reap the benefits of that change, and then return to the biological functions of his/her previous gender when it seemingly suits his/her needs. ${ }^{147}$ The medical community, which often supports the role of biology as absolute, certainly sees Beatie's gender and pregnancy to be a matter of error; he was refused medical treatment from numerous doctors and his legitimacy as a father is constantly questioned by psychologists, and now even by the LGBQT community (Beatie 198-206). ${ }^{148}$ Beatie is not an "error" as these commentators claim; rather, the commentators have bought, wholesale, the absolute truths of American culture and identity. The homonormative reaction is to cast Beatie out and disclaim him as a community member. The decision to question how concepts of error are formed would benefit the LGBTQ community; it allows us to examine how cultural truths are formed, and to reveal the fractures of those truths, without having to exclude individuals who do not fit into narrow definitions of acceptable homosexuality.

$\underline{\text { Toward a New Regime of Error }}$

${ }^{147}$ Such a perspective overlooks the rampant transphobia and the trauma of living in the closet, but it is a point of view that is widely held by the public and therefore considered by political engines interested in maintaining a normative queer community.

${ }^{148}$ It would be unfair to place the entire medical community in the same category; eventually Beatie found doctors who supported his decision. One instance is recalled by Beatie:

Before I left, Dr. R. drafted a letter attesting to the reasons for my reconstructive surgery, which would later serve my purpose in changing my legal gender from female to male. 'Psychological and medical testing has been carried out to determine this patient's true gender,' he wrote. 'In this case, this was determined to be male. Tracy has undergone extensive hormonal and psychological treatment and has been referred for and undergone surgical procedures performed by me to irreversibly correct his anatomy and appearance. This should qualify Tracy to be legally considered male.' Dr. R.'s letter remains one of the most important documents of my life. (Beatie 159) 
Beatie submitted himself to every demand of the law to obtain his legal status as male, even if he was a man long before that legal recognition took place. He seemingly felt that to be a man, the state needed to recognize him as male. The insistence that his maleness is illegitimate because of his reproductive capabilities is rooted in the idea of biology as truth and the mistaken connection between gender and sex. The insistence that he is not a father because he carried his child is based on narrow definitions about the human body and its capabilities and the connection between those capabilities and identity. Beatie recognized that "perhaps it's the government that has the final say on what makes a man or a woman. Still, there are those who insist on calling [him] female, despite [his] legal male credentials. So it seems that the government doesn't have more pull than biology over this question of what makes a man" (Beatie 259). Beatie has overlooked the perceived slip-up on the part of government by those who frame his identity and pregnancy as an error. The lack of government action to return Beatie's sex to female or to nullify his marriage with Nancy neither supports nor denies trans rights or the redefining of family. The real power, in this instance, doesn't lie in the hands of the state to determine what makes a man or a woman, but in the public who believes in the absolutism of science and often sees their government as wrong. Americans are accustomed "to test[ing] governmental action, gaug[ing] its validity, and...object[ing] to activities of the public authorities on the grounds of their abuses, excesses, futility, and wasteful expenditure" (Birth of Biopolitics 246). American definitions of democracy "[involve] anchoring and justifying a permanent political criticism of political and governmental action," continually challenging our government to further regulate our bodies or claiming that the government's power over our bodies is too great (Beatie 246$).{ }^{149}$

149 The 2009/10 healthcare debates are a perfect example of this. 
There must be possibilities for a system that accounts for fractures in the regime of truth, a system that doesn't react with hate and violence. Our current system of government leads us to believe that we are free; it needs to claim our freedom to consume it. Government "is not so much the imperative of freedom as the management and organization of the conditions in which one can be free"; the problem is that in this relationship between the government and its people is "the production of freedom and that which in the production of freedom risks limiting and destroying it" (Birth of Biopolitics 63-64). We must be free according to rules of governance, but that insistence on freedom imprisons us. We aren't free, however; instead, "society forces you to choose one or the other...[Beatie] could have easily lived [his] life as a man without legally changing [his] gender;... [He] didn't have to define [his] gender one way or the other for [him] self, because that definition wouldn't have affected the way [he] was living [his] life" (Beatie 249, emphasis added). The instance of binaries of identity functions in the same way.

Beatie is free to move from female to male (and absolutely stay there), but he is prohibited from occupying an intersubjective position, a position that allows him to carry a child while maintaining his gender identity as a man, to call himself "father" while nourishing a fetus in his womb. Beatie "realized the world [he] live[s] in doesn't tolerate fence sitters when it comes to gender. It doesn't invite grayness_-it insists on black and white. The spectrum of gender and sexuality is constantly broadening, and far from fixed, yet the poles on either endmale and female- are, in our society, absolute" (Beatie 249). His decision to become a "legal" man was motivated by his desire for "the world to see [him] as [he] already saw [him]self, and for that to happen, [he] had to come down squarely in one camp or the other. When [he] officially switched from an 'F' to an 'M,' [his] life became immeasurably easier' (Beatie 249). Immeasurably easier because he was able to marry the woman he loved since gay and lesbian 
marriage remained illegal at the time, and therefore, if he had not "switched from an ' $\mathrm{F}$ ' to an 'M,' this would have been impossible in most states in the country. Life became easier because he felt that he was finally able to use a public restroom without fear of being called a pervert or being assaulted - easier because he could live his life in a body and with an identity that he was most comfortable with (Beatie 247).

Beatie is made an error by a set of practices that purport themselves as truths. Foucault argues that "error is eliminated not by the blunt force of a truth that would gradually emerge from the shadows but by the formation of a new way of "truth-telling"” ("Life: Experience and Science" 11). Beatie begins this "new way of "truth-telling"” by allowing the public to see into his life, however (im)perfect it may be. Not as an individual, but as an instance of experience, Beatie thrusts us to see our "truths" as illusions, to see what we once believed to be inherent truths as fractured lies. "Error is the root of what produced human thought and its history" (Life: Experience and Science 15). The faulty response to Beatie's experience, and to the idea of malepregnancy in general, will help us to develop our knowledge, to expand our understanding of what is possible by considering and taking up errant subjects, and to form a new powerknowledge dynamic-- perhaps one that considers error as truth. 


\section{Works Cited}

The Analytical Review, or History of Literature, Domestic and Foreign, on an Enlarged Plan. Vol. 28. London: J. Johnson, 1799. Web.

Angelides, Steven. A History of Bisexuality. Chicago: The University of Chicago Press, 2001. Print.

Angry Dyke. "Re: Trans Positions.” Online Posting. 7 May 2008. "Trans Positions” Discussion Board. Web. 10 December 2009.

The Anti-Jacobin Review and Magazine; or, Monthly Political and Literary Censor. From July to December, (Inclusive) 1798. Vol. 1. London: J. Whittle, 1799. Web.

Armstrong, Nancy. Desire and Domestic Fiction: A Political History of the Novel. Oxford: Oxford UP, 1987. Print.

Bainbridge, Simon. Napoleon and English Romanticism. Cambridge: Cambridge UP, 1995. Print.

Barker-Benfield, G. J. The Culture of Sensibility: Sex and Society in Eighteenth-Century England. Chicago: U of Chicago P, 1992. Print.

Beatie, Thomas. "Labor of Love.” The Advocate. April 2008. Web. 10 December 2009.

---. Labor of Love: The Story of One Man's Extraordinary Pregnancy. Berkeley: Seal Press, 2008. Print.

Bindman, David. Hogarth and His Times. Berkeley: U of California P, 1997. Web.

Boe, Ana de Freitas. “I Call Beauty a Social Quality’: Mary Wollstonecraft and Hannah More's Rejoinder to Edmund Burke's Body Politic of the Beautiful.” Women's Writing (18:3) August 2011, 348-366. Web.

Bornstein, Kate. Gender Outlaw. New York: Routledge, 1994. Print. 
Bourdieu, Pierre. "The Production of Belief: Contribution to an Economy of Symbolic Goods." The Field of Cultural Production. Cambridge: Polity Press, 1993. 74-111. Print.

Braunschneider, Theresa. Our Coquettes: Capacious Desire in the Eighteenth Century. Charlottesville: U of Virginia P, 2009. Print.

Brightwell, Cecelia Lucy and Amelia Opie. Memorials of the Life of Amelia Opie: Selected and Arranged from her Letters, Diaries, and Other Manuscripts. London: Longman, Brown \& Co., 1854. Web.

Burke, Edmund. A Philosophical Enquiry into the Origin of our Ideas of the Sublime and Beautiful. Ed. J.T. Boulton. New York: Columbia UP, 1958. Print.

---. A Philosophical Enquiry into the Origin of our Ideas of the Sublime and Beautiful. London: R. and J. Dodsley, in Pall-Mall: 1757. Eighteenth Century Collections Online. 21 November 2013.

---. A Philosophical Enquiry into the Origin of our Ideas of the Sublime and Beautiful. With an Introductory Discourse Concerning Taste; and Several Other Additions. London: Vernor and Hood, F. and C. Rivington, T.N. Longman, Cadell and Davies, J. Cuthell, J. Walker, Lackington, Allen, and co. Ogilvy and Son, and J. Nunn: 1798. Eighteenth Century Collections Online. 23 June 2016.

Butler, Judith. Gender Trouble: Feminism and the Subversion of Identity. New York: Routledge, 1990. Print.

Bywaters, David. Dryden in Revolutionary England. Berkeley: University of California Press, 1991. Web.

Chandler, David. "“The Athens of England: Norwich as a Literary Center in the Late Eighteenth Century." Eighteenth-Century Studies. 43.2 (Winter 2010): 171-192. Print. 
Christensen, Jen. "Trans Positions.” The Advocate. May 2008. Web. 10 December 2009.

Clark, Anna. "Anne Lister's Construction of Lesbian Identity." Journal of the History of Sexuality. 7.1 (July 1996): 23-50. Print.

Clemit, Pamela. "Writing a Revolutionary Life: Godwin's Memoirs of Wollstonecraft." Romantic Circles. 2 November 2012.

---. The Godwinian Novel: The Rational Fictions of Godwin, Brockden Brown, Mary Shelley. Oxford: Clarendon Press, 1993. Print.

Cody, Lisa Forman. "The Politics of Illegitimacy in an Age of Reform: Women, Reproduction, and Political Economy in England's New Poor Law of 1834." Journal of Women's History. 11.4 (2000): 131-156. Print.

Coffman, Chris. "The Sinthomosexual's Failed Challenge to (Hetero)sexual Difference.” Culture, Theory and Critique Vol. 54, No. 1 (October 2012): 56-73. Print.

Cohen, Ed. "Who Are 'We’? Gay ‘Identity’ as Political (E)motion (A Theoretical Rumination).” Inside/Out: Lesbian Theories, Gay Theories. Ed. Diana Fuss. New York: Routledge, 1991. 71-92. Print.

Coleridge, Samuel Taylor. Biographia Literaria. 2 pts., Ed. James Engell and W. Jackson Bate, vol. 7 in The Collected Works of Samuel Taylor Coleridge. Princeton: Princeton UP, Bolligen Series 75, 1983. Web.

Colker, Ruth. Hybrid: Bisexuals, Multiracials, and Other Misfits under American Law. New York: New York UP, 1996. Print.

Cracium, Adriana. "Epilogue: Napoleonic Challenges and Cosmopolitan Legacies." British Women Writers and the French Revolution. New York: Palgrave Macmillan, 2005: 179192. Print. 
Crew, Hilary S. and Donna Jo Napoli. Writing with Passion. Lanham, Maryland: Scarecrow Press, 2010. Web.

Cromwell, Jason. Transmen and FTMs: Identities, Bodies, Genders, and Sexualities. Urbana: Univ. of Illinois Press, 1999. Print.

Csengei, Ildiko. "She Fell Senseless on His Corpse: The Woman of Feeling and the Sentimental Swoon in Eighteenth-Century Fiction.” Romantic Circles. Web. 25 October 2012.

Currah, Paisley. "Expecting Bodies: The Pregnant Man and Transgender Exclusion from the Employment Non-Discrimination Act." WSQ: Women's Studies Quarterly 36:3\&4 (Fall/Winter 2008): 330-336. Print.

David, Deidre. Intellectual Women and Victorian Patriarchy: Harriet Martineau, Elizabeth Barrett Browning, George Eliot. London: Macmillan, 1987. Print.

Davis, Whitney. Queer Beauty: Sexuality and Aesthetics from Winckelmann to Freud and Beyond. New York: Columbia UP, 2010. Print.

Dollimore, Jonathan. Sex, Literature and Censorship. Cambridge: Polity Press, 2001. Print. Duggan, Lisa. The Twilight of Equality?: Neoliberalism, Cultural Politics, and the Attack on Democracy. Boston: Beacon Press, 2004. Print.

Eberle, Roxanne. Chastity and Transgression in Women's Writing, 1792-1897: Interrupting the Harlot's Progress. New York: Palgrave, 2002. Print.

Edelman, Lee. No Future: Queer Theory and the Death Drive. Durham: Duke UP, 2004. Print. Elfenbein, Andrew. Romantic Genius: The Prehistory of a Homosexual Role. New York: Columbia UP, 1999. Print.

The English Review. 17 (March 1791): 234. Web.

"err, v.". OED Online. September 2012. Oxford University Press. 11 October 2012. Web. 
Ferguson, Roderick A. Aberrations in Black: Toward a Queer of Color Critique. Minneapolis: University of Minnesota Press, 2004. Print.

Fletcher, Max E. "Harriet Martineau and Ayn Rand: Economics in the Guise of Fiction." American Journal of Economics and Sociology. 33.4 (Oct. 1974): 367-379. Print.

Foucault, Michel. ““”Des Espace Autres (Of Other Spaces: Utopias and Heterotopias).” Trans. Jay Miskowiec. Architecture/Mouvement/Continuité. (October 1984): 46-49. mit.edu. AllanMC. PDF: 1-9. Web. 15 July 2016. http://web.mit.edu/allanmc/www/foucault1.pdf

---. "Life: Experience and Science." The Essential Foucault: Selections from The Essential Works of Foucault 1954-1984. Ed. Paul Rabinow and Nikolas Rose. New York: New Press, 1994. Print.

---. "Truth and Power." The Essential Foucault: Selections from the Essential Works of Foucault 1954-1984. Ed. Paul Rabinow and Nikolas Rose. New York: The New Press, 1994. 300318. Print.

---. Discipline and Punish, The Birth of the Prison. Trans. Alan Sheridan. New York: Vintage Books, 1995. Print.

---. The Birth of Biopolitics Lectures at the College de France, 1978-79. Ed. Michel Senellart et al. Trans. Graham Burchell. New York: Palgrave Macmillan, 2008. Print.

---. The History of Sexuality, Volume 1: An Introduction. Trans. Robert Hurley. New York: Vintage Books, 1990. Print.

Freccero, Carla. Queer/Early/Modern. Durham; Duke UP, 2006. Print. Freedgood, Elaine. "Banishing Panic: Harriet Martineau and the Popularization of Political Economy.” Victorian Studies 39.1 (Autumn 1995): 33-53. Print. 
Gallagher, Catherine. "The Body Versus the Social Body in the Works of Thomas Malthus and Henry Mayhew." The Making of the Modern Body: Sexuality and Society in the Nineteenth Century. Ed. Catherine Gallagher and Thomas Laqueur. Berkeley: Univ. of California Press, 1987. 83-106. Print.

Garber, Marjorie. Vice Versa: Bisexuality and the Eroticism of Everyday Life. New York: Touchstone, 1995. Print.

Godwin, William. Enquiry Concerning Political Justice and Its Influence on Modern Morals and Happiness. Ed. Isaac Kramnick. 1793. New York: Penguin Books, 1985. Print.

---. Letters of William Godwin. Vol. 1. Ed. Pamela Clemit. Oxford: Oxford UP, 2011. Print.

---. Memoirs of the Author of a Vindication of the Rights of Woman. Ed. Pamela Clemit and Gina Luria Walker. Ontario: Broadview, 2001. Print.

---. The Enquirer: Reflections on Education, Manners, and Literature. In A Series of Essays. London: G.G. and J. Robinson, 1797. Web.

Gordon, Lyndall. Vindication: A Life of Mary Wollstonecraft. New York: HarperCollins, 2005. Print.

Green, Jamison. Becoming a Visible Man. Nashville: Vanderbilt UP, 2004. Print.

Greenfield, Susan C. Mothering Daughters: Novels and the Politics of Family Romance Frances Burney to Jane Austen. Detroit: Wayne State UP, 2002. Print.

Griswold, Jerome. The Meanings of 'Beauty and the Beast': A Handbook. New York: Broadview, 2004. Print.

Haaland, Robert. "In Response to 'Labor of Love."” The Advocate. 1 April 2008. Web. 10 December 2009. 
Halberstam, J. Jack. Gaga Feminism: Sex, Gender, and the End of Normal. Boston: Beacon, 2012. Print.

Halberstam, Judith. Female Masculinity. Durham: Duke UP, 1998. Print.

---. The Queer Art of Failure. Durham: Duke UP, 2011. Print.

Hall, Donald. Reading Sexualities: Hermeneutic Theory and the Future of Queer Studies. New York: Routledge, 2009. Print.

Halperin, David M. How to Do the History of Homosexuality. Chicago: The University of Chicago Press, 2002. Print.

Hemans, Felicia. Records of Woman with Other Poems. Ed. Paula R. Feldman. Lexington: The UP of Kentucky, 1999. Print.

Hobart, Ann. "Harriet Martineau's Political Economy of Everyday Life.” Victorian Studies 37.2 (Winter 1994): 223-251. Print.

Howard, Carol. “"The Story of the Pineapple': Sentimental Abolitionism and Moral Motherhood in Amelia Opie's Adeline Mowbray" Studies in the Novel. Vol. 30, No. 3 (Fall 1998): 355-376. Web. 2 September 2011.

Inchbald, Elizabeth. Nature and Art. Ed. David Price. London: Cassell \& Co., 1886. Project Gutenberg. Web. 28 October 2012.

Johnson, Claudia. Equivocal Beings: Politics, Gender, and Sentimentality in the 1790s: Wollstonecraft, Radcliffe, Burney, Austen. Chicago: U of Chicago P, 1995. Print.

Johnson, Samuel. "No. 60. Saturday, October 13, 1750.” The Rambler; a Periodical Paper. London: Jones \& Company, 1826. Web.

Johnston, Josephine. “Field Notes.” Hastings Center Report 38.3 (May-June 2008): c2 
Kaplan, Ann E. Looking for the Other: Feminism, Film, and the Imperial Gaze. New York: Routledge, 1997. Print.

Kaye, Richard A. The Flirt's Tragedy: Desire Without End in Victorian and Edwardian Fiction. Charlottesville: U of Virginia P, 2002. Print.

King, Shelley and Yaël Schlick. Refiguring the Coquette: Essays on Culture and Coquetry. Lewisburg: Bucknell UP, 2008. Print.

King, Shelley. "Politics, Poetics and Propriety: Reviewing Amelia Opie." Romanticism on the Net. Vol. 29-30 (February-May 2003). Web. 4 September 2011.

---. "Portrait of a Marriage: John and Amelia Opie and the Sister Arts." Studies in Eighteenth Century Culture. Vol. 40 (2011): 27-62. Print.

Lacan, Jacques. Ecrits: The First Complete Edition in English. Trans. Bruce Fink with Héloïse Fink and Russell Grigg. New York: W. W. Norton, 2006. Print.

Langland, Elizabeth. Nobody's Angels: Middle Class Women and Domestic Ideology in Victorian Culture. Ithaca: Cornell UP, 1995. Print.

Laqueur, Thomas and Catherine Gallagher. The Making of the Modern Body: Sexuality and Society in the Nineteenth Century. Berkeley: U of California P, 1987. Print.

Laqueur, Thomas. Making Sex: Body and Gender from the Greeks to Freud. Cambridge: Harvard UP, 1992. Print.

Lerer, Seth. Error and the Academic Self: The Scholarly Imagination, Medieval to Modern. New York: Columbiana UP, 1998. Print.

"lionel, n." OED Online. Oxford University Press, June 2014. Web. 29 July 2014. 
MacLean, Gerald. "Re-siting the Subject.” Epistolary Histories: Letters, Fiction, Culture. Eds. Amanda Gilroy and W. M. Verhoeven. Charlottesville: UP of Virginia, 2000, 176-197. Print.

Malthus, Thomas Robert. An Essay on the Principle of Population and A Summary View of the Population Principle. Ed. Antony Flew. 1798. New York: Penguin Books, 1985. Print.

Manlove, Clifford T. 'Visual 'Drive' and Cinematic Narrative: Reading Gaze Theory in Lacan, Hitchcock and Mulvey.” Cinema Journal. (46:3) Spring 2007, 83-103. Web. 7 July 2013.

Marcus, Sharon. Between Women: Friendship, Desire, and Marriage in Victorian England. Princeton: Princeton UP, 2007. Print.

Martineau, Harriet. Harriet Martineau's Autobiography. 2 vols. London: Virago, 1983. Print.

Martineau, Harriet. Illustrations of Political Economy: Selected Tales. Ed. Deborah Anna Logan. Toronto: Broadview, 2004. Print.

McRuer, Robert. Crip Theory: Cultural Signs of Queerness and Disability. New York: New York UP, 2006. Print.

Mellor, Anne K. Romanticism and Gender. New York: Routledge, 1993. Print.

Memoirs of a Coquet; or the History of Miss Harriot Airy. By the author of Emily Willis; or, The History of a Natural Daughter. London: W. Hoggard, 1765. Eighteenth Century Collections Online. Web. 2 Feb. 2013

Monro, D. H. Godwin's Moral Philosophy: An Interpretation of William Godwin. London: Oxford UP, 1953. Print.

The Monthly Review; or Literary Journal, Enlarged: From September to December, inclusive, MDCCXCVIII. Vol. XXVII. London: R. Griffiths, 1798. Web. 
More, Hannah. Strictures on the Modern System of Female Education: With a View of the Principles and Conduct Prevalent Among Women of Rank and Fortune. by Hannah More. in Two Volumes. London: T. Cadell Jun. and W. Davies, 1799. Web. 1 October 2012.

Myers, Mitzi. “Godwin's 'Memoirs' of Wollstonecraft: The Shaping of Self and Subject.” Studies in Romanticism 20.3 (Fall 1981): 299-316. Web. 25 August 2011.

Nagle, Christopher C. Sexuality and the Culture of Sensibility in the British Romantic Era. New York: Palgrave Macmillan, 2007. Print.

Namaste, Viviane K. Invisible Lives: The Erasure of Transsexual and Transgendered People. Chicago: University of Chicago Press, 2000. Print.

Novelli, Rob. "Re: Trans Positions." Online Posting. 5 May 2008. "Trans Positions” Discussion Board. Web. 10 December 2009.

O’Donnell, Margaret G. “Harriet Martineau: A Popular Early Economics Educator.” The Journal of Economic Education 14. 4 (Autumn 1983): 59-64. Print.

Opie, Amelia. Illustrations of Lying, in All Its Branches. Vol. I. London: Longman, Hurst, Rees, Orme, Brown, and Green, 1825. Web. 26 September 2012.

Opie, Amelia. The Father and Daughter and The Dangers of Coquetry. Eds. Shelley King and John B. Pierce. Peterborough, Ontario, Canada: Broadview, 2003. Print.

Paul, Kegan C. William Godwin: His Friends and Contemporaries. Vol. 1. Boston: Roberts Brothers, 1876. Print.

Phelan, Shane. Sexual Strangers: Gays, Lesbians, and Dilemmas of Citizenship. Philadelphia: Temple UP, 2001. Print.

Philp, Mark. Godwin's Political Justice. Ithaca: Cornell UP, 1986. Print. 
Plumptre, Anne. Something New: or, Adventures at Campbell-House. Ed. Deborah McLeod. Ontario: Broadview, 1996. Print.

Postlethewaite, Diana. "Mothering and Mesmerism in the Life of Harriet Martineau." Signs 14.3 (Spring 1989): 583-609. Print.

Rajan, Tilottama. "Framing the Corpus: Godwin's 'Editing' of Wollstonecraft in 1798" Studies in Romanticism. Vol. 39 No. 4 (Winter 2000): 511-531. Print.

Rescher, Nicholas. Error: On Our Predicament When Things Go Wrong. Pittsburgh: U of Pittsburgh Press, 2007. Print.

Rev. of Dangers of Coquetry. The European Magazine, and London Review. Vol. 17. London: J. Sewell, 1790. 352. Web. 12 September 2011.

Ricardo, David. On the Principles of Political Economy and Taxation. New York: Dover Publications, 2004. Print.

Roberts, Caroline. The Woman and the Hour: Harriet Martineau and Victorian Ideologies. Toronto: University of Toronto Press, 2002. Print.

Robinson, Henry Crabb. Diary, Reminiscences, and Correspondence of Henry Crabb Robinson, Barrister-at-Law, F.S.A. Ed. Thomas Sadler. Boston: Houghton, Mifflin and Company, 1898. Web.

Roof, Judith. A Lure of Knowledge: Lesbian Sexuality and Theory. New York: Columbia U.P., 1991. Print.

Rubin, Henry. Self-Made Men: Identity and Embodiment among Transsexual Men. Nashville: Vanderbilt UP, 2003. Print.

Salamon, Gayle. Assuming a Body: Transgender and Rhetorics of Materiality. New York: Columbia UP, 2010. Print. 
Saxena, Vandana. "Beauty and the Beast: Reclaiming the Monsters." Inhabited by Stories: Critical Essays on Tales Retold. Eds. Nancy A. Barta-Smith and Danette DiMarco. Newcastle upon Tyne: Cambridge Scholars, 2012. Print.

Sha, Richard C. Perverse Romanticism: Aesthetics and Sexuality in Britain, 1750- 1832. Baltimore: The John Hopkins UP, 2009. Print.

Shelley, Percy Bysshe. The Major Works. Eds. Zachary Leader and Michael O’Neill. Oxford: Oxford UP, 2009. Print.

Smith, Adam. An Inquiry into the Nature and Causes of the Wealth of Nations. London: 1776. Web. 1 August 2016.

Smith, Elton Edward and Esther Greenwell Smith. William Godwin. New York: Twayne Publishers, 1965. Print.

Sng, Zachary. The Rhetoric of Error from Locke to Kleist. Stanford: Stanford UP, 2010. Print. Straub, Kristina. Divided Fictions: Fanny Burney and Feminine Strategy. Lexington: UP of Kentucky, 1987. Print.

Swain, Virginia E. "Beauty and the Beast." The Greenwood Encyclopedia of Folktales and Fairy Tales. Vol. 1 Ed. Donald Haase. Westport, CT: Greenwood, 2008. Print.

Todd, Janet, ed. British Women Writers: A Critical Reference Guide. New York: Continuum, 1989. 514-16. Print.

---. Mary Wollstonecraft: A Revolutionary Life. New York: Columbia UP, 2000. Print. ---. Sensibility: An Introduction. London: Methuen, 1986. Print.

Tom. "Re: Trans Positions.” Online Posting. 7 May 2008. “Trans Positions” Discussion Board. Web. 10 December 2009. 
Trumbach, Randolph. Sex and the Gender Revolution, Volume 1: Heterosexuality and the Third Gender in Enlightenment London. Chicago: U of Chicago P, 1998. Print.

The United States Review and Literary Gazette. Vol. 1. October 1, 1826 to April 1, 1827. "Illustrations of Lying, in all its Branches. By Amelia Opie. From the Second London Edition. Boston. 1826. Munroe \& Francis and others. 12mo. pp. 280" New York: G. and C. Carvill, 1827: 98-109. Web.

von Krafft-Ebing, Richard. Psychopathia Sexualis, with especial reference to Contrary Sexual Instinct: A Medico-Legal Study. Tr.Charles Gilbert Chaddock. London and Philadelphia: F.A. Davis Co., 1894. Web.

Walker, Gina Luria. “Women's Voice.” The Cambridge Companion to British Literature of the French Revolution in the 1790s. Ed. Pamela Clemit. Cambridge: Cambridge UP, 2011. 145-59. Print.

Warner, Marina. From the Beast to the Blonde: On Fairy Tales and Their Tellers. New York: Farrar, Straus, and Giroux, 1995. Print.

Warner, Michael. The Trouble with Normal: Sex, Politics, and the Ethics of Queer Life. Cambridge: Harvard UP, 1999. Print.

Wolfson, Susan J. Borderlines: The Shiftings of Gender in British Romanticism. Stanford: Stanford UP, 2006. Print.

Wollstonecraft Godwin, Mary. Posthumous Works of Mary Wollstonecraft Godwin. Ed. William Godwin. 2 Vols. 1798. Clifton, New Jersey: Augustus M. Kelley Publishers, 1972. Print. Wollstonecraft, Mary and Mary Shelley. Mary; Maria; Matilda. Ed. Janet Todd. New York: Penguin, 1992. Print. 
Wollstonecraft, Mary. A Vindication of the Rights of Woman and A Vindication of the Rights of Men. Ed. Janet Todd Oxford: Oxford UP, 1993. Print.

---. Collected Letters of Mary Wollstonecraft. Ed. Ralph M. Wardle. Ithaca: Cornell UP, 1979.

Print. 